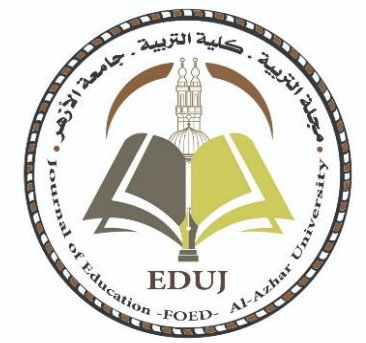

هجتمعات التعلم المهنية عبر الإنترنت لمواجهة جائحة فيروس كورونا في ضوء خبرات بعض الدول الأجنبية وإمكان الإفادة هنها في هصر

\title{
إعداد
}

د/ أحمد أنور السيد سند شاهين

دكتوراه في التربية المقارنة والإدارة التعليهية

ومعلم بالأزهر الشريف 
مجتمعات التعلم المهنية عبر الإنترنت لمواجهة جائحة فيروس كورونا في ضوء خبرات الإنهات بعض الدول الأجنبية وإمكان الإفادة منها في مصرئ فير كورنا في

$$
\text { أحمد أنور السيد سند شاهين }
$$

دكتوراه في التربية المقارنة والإدارة التعليمية، قسم الإدارة والتخطيط، كلية التربية، جامعة

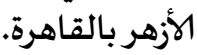

ahmadenglish12@gmail.com : البريد الإلكتروني:

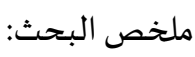

هـدف البحــث إلى التعـرف على طبيعـة مجتمعـات الـتعلم المهنيـة عبير الإنترنـت وممارسـاتها

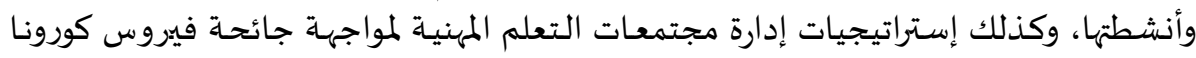

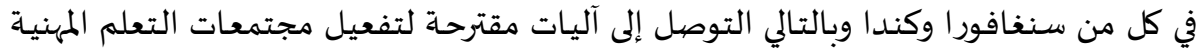

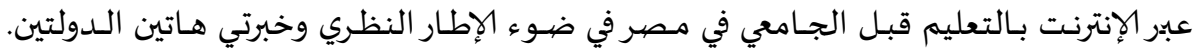

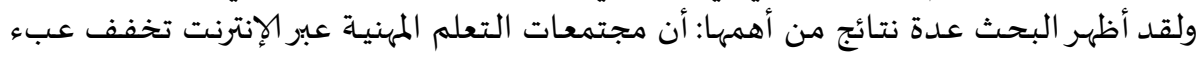

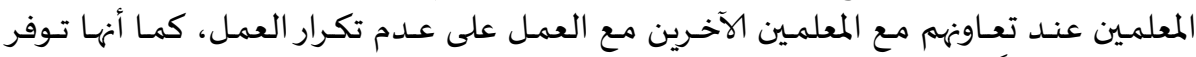

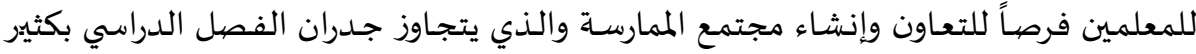

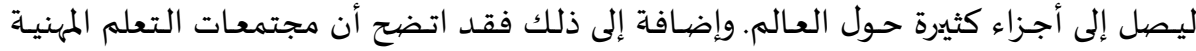

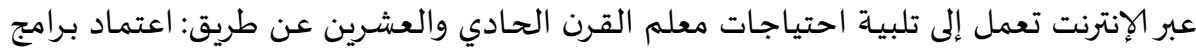

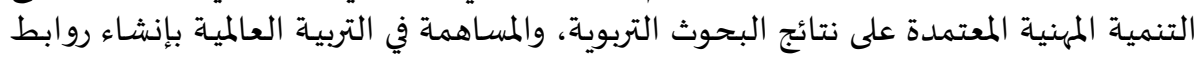

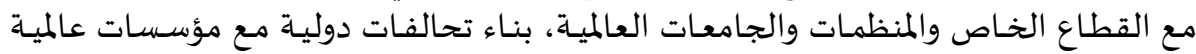
لرفع جودة أداء المعلم. الكلمات المفتاحية: مجتمعات التعلم المهنية عبر الإنترنت، جائحة فيروس كورونا، سنغافورا ،

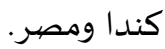


Online professional learning communities to confront the Coronavirus pandemic in light of the experiences of some foreign countries and the possibility of benefiting from them in Egypt

\title{
Ahmed Anwar Alsayed Sanad Shaheen
}

$\mathrm{PhD}$ in Comparative Education and Educational Administration, Department of Administration and Planning, Faculty of Education, AlAzhar University in Cairo.

Email:ahmadenglish12@gmail.com

\begin{abstract}
:
This research seeks to identify the nature, practices and activities of professional learning societies via the Internet, as well as strategies for managing professional learning societies to confront the Coronavirus pandemic in both Singapore and Canada, thus reaching mechanisms. A proposal to activate professional learning communities via the Internet in pre-university education in Egypt in light of the theoretical framework and the experiences of these two countries. The research has shown several results, the most important of which are: Online professional learning societies reduce the teachers 'burden when they collaborate with other teachers while working on non-repetition of work. They also provide teachers with opportunities for cooperation and the creation of a community of practice that goes far beyond the classroom walls to reach many parts around the world. In addition, it has become clear that online professional learning societies aim to meet the needs of the twenty-first century teacher by: adopting professional development programs based on educational research results, contributing to global education by establishing links with the private sector, international organizations and universities, and building international alliances with international institutions to raise the quality of teacher performance.
\end{abstract}

Keywords: Professional Learning Communities, Coronavirus pandemic, Singapore, Canada and Egypt 
مجتمعات التعلم المهنية عبر الإنترنت لمواجهة جائحة فيروس كورونا في ضوء خبرات بعض فئل

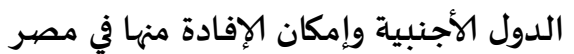

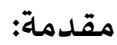

تواجه المنظمات على اختلاف مشاربها حقبة جديدة متطورة يغذيها التوسع السريع

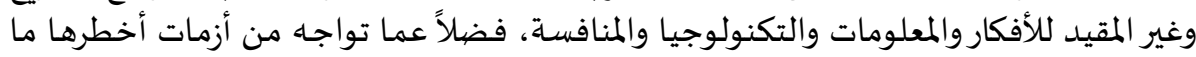
يعرف بجائحة فيروس كورونا

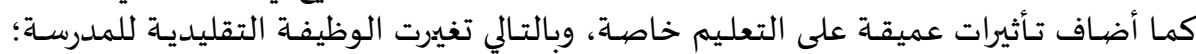

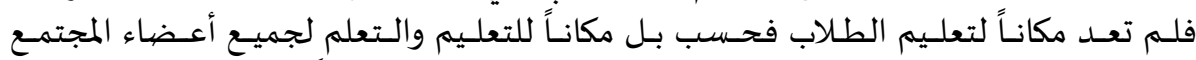

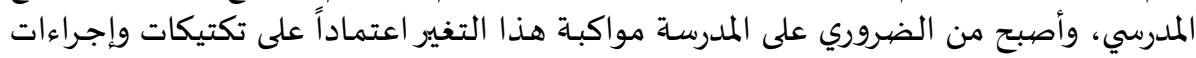
تمكنها من تطوير أداء رسالتها المطلوبة.

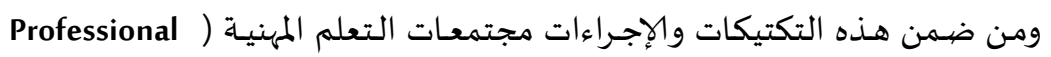
باعتار Learning Communities باعتبار المدرسـة المجتمع الرئيسي لصناعة التحولات الفعالة لتحسين أداء القيادادات والمعلمين التملين ونواتج تعلم الطلاب.

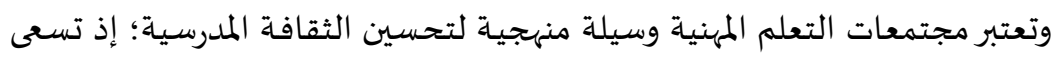

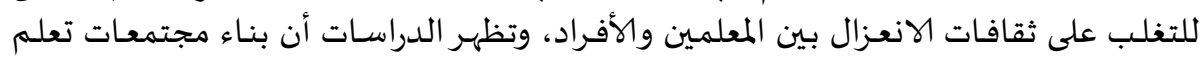

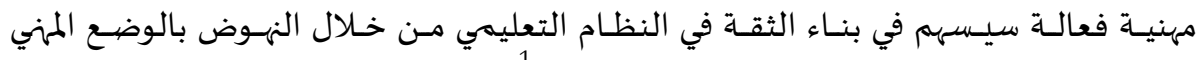

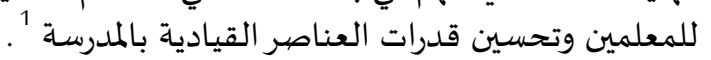

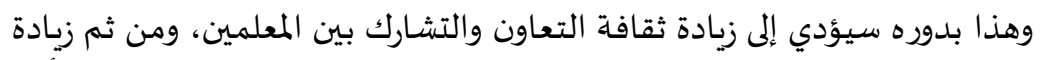

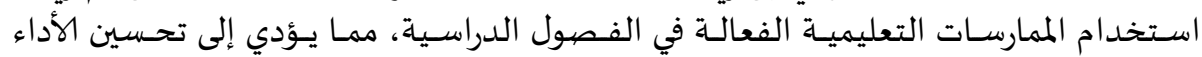

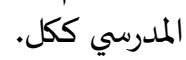

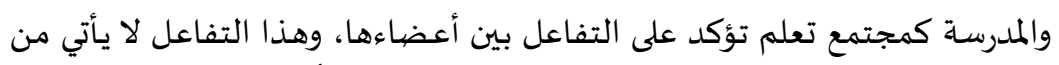

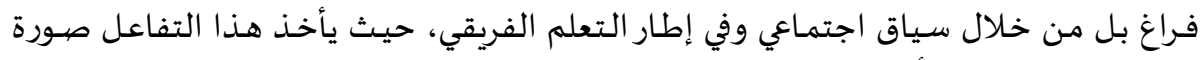

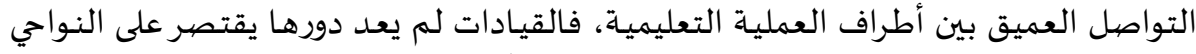

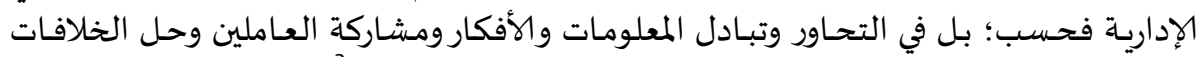

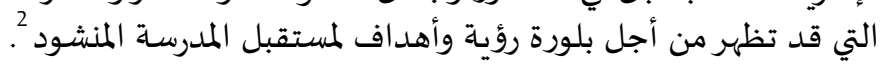

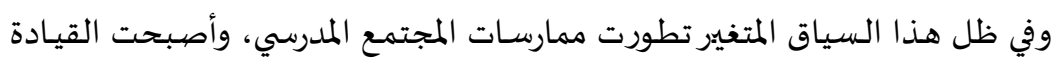

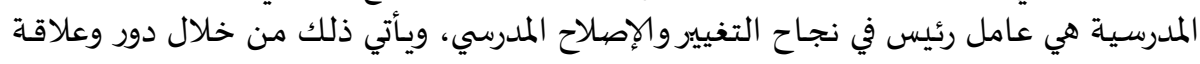

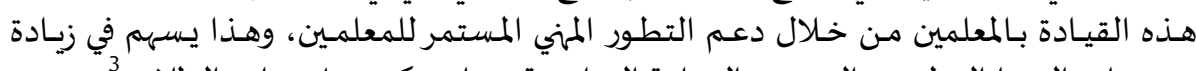

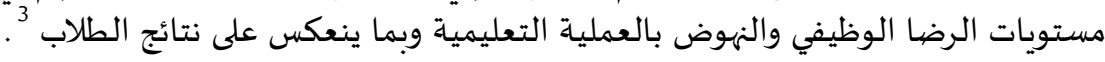

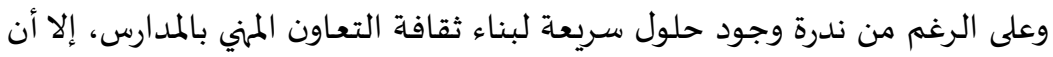

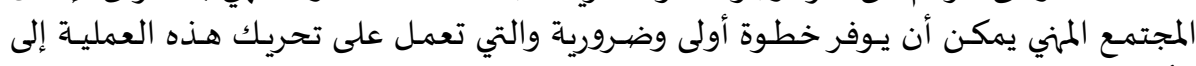

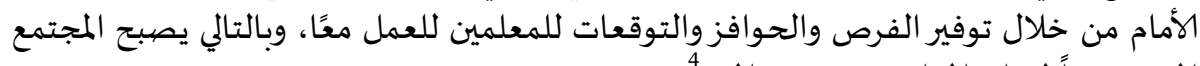

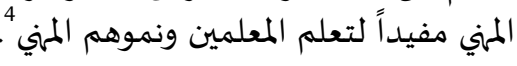




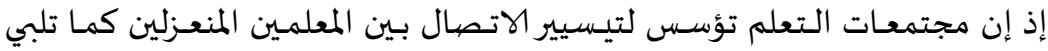

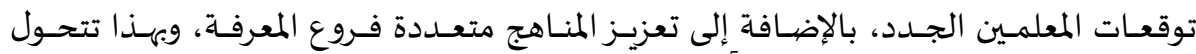

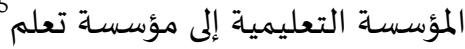

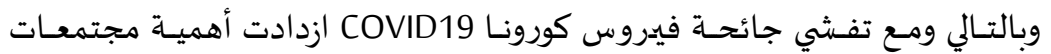

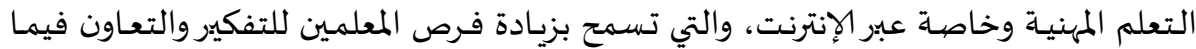

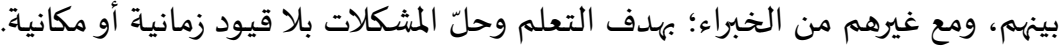

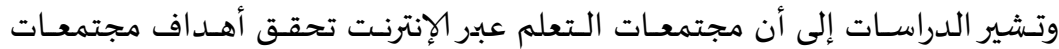

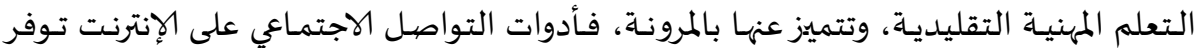

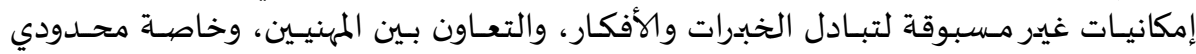

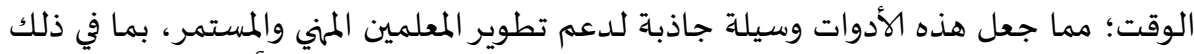

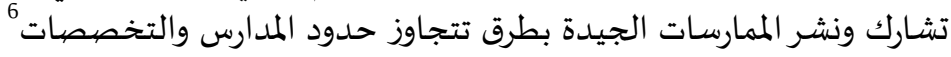

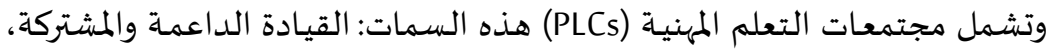

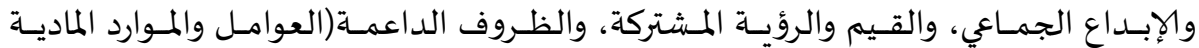

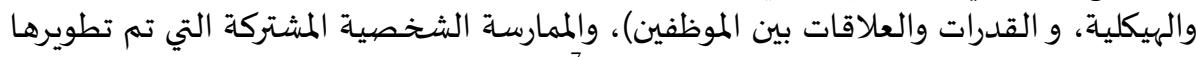

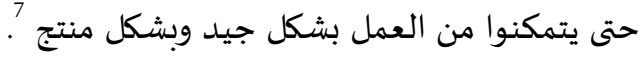

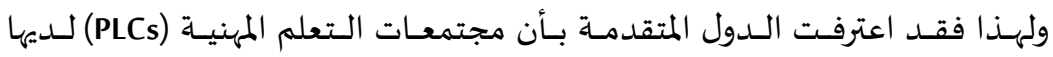

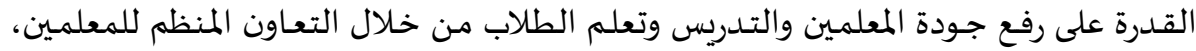

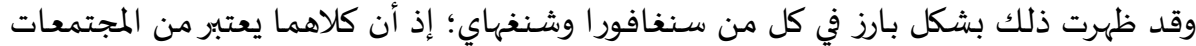

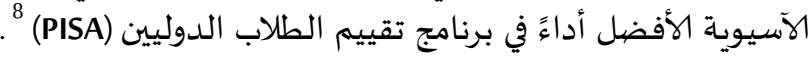

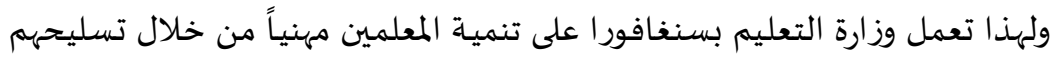

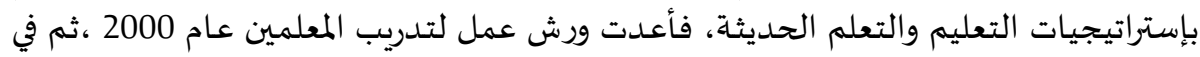

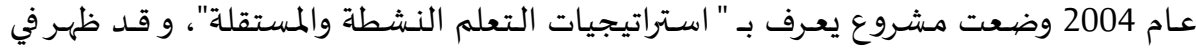

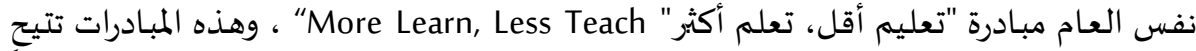

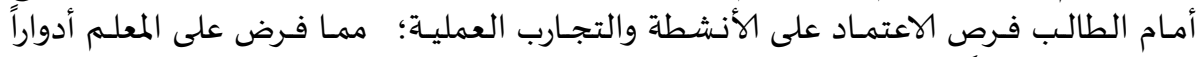

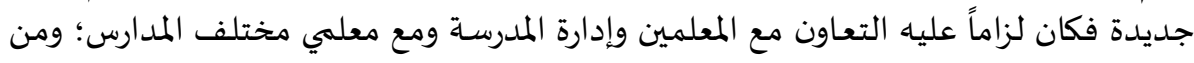

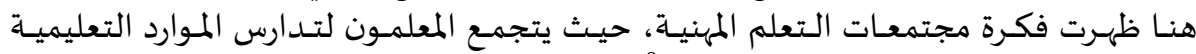

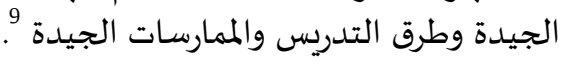

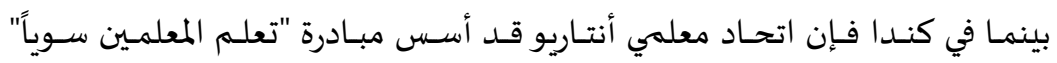

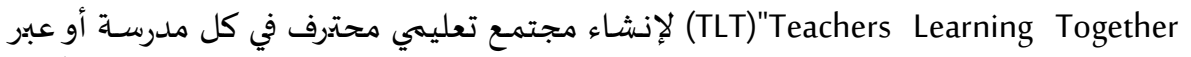

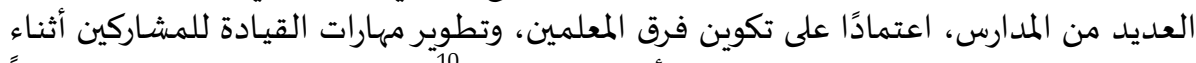

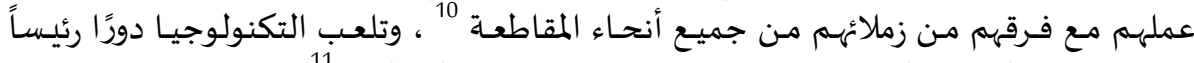

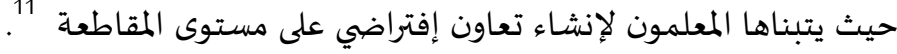




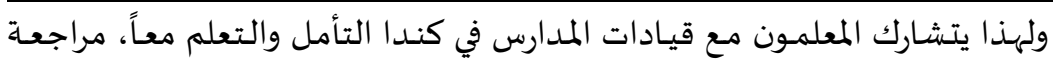

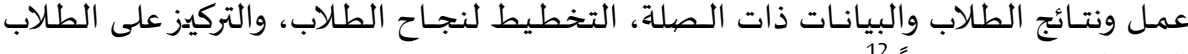
الذين لا يحرزون تقدماً 12

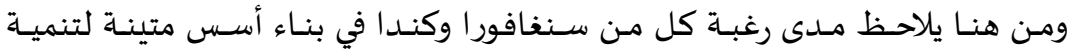

معلميها من خلال الابتكار في السياسات والمبادرات لتحقيق مجتمع مهني يخداف مناف عملية التطوير في

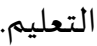

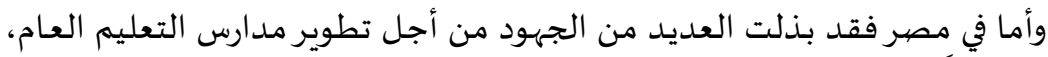

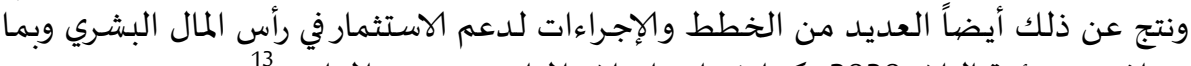

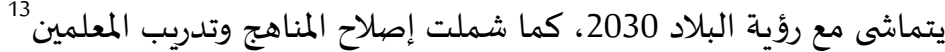

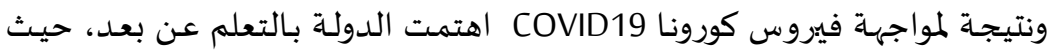

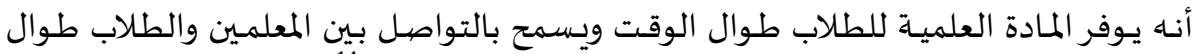

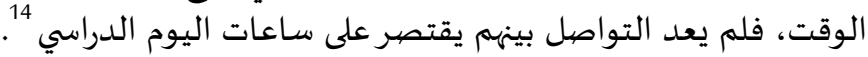

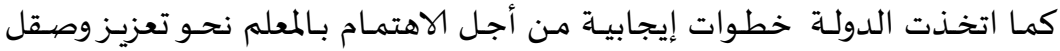

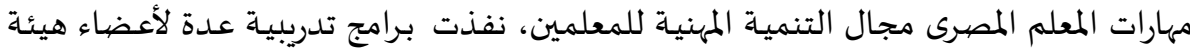

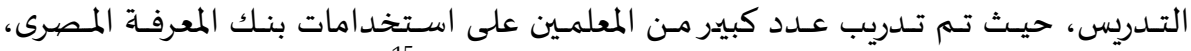

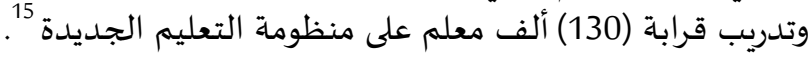

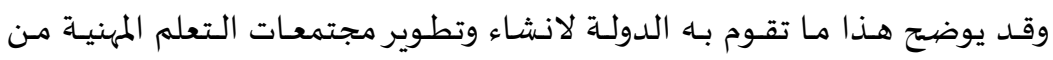

خلال الاهتمام بالتنمية المهنية وانشاء وحدات التدريب والجودة بالمدارس المصرية.

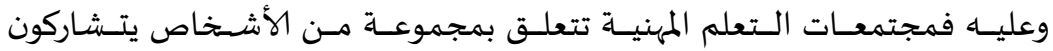

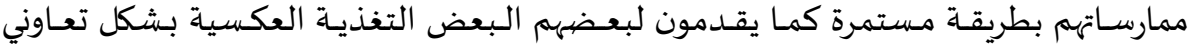
وشامل وموجه نحو التعلم والنمو.

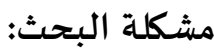

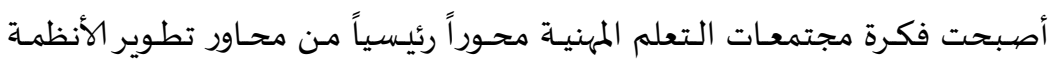

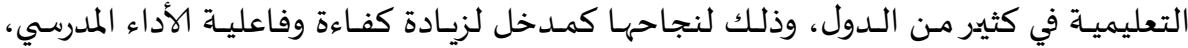

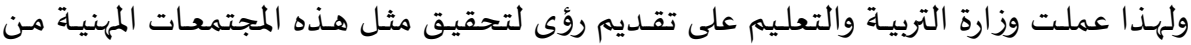

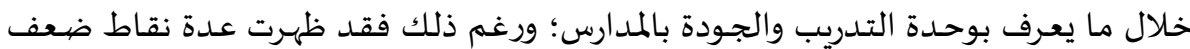
في تحقيق مجتمعات التعلم المهنية بالمدارس المصرية بلمارية ومنها مايلي:

- - قلة المخصصات المالية لدعم مجتمعات التعلم بالمدارس. - - - غياب الحوار الفكري التأملي حول الممارسات المهنية للمعلمين. - - ميادة الثقافة الهرمية بدلاً من ثقافة التعاون والتشارك. - قصور برامج التنمية المهنية عن تلبية الحاجات الفعلية للمعلمين ' . - - ضعف التزام العاملين بالمدرسة برؤيتها أو العمل على تطوير هذه الرؤية. 
- - مدرة عقد اجتماعات القيادة بالعاملين لمناقشة جودة التعليم والتعلم.

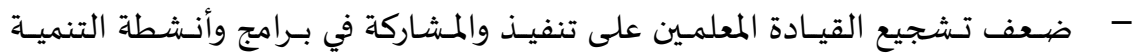

- - - ندرة تحفيز القيادة للعاملين المهتمين بتحسين أدائه.

- - مندرة توفير دورات وندوات وورش العمل لتبادل المعرفة والخبرات بين العاملين.

- قلة الاجتماعات الدورية بين العاملين لتحديث وتطوير القاعدة المعرفية باستمرار 17.

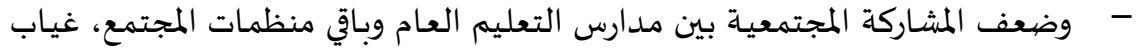

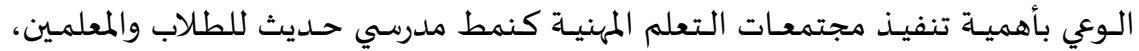

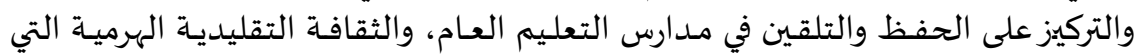

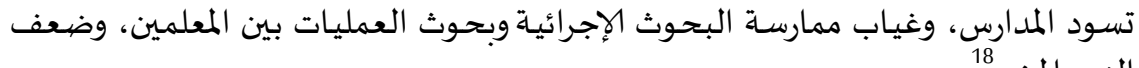

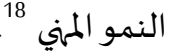

بناءً على ما سبق وما تم عرضيه من جوانب ضعف وأوجـه قصور فإن مشكلة البحث تتبلور

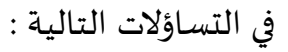

- ما الإطار النظري لمجتمعات التعلم المهنية عبر الإنترنت لمواجهة جائحة فيروس كورونا؟ - ما ملامح مجتمعات التعلم المهنية عبر الإنترنت في كل من سنغافورا وكندا لمواجهة جائحسة فيروس كورونا ؟ مامج مجتمات

- ما ملامع مجتمعـات التعلم المهنيـة عبر الإنترنت في التعليم قبل الجـامعي في مصر ملمواجهـة جائحة فيروس كورونا مجنات

ما الآليات المقترحة لتفعيل مجتمعات التعلم المهنية عبر الإنترنت بالتعليم قبل الجامعي في

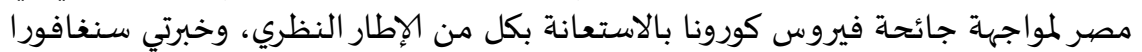

وكندا م

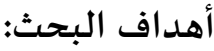

- التعـرف على الإطـار النظري لمجتمعـات الـتعلم المهنيـة عبير الإنترنـت وذلك مـن خـلال: طبيعـة

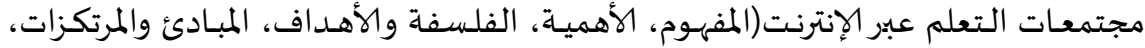

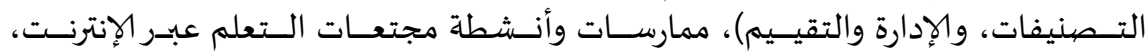

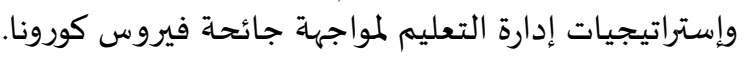
- التعـرف على واقع ملامع مجتمعـات التعلم المهنيـة عبر الإنترنت في سـنغافورا في ضـوء القـوى والعوامل الثقافية المؤثرة. 
- التعـرف على واقـع ملامـح مجتمعـات الـعلم المهنيـة عببر الإنترنـت في كنـــا في ضـوء القـوى والعوامل الثقافية المؤثرة.

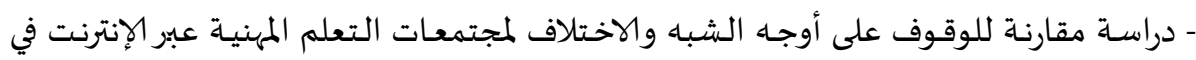
سنغافورا وكندا وتفسيرها في ضوء ألقوف الثوى والعوامل الثقافية المؤثرة.

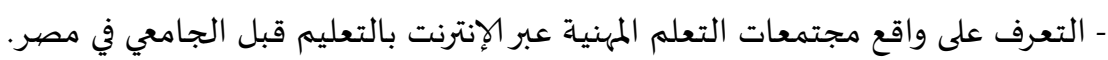

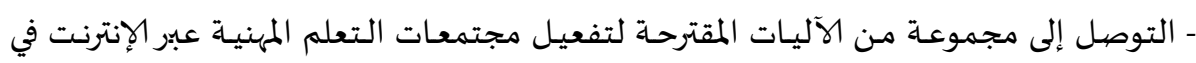

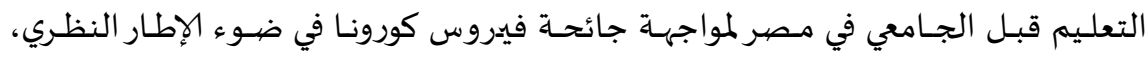
وخبرتي سنغافورا وكندا.

أهمية البحث:

تتمثل أهمية البحث في جانبين:

الجانب النظري ويتمثل في: - مان

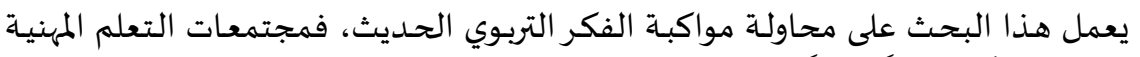

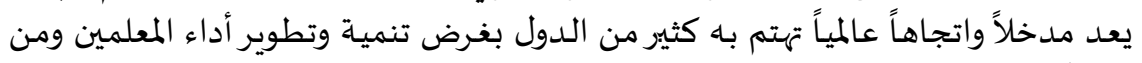

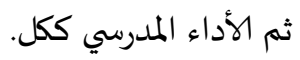

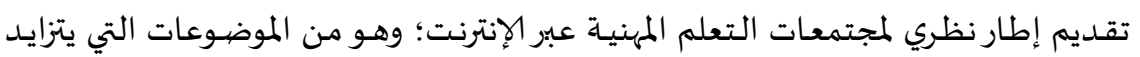

الاعتماد عليها بالدول المتقدمة هذه الأيام خاصة المنية مع تفشي جائحة فيرني فيروس كورونا.

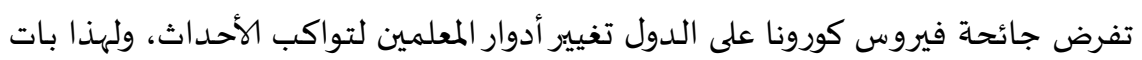

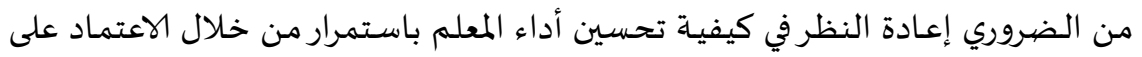

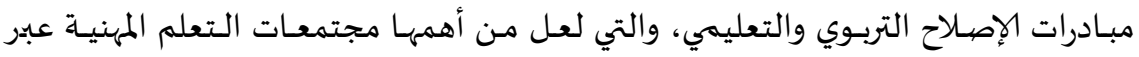
الإنترنت.

\section{الأهمية التطبيقية وتتمثل في}

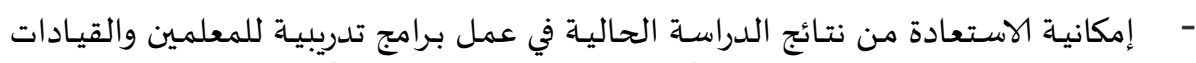

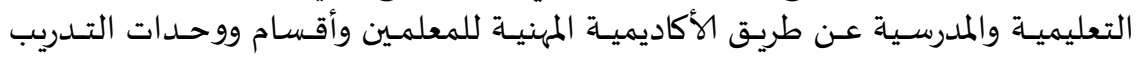

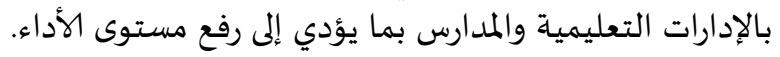

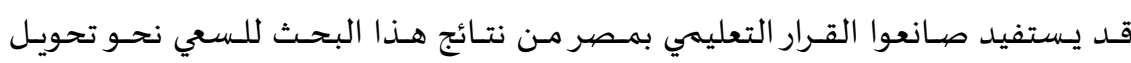

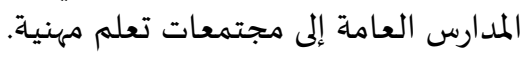

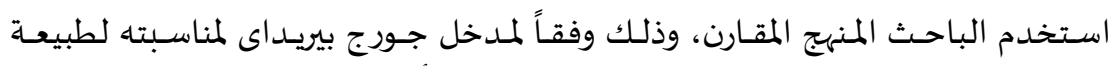

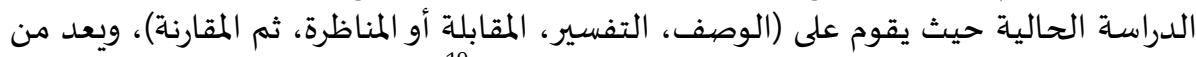

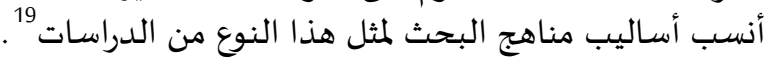




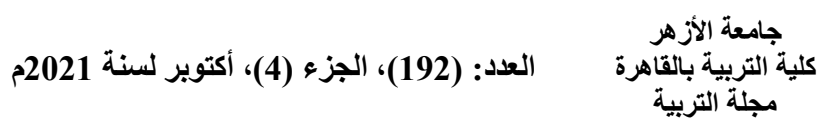

ولهذا فقد سارت خطوات البحث كالتالي:

الخطوة الأولى: الإطار النظري لمجتمعات التعلم المهنية عبر الإنترنت،

الخطوة الثانية: ملامح مجتمعات التعلم المهنية عبر الإنترنت في سنغافورا،

الخطوة الثالثة: ملامح مجتمعات التعلم المهنية عبر الإنترنت في كندا،

الخطوة الرابعة: التحليل المقارن، الخطوة الخامسـة:واقع ملامح مجتمعات التعلم المهنية عبر

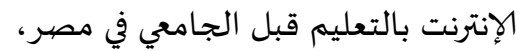

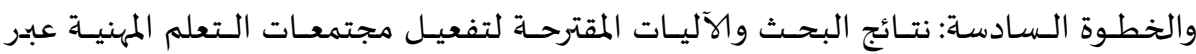
الإنترنت في التعليم قبل الجامعي في مصر لمواجهة جائحة فيروس كورونا.

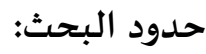

أ- الحدود المكانية:وقد شمل البحث دول المقارنة الآتية:

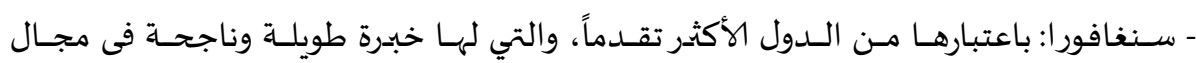

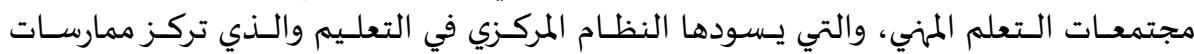

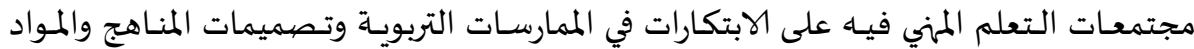

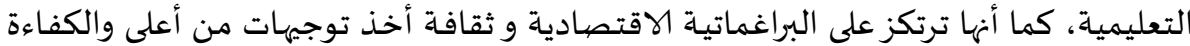
الإنتاجية

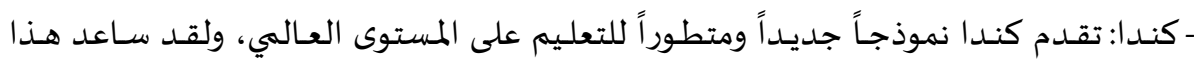

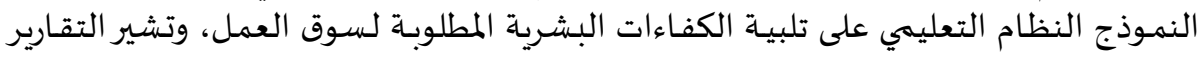

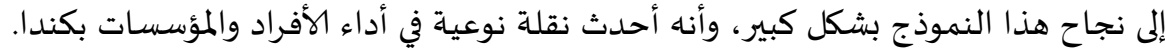

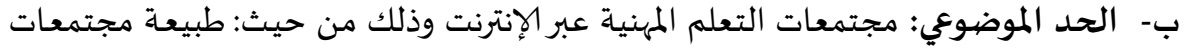

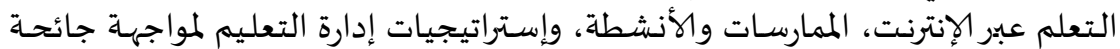

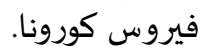

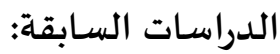

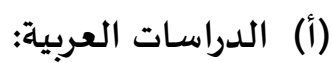

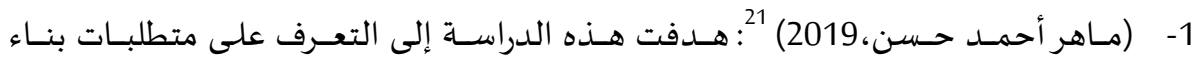

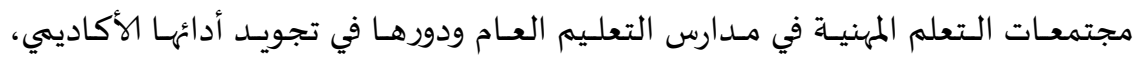

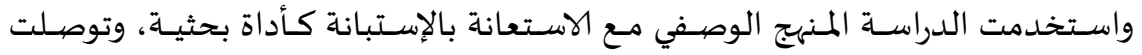

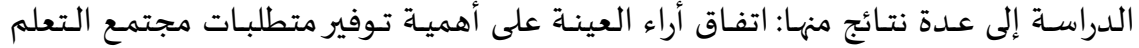

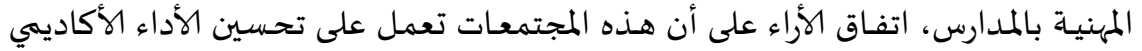

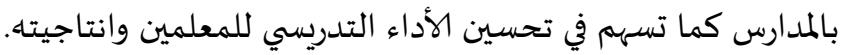

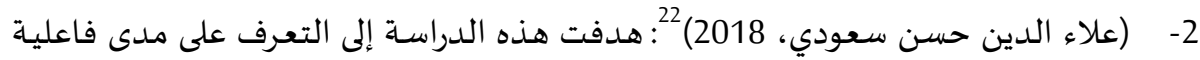

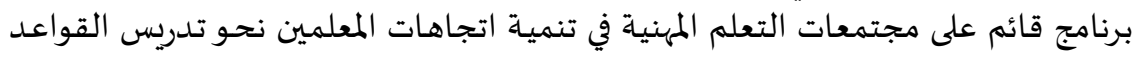




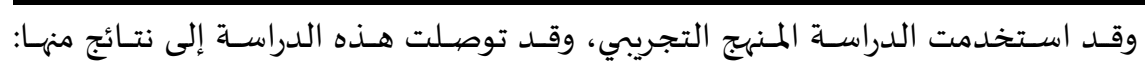

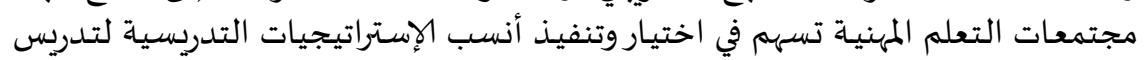

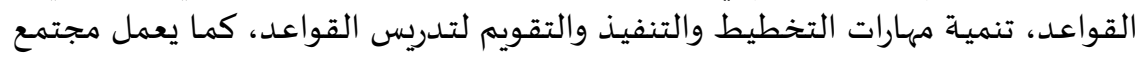

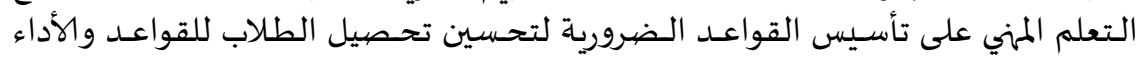
التدريسي لأعضاء المجتمع المنهي.

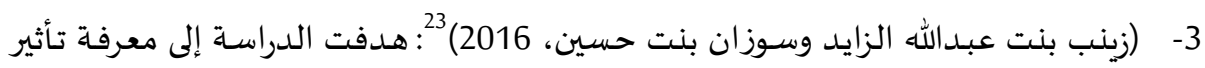

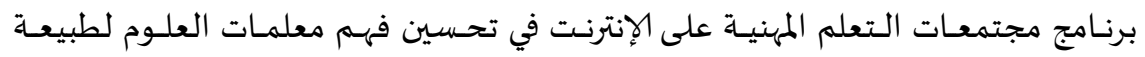

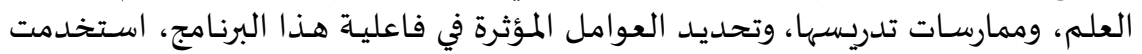

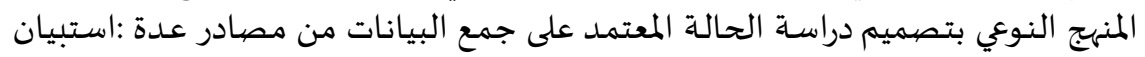

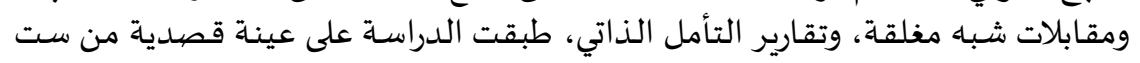

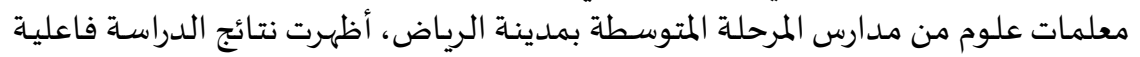

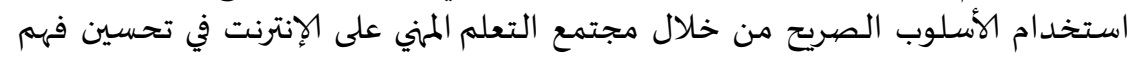

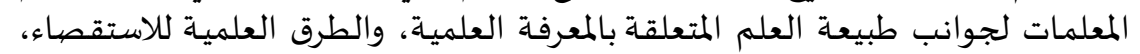

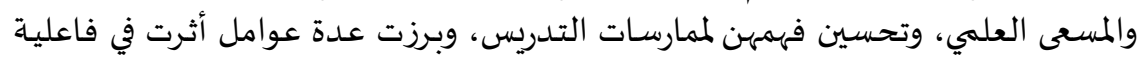

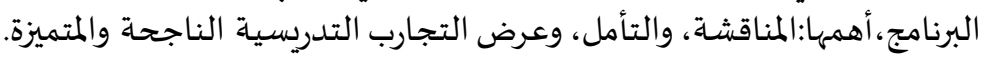

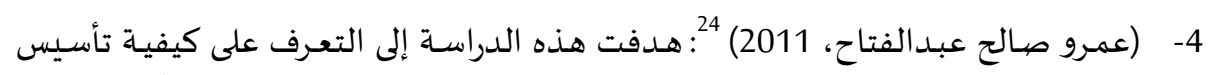

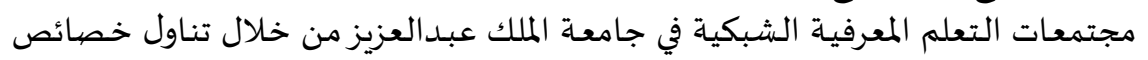

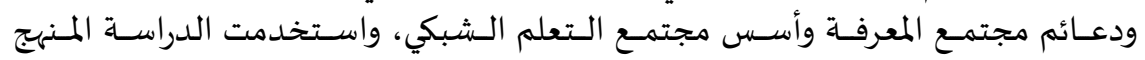

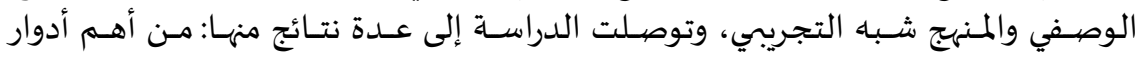

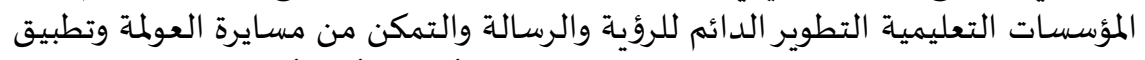

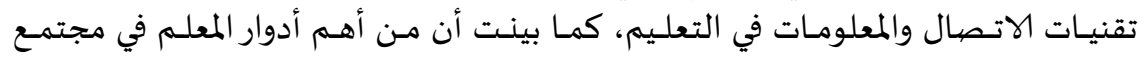

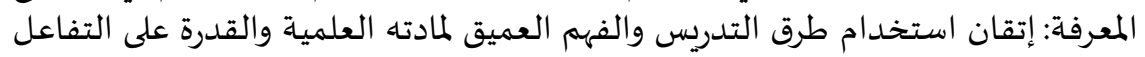

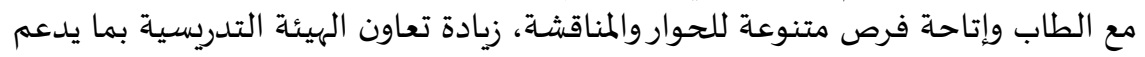

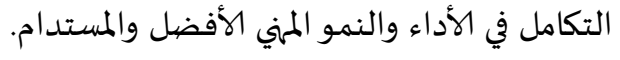

$$
\text { (ب ) الدراسات الأجنبية: }
$$

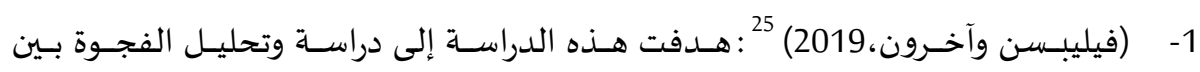

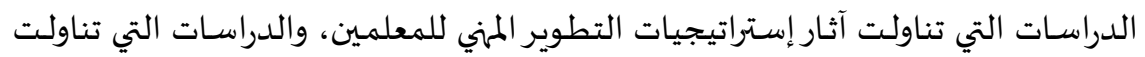

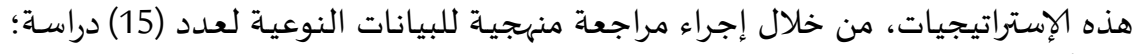

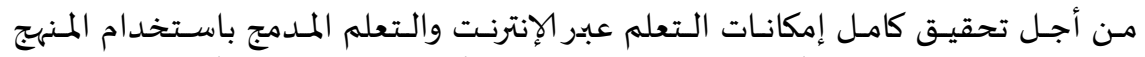

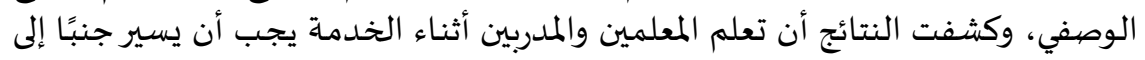

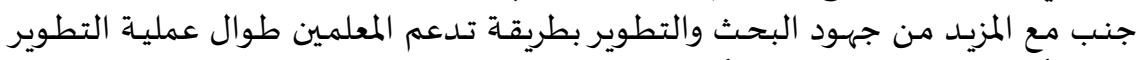

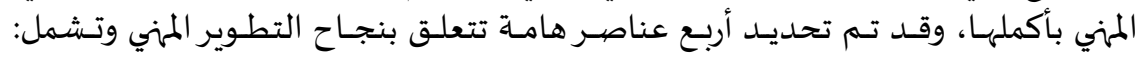

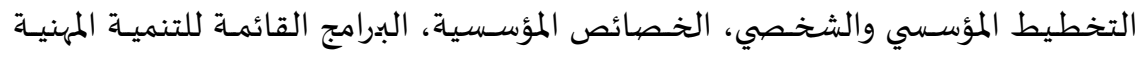
والتعلم المدمج، والعنصر الموسي والثخدي.

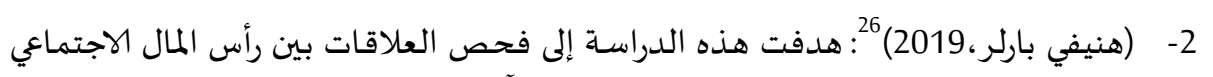

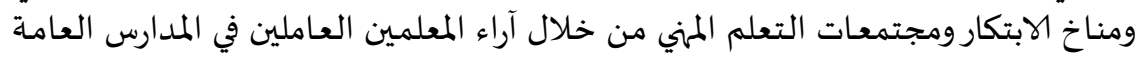


في اسـطنبول بتركيـا واسـتخدمت الدراسـة المنهنج الوصـفي، إذ اسـتخدمت نمـوذج إلمسيح

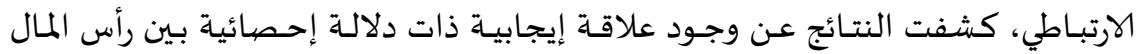

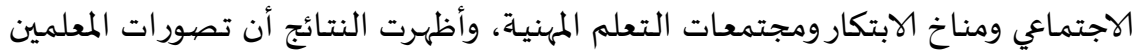

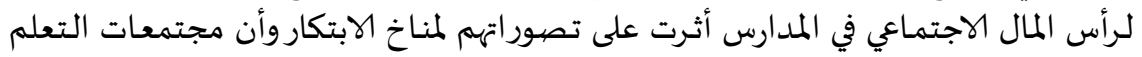

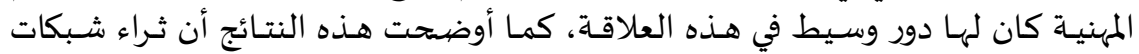

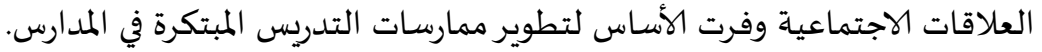

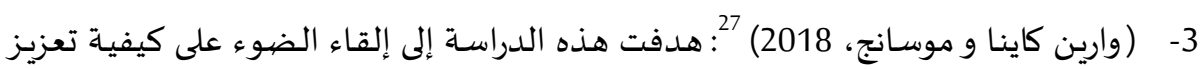

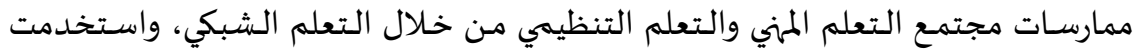

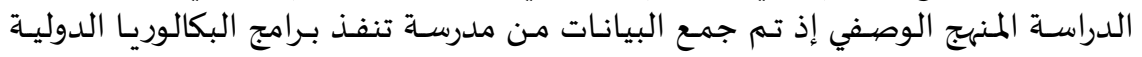

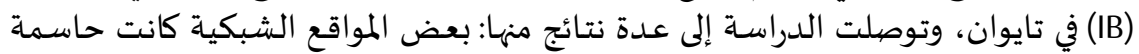

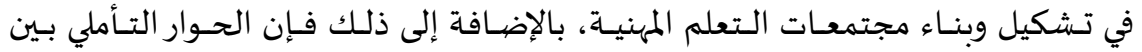
أعضاء المجتمع يعتبر العنصر الرئيسي في إنشاء وتحسين التعلم في هذه المدرسة.

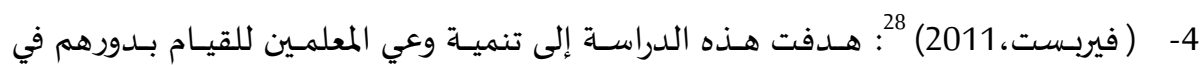

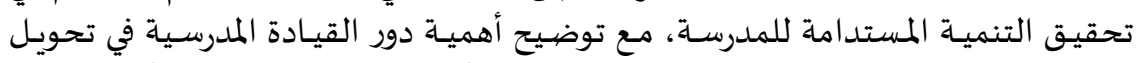

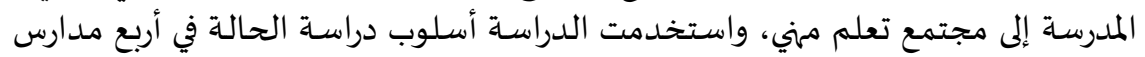

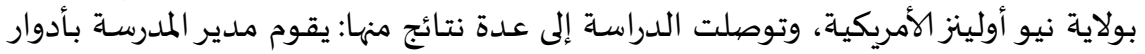

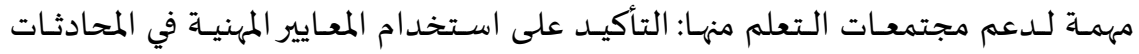

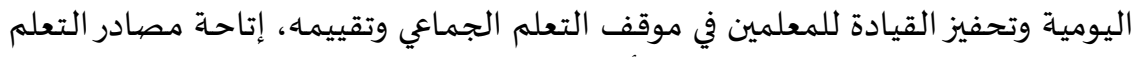

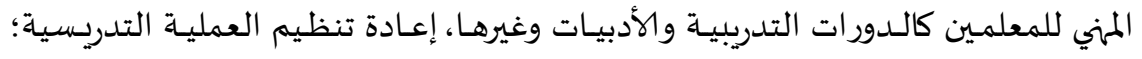

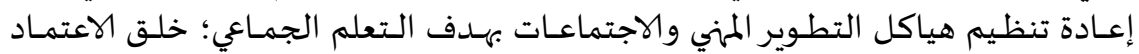

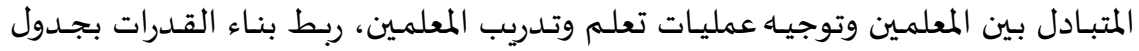

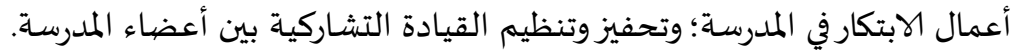

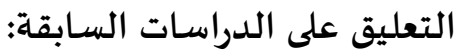

بعد استعراض وتحليل الدراسات السابقة العببية والأجنبية، يمكن التوصل إلى:

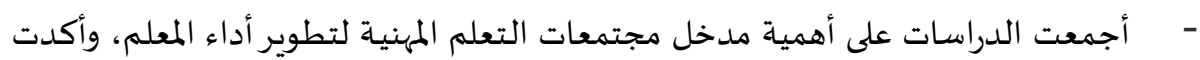
جميعها على ضرورة مشاركة المعلم في هذه المجتمعات أمعات داخل وخارج المدرسة.

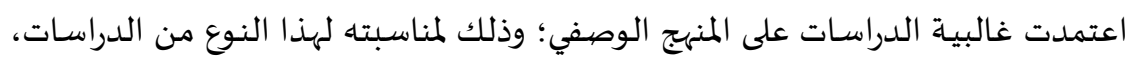

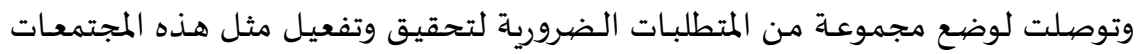

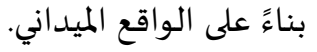

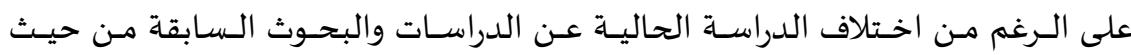

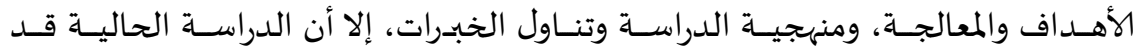

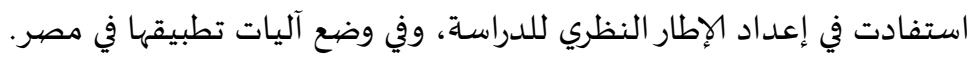




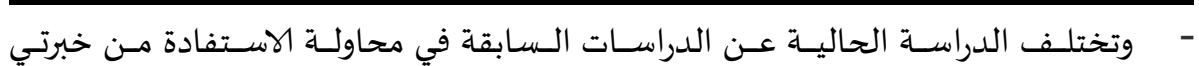

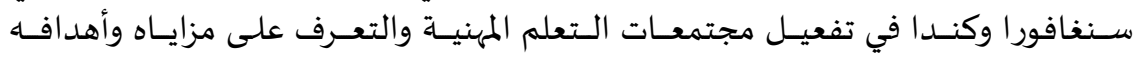

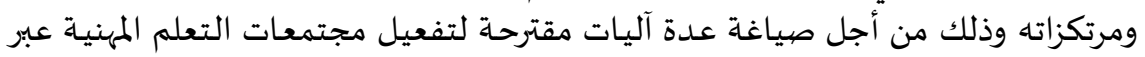

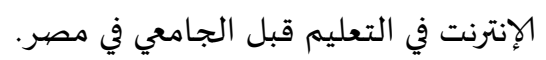
أولاً: الإطار النظري لمجتمعات التعلم المهنية عبر الإنترنت:

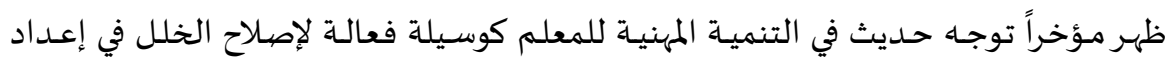

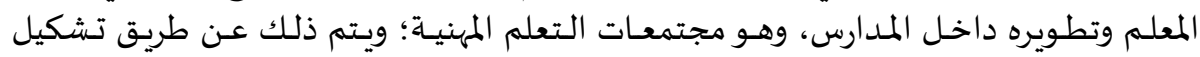

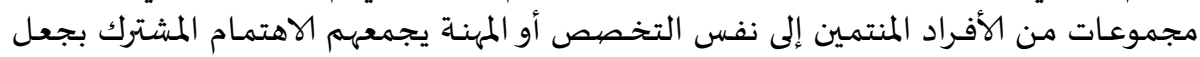

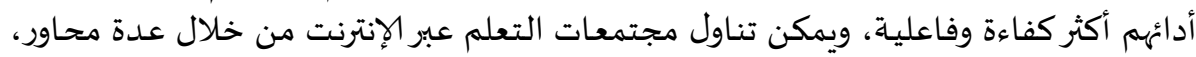
وهي كالتالي:

1- طبيعة مجتمعات التعلم المهنية عبر الإنترنت: ويتناول هذا المحور عدة مكونات وعناصر وهي كالتالي: أ- مفهوم مجتمعات التعلم المهنية عبر الإنترنت:

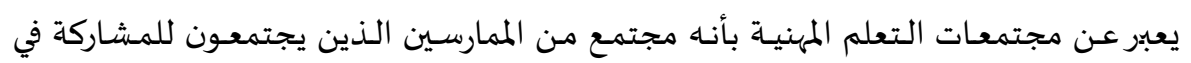
تعاوني في ${ }^{29}$ دمرة من تعلم المعلمين القائم على الاستفسار؛ والتي تتضمن مشاركة المعلمين بشكل (أ) تحديد التحديات التي تواجـه تعلم الطلاب على أساس المشكلات، (ب) جمع البيانات من الطلاب لإضفاء فهم سياقي لهذه المشكلات،

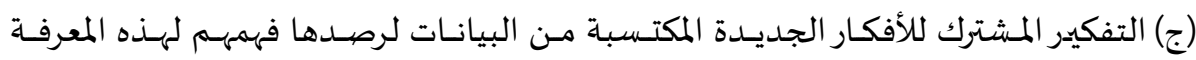

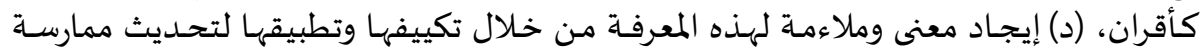
التدريس

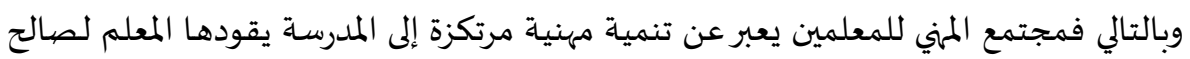

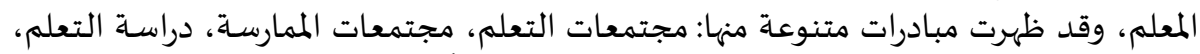

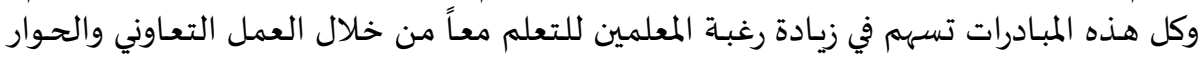
التأملي.

وتعرف مجتمعات التعلم المهنية بأنها مجموعة من فرق العمل المدرسي والتي تعمل على تطوير

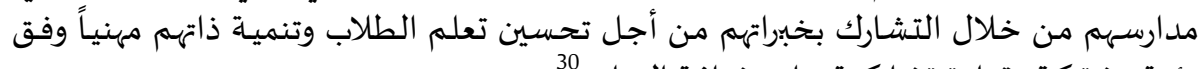
رؤية مشتركة وقيادة تشاركية تراعي ثقافة التعلم 30.

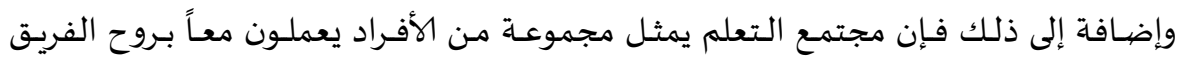

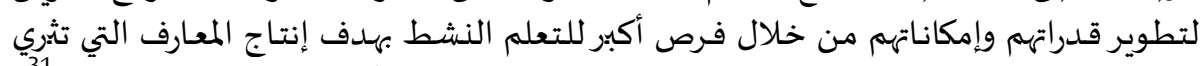

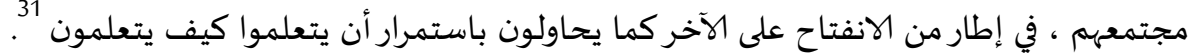


في حين أهها تعرف بأهها فرق وجماعات مسئولة عن قيادة المعرفة والتحليل والتطوير لتحسين التماني

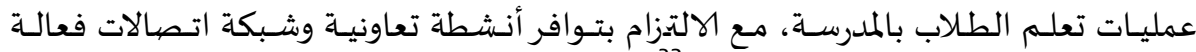

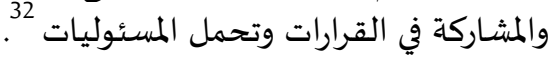

ومن خلال هذه التعريفات تتضح معالم مجتمعات التعلم المهنية عبر الإنترنت بأنها : - عدة فرق تعاونية من المعلمين بالمدرسة وعبر الإنترنت تتشارك الخبرات والمعارف المهنية. - تجمع هذه الفرق رؤية واحدة خاصية بالاهتمام المشترك والهدف الواحد. - تحفز القيادة الداعمة المعلمين على إنشاء مجتمعات التعلم عبر الإنترنت في ظل ثقافة تعاونية - تسهم اجتماعـات هـذه الفرق الواقعيـة والإفتراضية عبر الإنترنت في مناقشة أفضل الحلول لمواجهة الصعاب في العملية التدريسية بالمدرسة.

- تعمـل هـذه الفـرق على إيجـاد المعرفـة وتبادلهـا وتشـاركها وتحـديثها وابتكارهـا بـصورة فعالـة

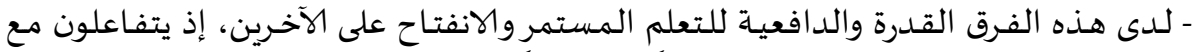

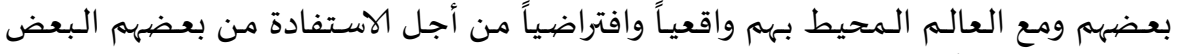

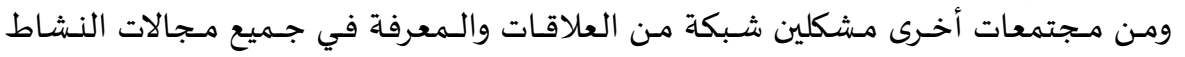
التربوي والتعليمي. ب- أهمية مجتمعات التعلم المهنية عبر الإنترنت: تشير الأدبيات إلى أهمية مجتمعات التعلم من حيث:

- توفير بيئة آمنة ومنظمة ومركزة على تعلم كل طالب مع منح كل طالب فرص إضيافية للتعلم حال التعثر 33 ـ الارتقاء بتعلم الطلاب من خلال تغيير سلوكيات وممارسات المعلمين 34.

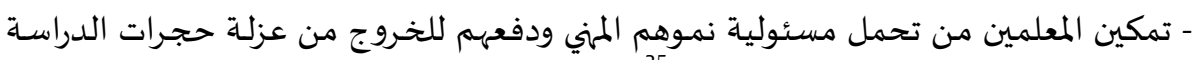

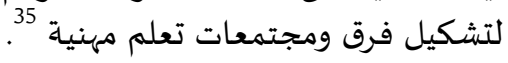

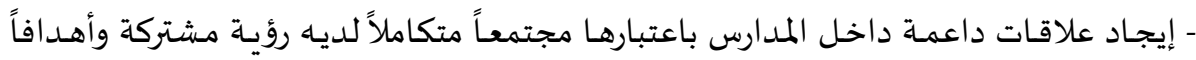
واقعية لتنمية جميع أعضاء المدرسة من معلمين وطلاب وقيادة.

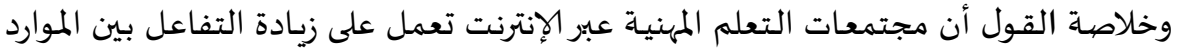

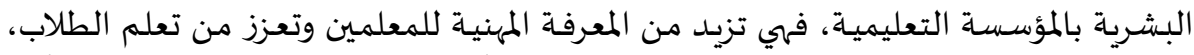

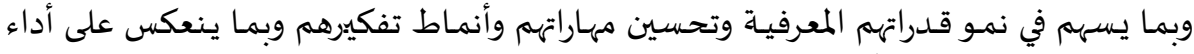

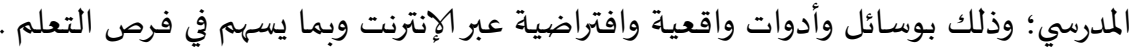


ج- فلسفة وأهداف مجتمعات التعلم المهنية عبر الإنترنت: تهن:

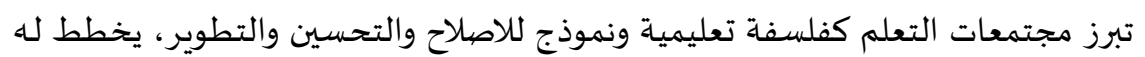

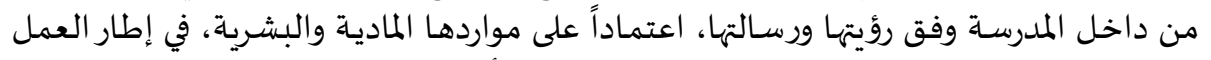

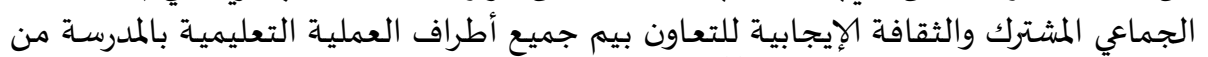
طلاب ومعلمين وإدارة ومجتمع محلي الإيجابية 36

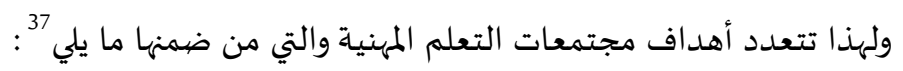
- تحسين الأداء الأكاديمي للطلاب والمدارس باستمرار. - - تحسين الثقافة التنظيمية التعاونية بالمدرسة. - - مطاء الفرصة للمعلمين لممارسة القيادة مع تطويروتحسين خبرات ومعارف المعلمين . - بناء بيئة داعمة للتعلم كما أهها وسيلة لتحسين جودة أداء المعلم. - - ميادة دافعية المعلمين نحو العمل، وتغيير نظرتهم للمهنة التعليم لتكون إيجابية. - تنمية الشخصية الجماعية وانعدام العزلة الفردية . وتنفرد مجتمعات التعلم المهنية عبر الإنترنت بعدد من الأهداف منها

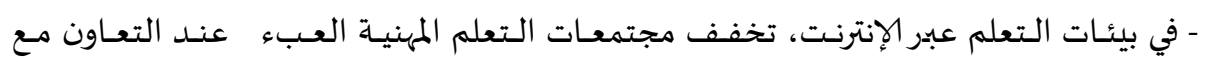

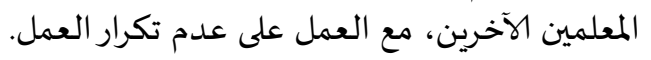

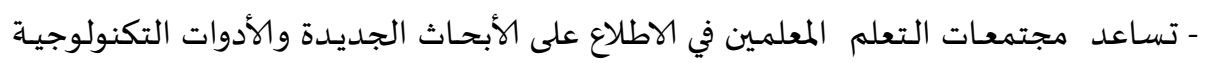

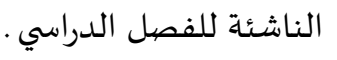

- كما توفر مجتمعات التعلم المهنية عبر الإنترنت للمعلمين نظرة مختلفة على ما يمارسه معلمو

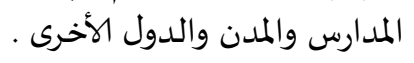

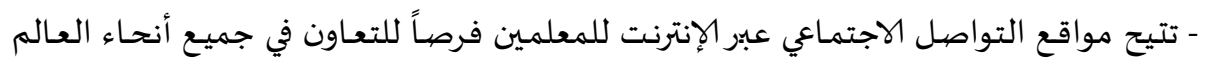

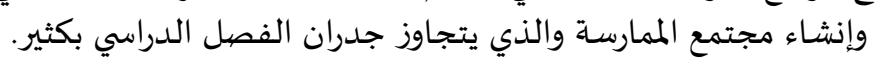

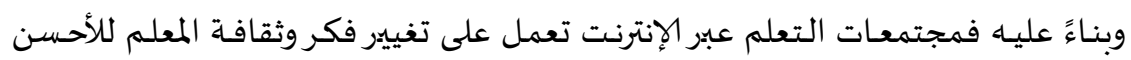

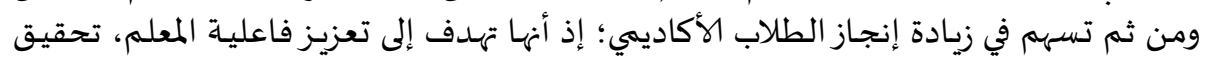

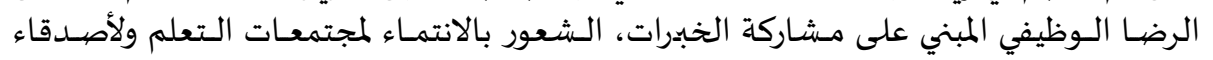

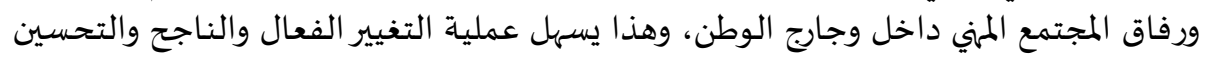


د- مبادئ ومرتكزات مجتمعات التعلم المهنية عبر الإنترنت:

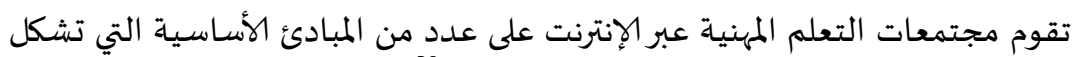

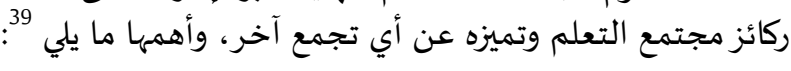

$$
\text { 1- الرؤية والقيم والأهداف المشتركة: }
$$

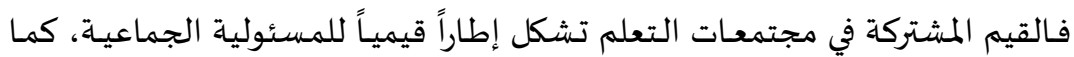

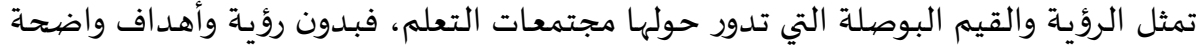

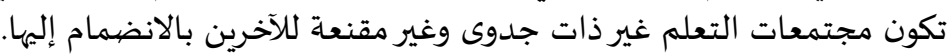

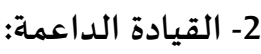

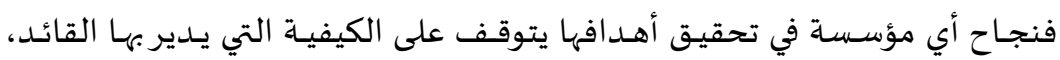

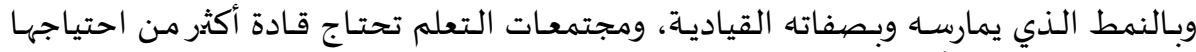

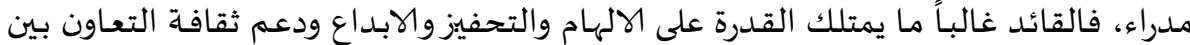

أعضاء مدرسته.

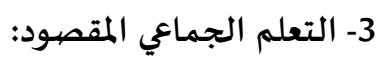

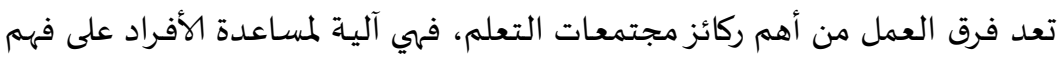

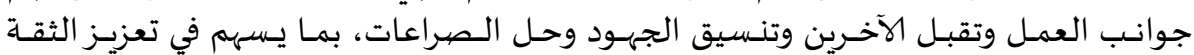
والتعاون و تحقيق الأهداف.

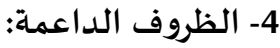

إن تحويل المدرسة إلى مجتمع تعلم مهني يتطلب توفير البيئة الداعمة، والتي تتمثل في

الثقافة التنظيمية الداعمة، والهيكل التنظيمي المرن.

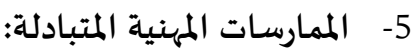

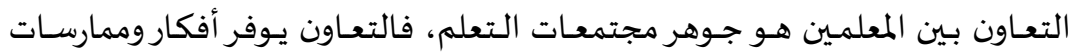

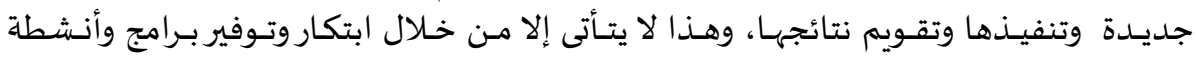

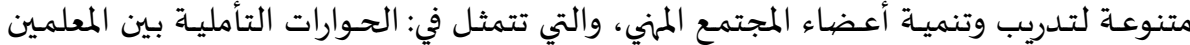

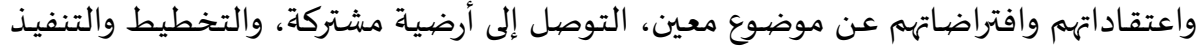

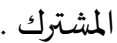

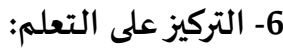

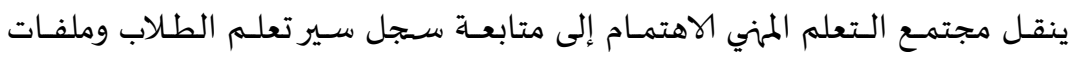

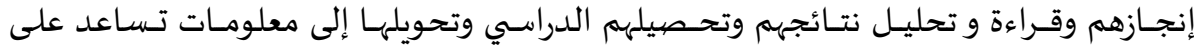

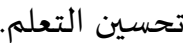

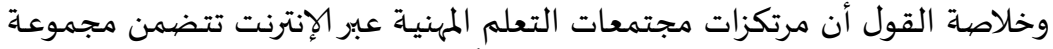

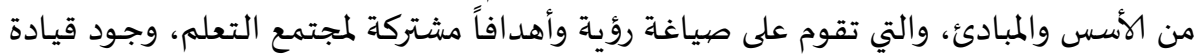




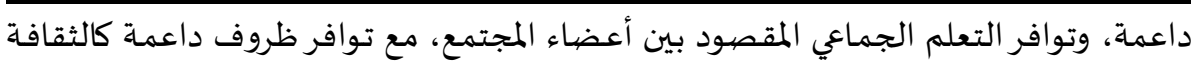

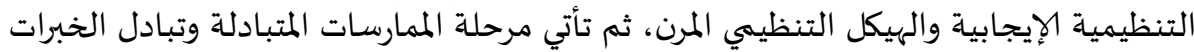

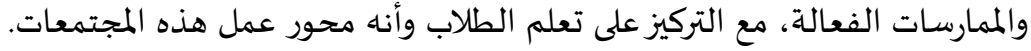
هـ - تصنيفات وأنواع مجتمعات التعلم المهنية عبر الانترنت:

يمكن تصنيف مجتمعات التعلم عبر الإنترنت حسب محور اهتمامها إلى ما يلي :40: - مجتمع يركز على الطالب:والذي يبحث في تعلم الطلاب عبر عدة مواد دراسية. - - مجتمع تعلم يركزعلى المادة الدراسية:والذي يبحث في تطوير الممارسات التدريسية. - - مجتمع تعلم يركز التطوير التربوي داخل وخارج المدرسـة.

كما تصنفف مجتمعـات التعلم على حسب الاحتياجـات الفرديـة للمدرسـة فمنهـا

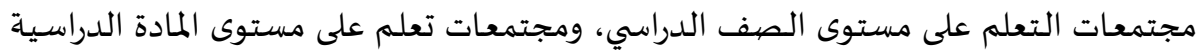
والمحتوى التعليمي، ومجتمعات تعلم على مستوى المدرسة ككل وخارجها.

وإضـافة إلى ذلك فيتم تقسيم المجتمعات المهنيـة كبيرة الحجـم إلى مجتمعات صغيرة

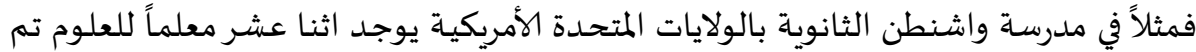

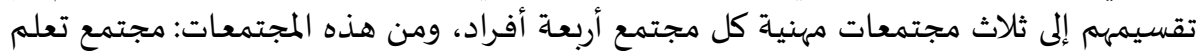

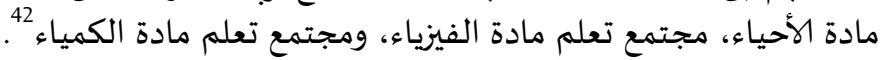

ومما تقدم تتضح أن تصنيفات مجتمعات التعلم منها ما يدور حول المادة الدراسية

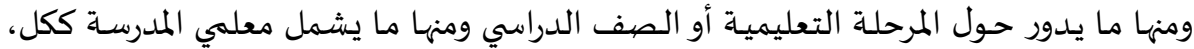

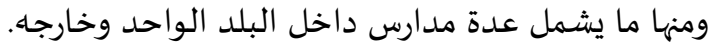
و - إدارة وتقييم مجتمعات التعلم المهنية عبر الإنترنت:

إن نجـاح المـدارس في تطبيـق وتفعيـل مجتمعـات الـتعلم يعتمـد على حسـن الإدارة

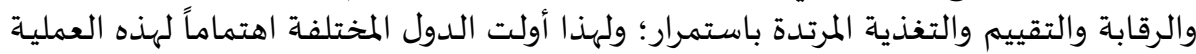

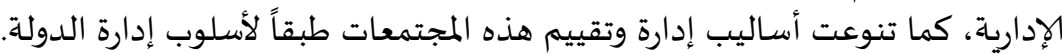

ولهذا تعتبر مجتمعات التعلم المهنية أو ما يعرف ب( Teaching Research Groups

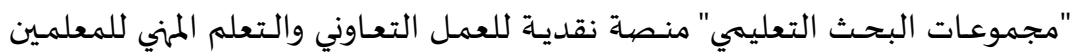

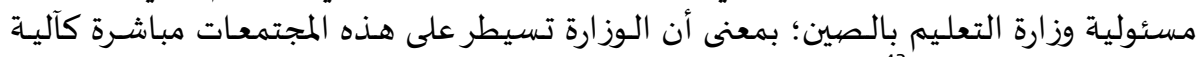

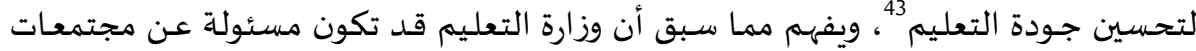
التعلم عبر الإنترنت.

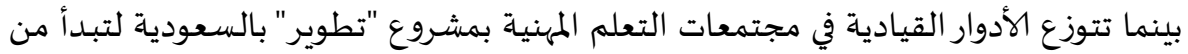

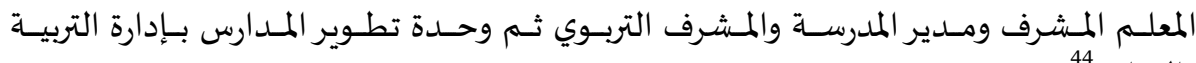




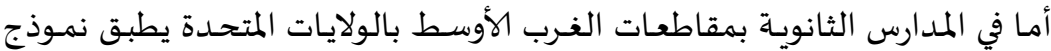

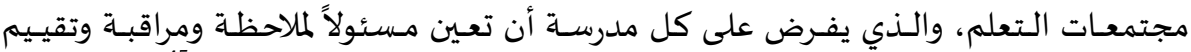

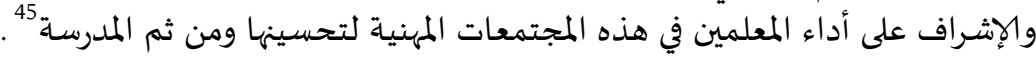

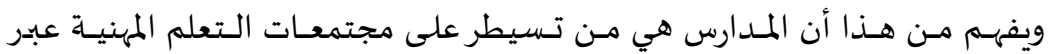

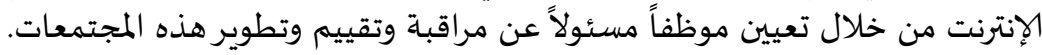

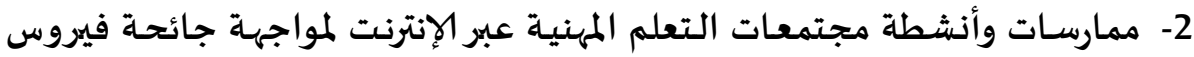

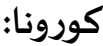

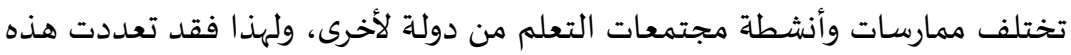

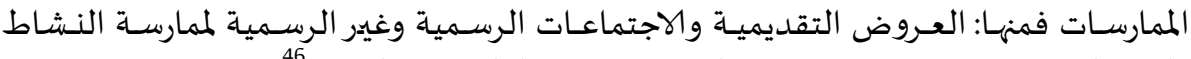

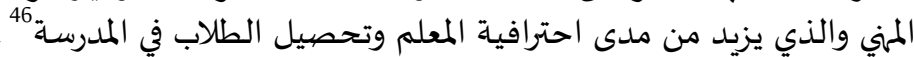

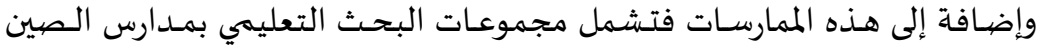

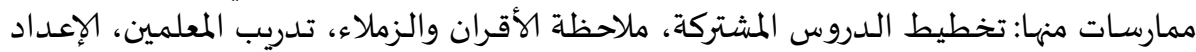

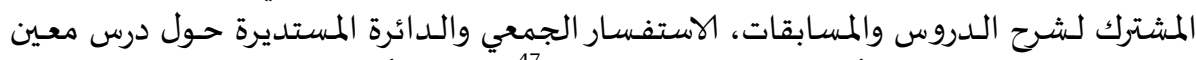

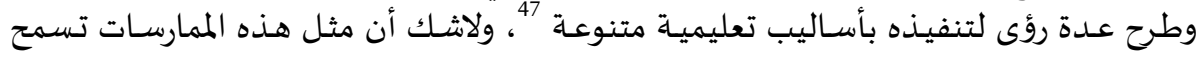
للمعلمين بمشاركة ومناقشة ممارساتهم والبناء المشترك للمعارف بشأن التعليم والتعلم.

كما تتنوع هذه الممارسات والأنشطة في برنامج "تطوير" بالسعودية والتي من أهمها:

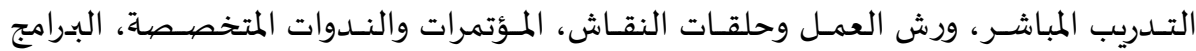

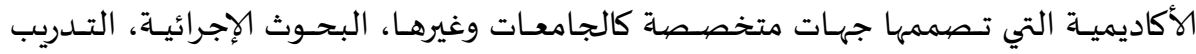

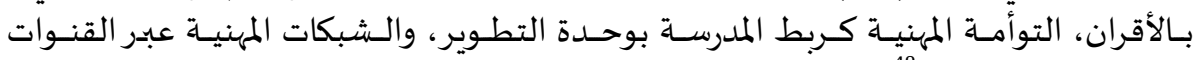
والمنصات الإلكترونية التوانية

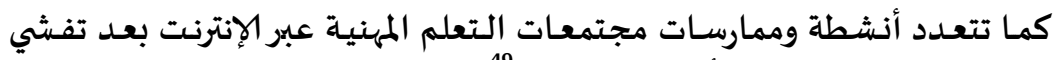
الجائحة ففي المملكة المتحدة و ويلزو وأسكتلندا فمنهنهات

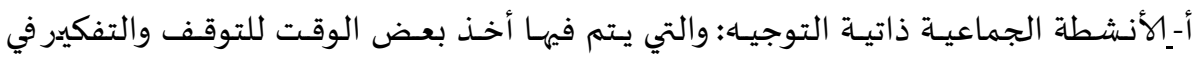

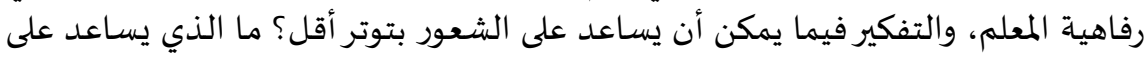

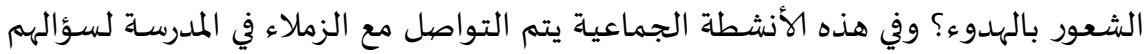

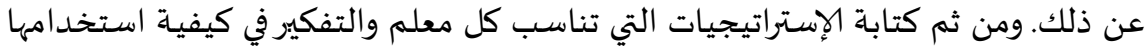

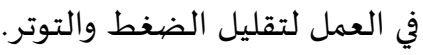

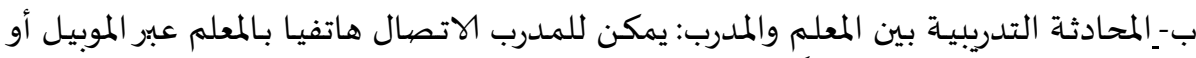

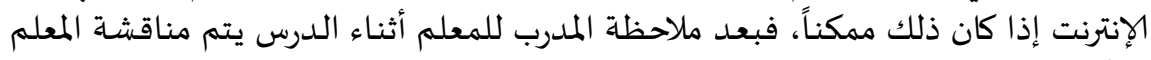

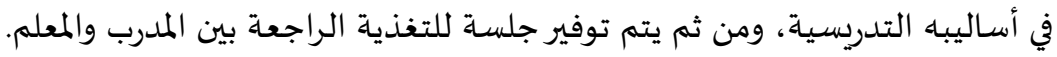

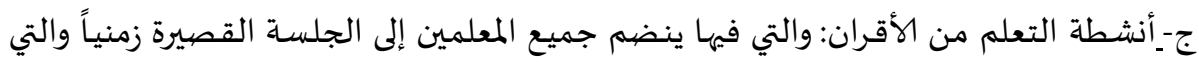

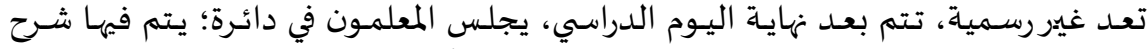

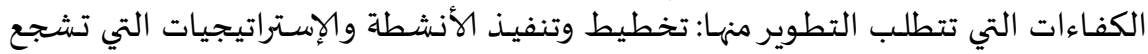




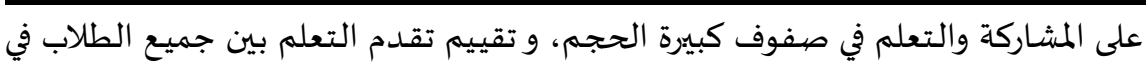

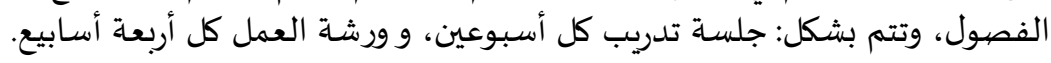

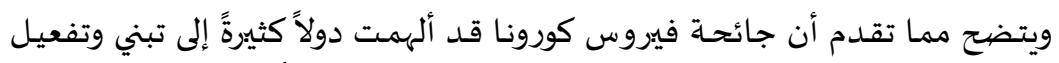

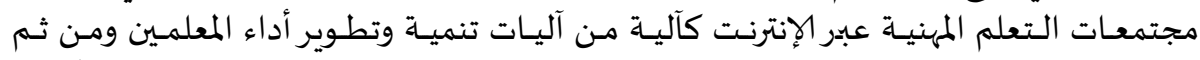

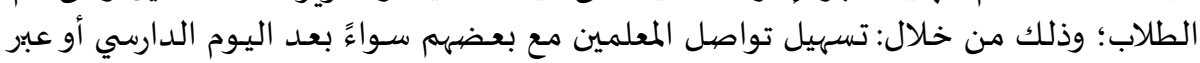

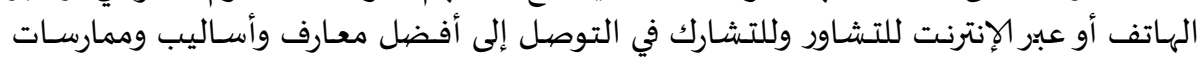
تدريسية.

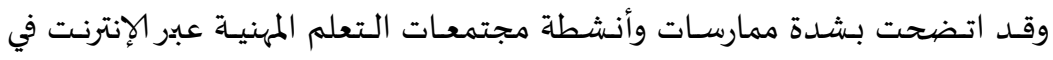

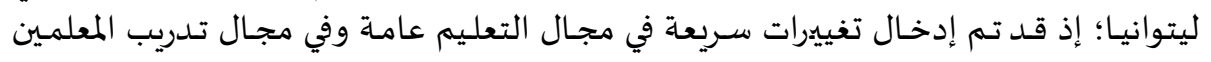

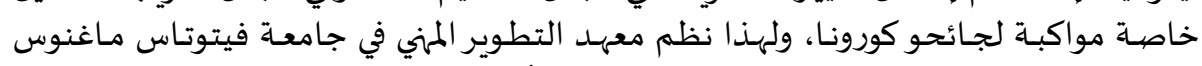

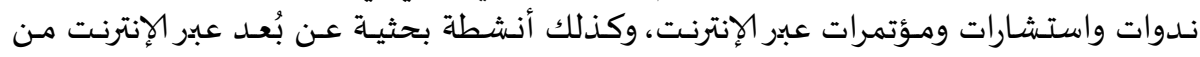

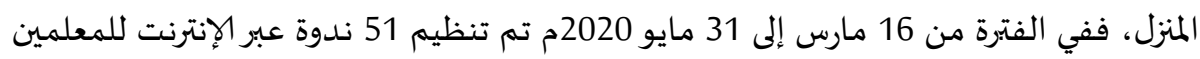

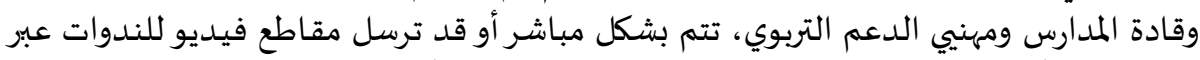

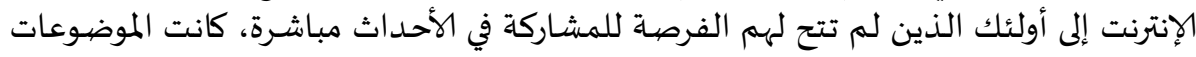

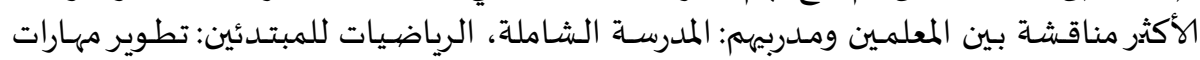

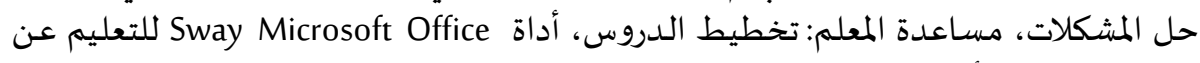

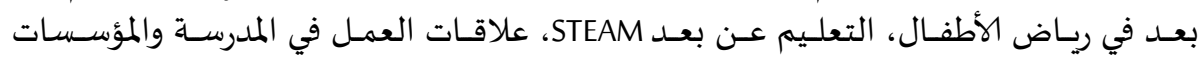

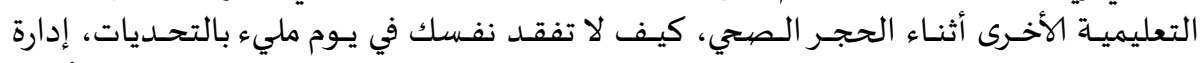

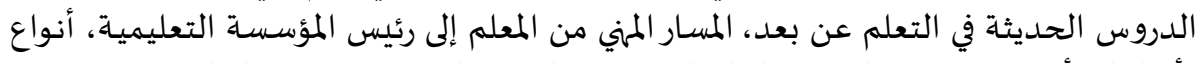

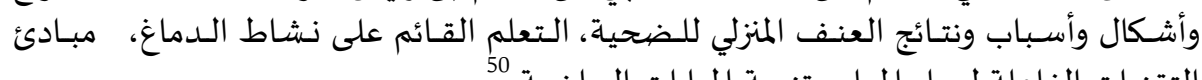

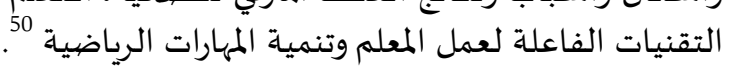

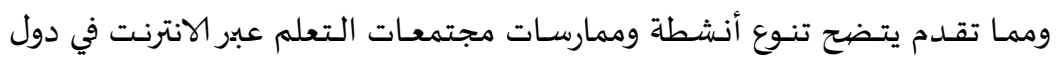

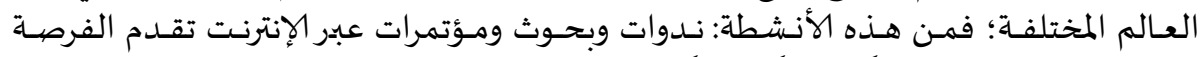
لتطوير أداء المعلمين علمياً وتربوياً وإدارياً. 3- إستراتيجيات إدارة التعليم لمواجهة جائحة فيروس كوروناء المعان عاديا:

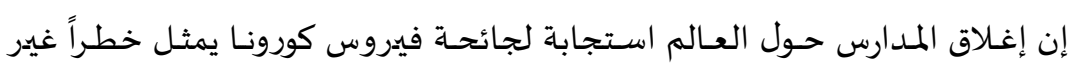

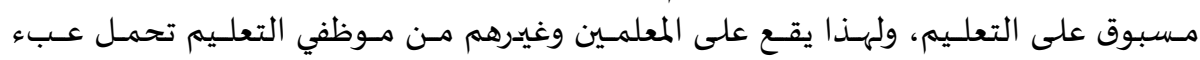

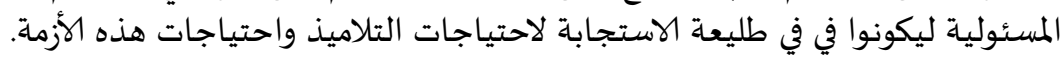

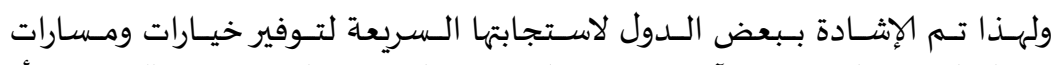

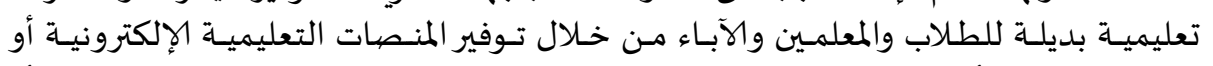

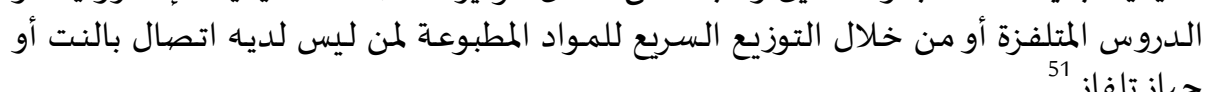

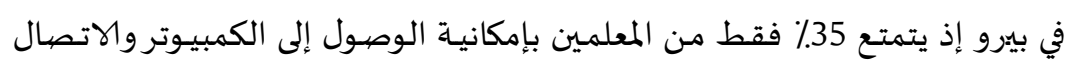

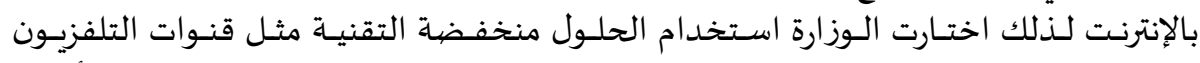

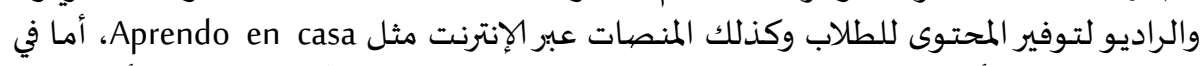

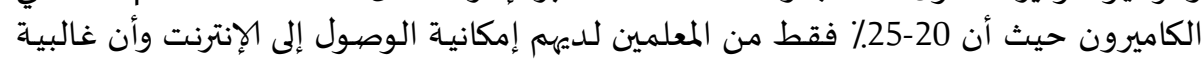




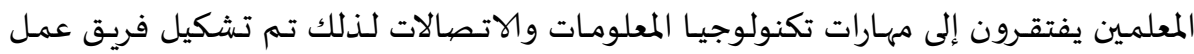

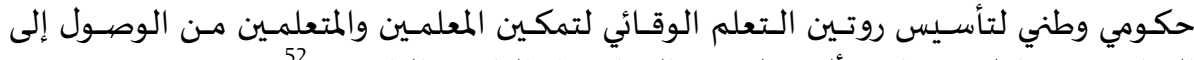

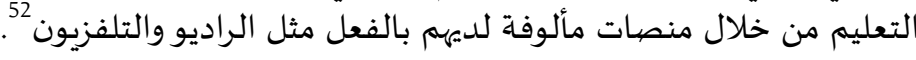

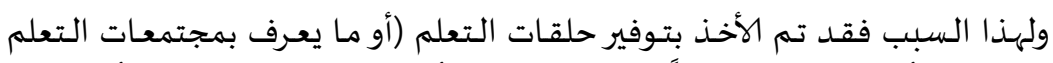

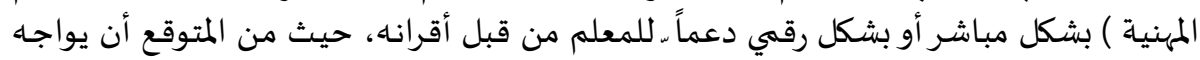

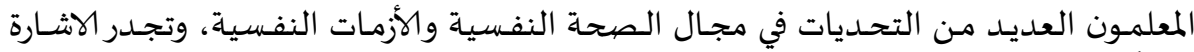

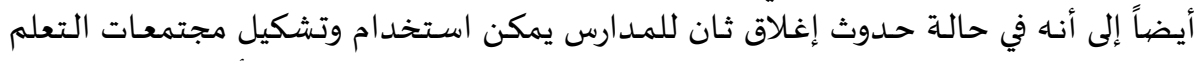

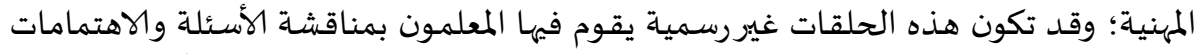

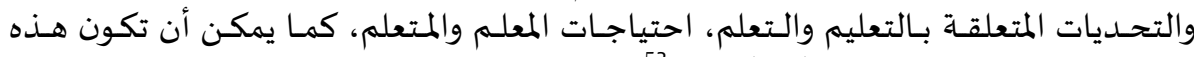

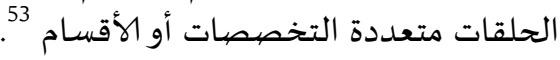

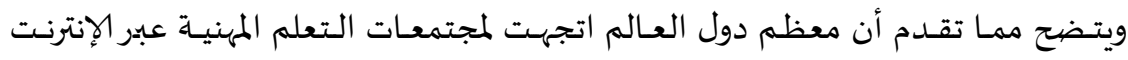

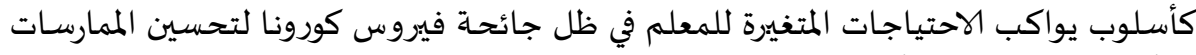

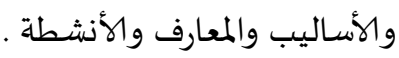

\section{الخبرات الأجنبية في تفعيل مجتمعات التعلم المهنية عبر الإنترنت:}

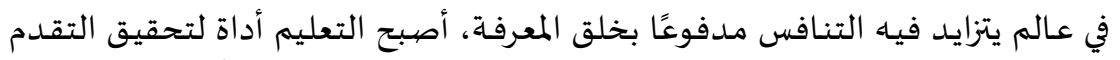

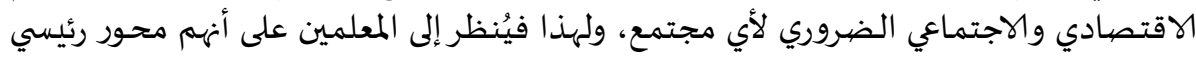

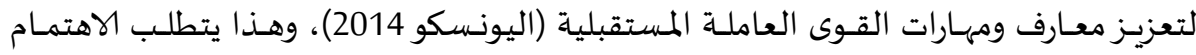

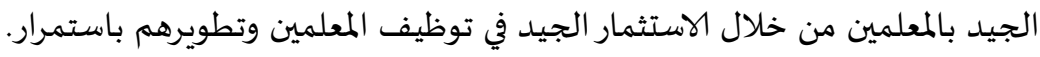

ثانياً ملامح مجتمعات التعلم المهنية عبر الإنترنت في سنغافورا:

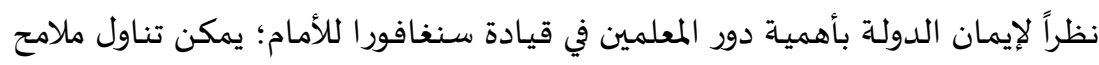

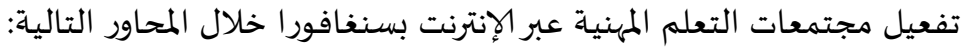
1- طبيعة مجتمعات التعلم المهنية عبر الإنترنت: ويتناول هذا المحور عدة مكونات وعناصر فرعية، وهي كالتالي: أ- فلسفة وأهداف مجتمعات التعلم المهنية عبر الإنترنت :

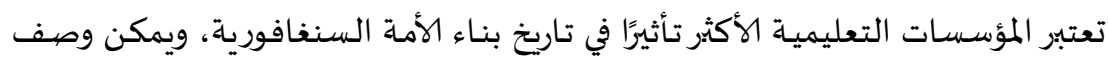

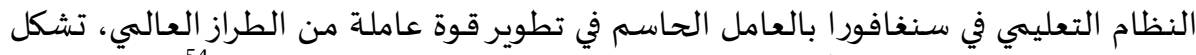

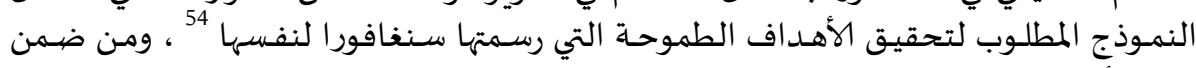

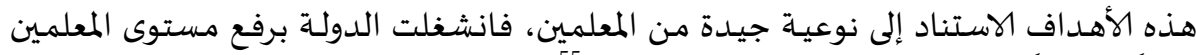
مادياً ومعنوياً وعبر مبادرات التطوير المهني المكثف من لمعيد

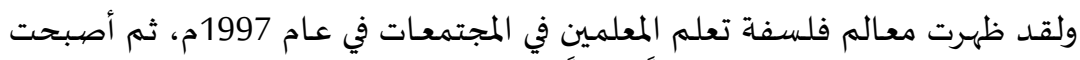

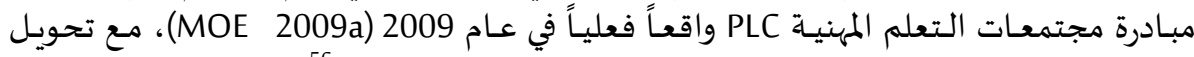

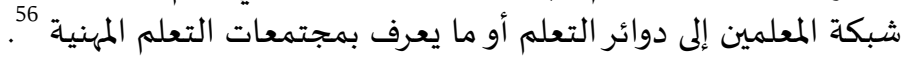




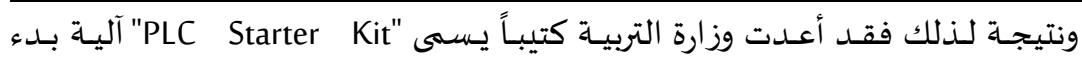

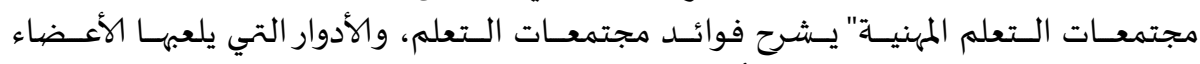

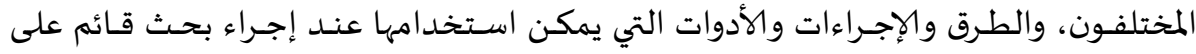

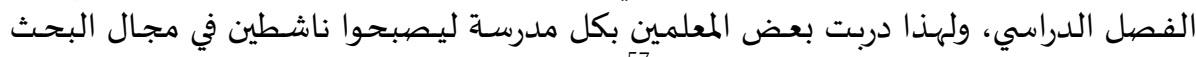

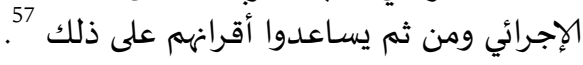

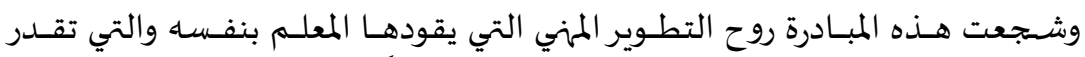

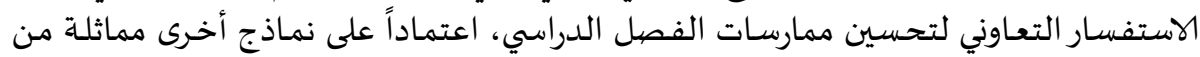

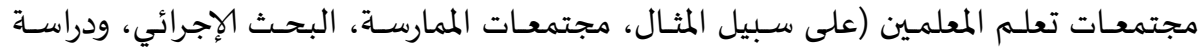

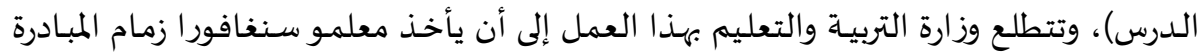

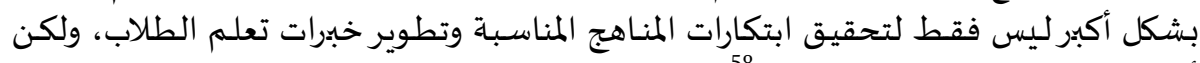

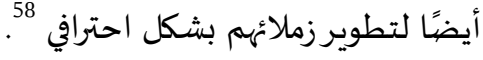

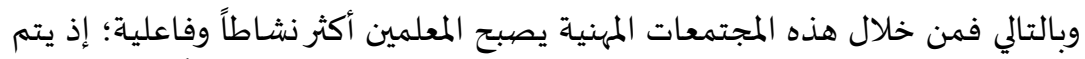

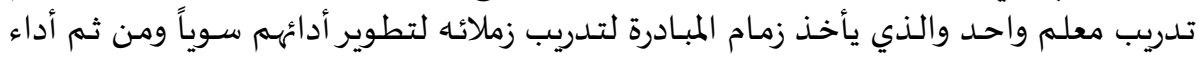

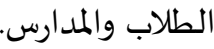

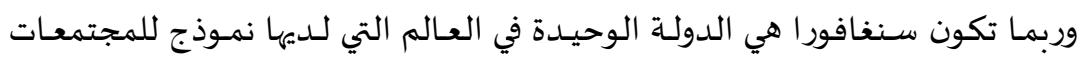

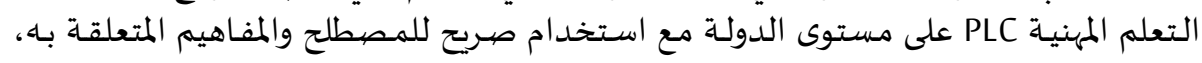

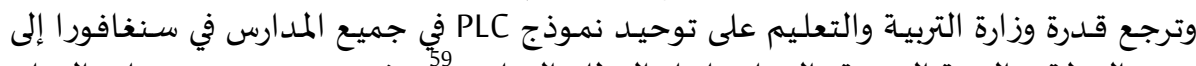

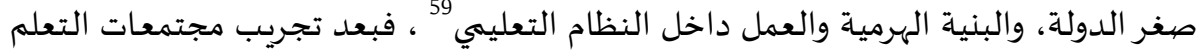

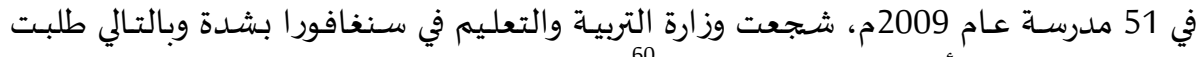

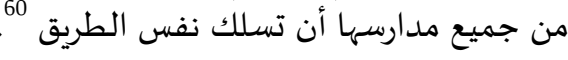

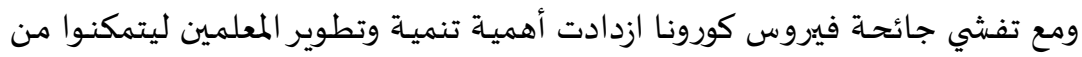

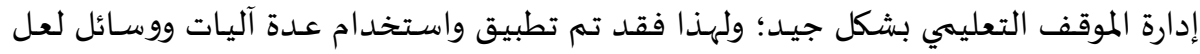
من أهمها مجتمعات التعلم المهنية عبر الإنترنت.

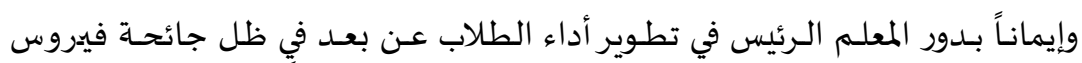

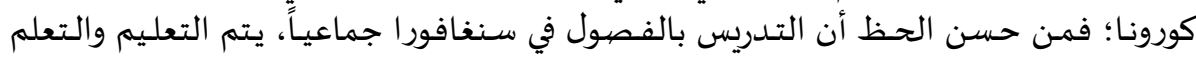

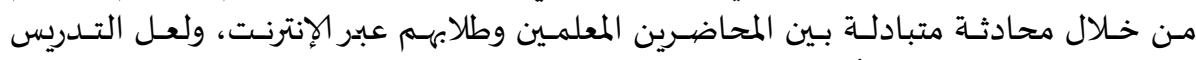

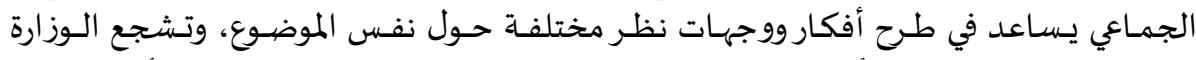

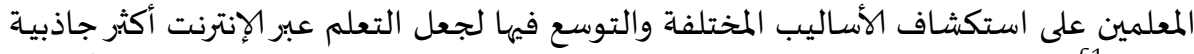

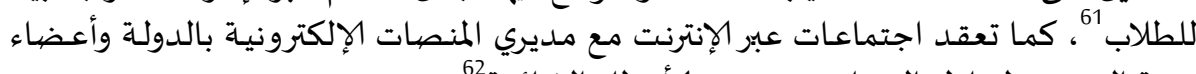

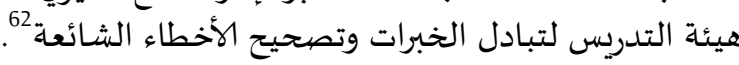

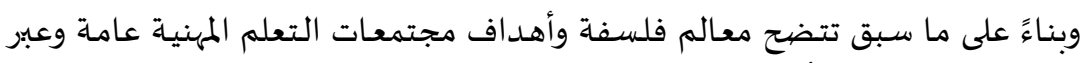

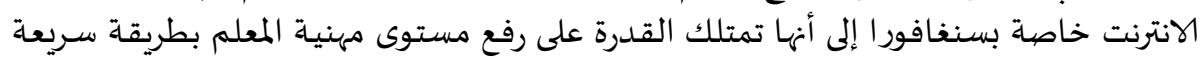

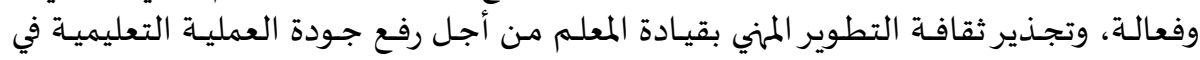
جميع المدارس والفصول الدراسية في سنغافورا. 
ترتكز مجتمعات التعلم المهنية في سنغافورا إلى ثلاثة أفكار كبيرة: تمكين الطلاب من التهرئ

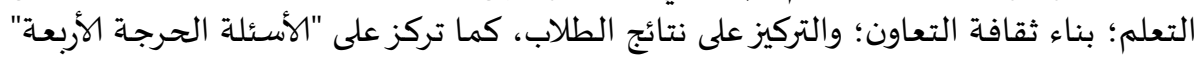

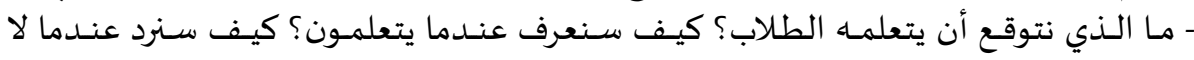

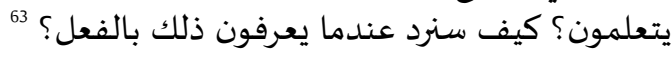

وبالتأكيد تعمل هذه الأفكاروالأسئلة الحرجة على التأثير بشكل إيجابي على التهائل التدريس

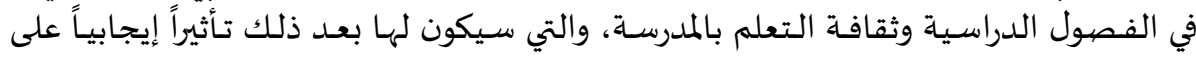
نتائج الطلاب.

ج- تصنيفات وأنواع مجتمعات التعلم المهنية عبر الإنترنت:

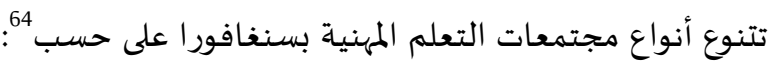

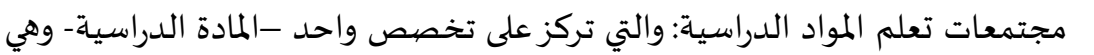

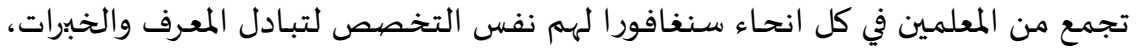

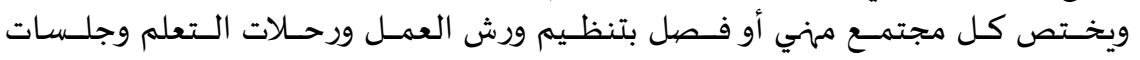

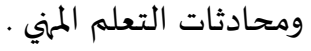

مجتمعات تعلم الفصول الدراسية: والتي تركز على تعلم كل مرحلة دراسية في كل

التخصصصات. مجتصات

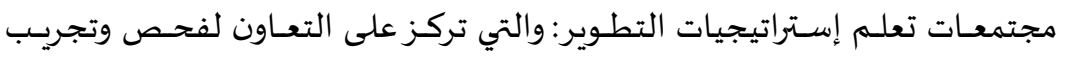

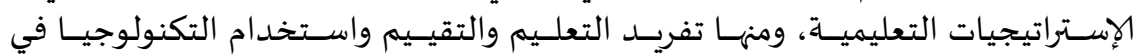

التدريس والتعلم

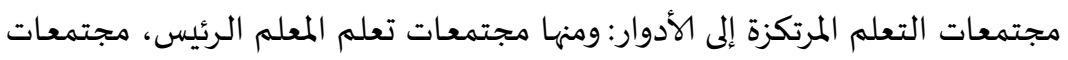

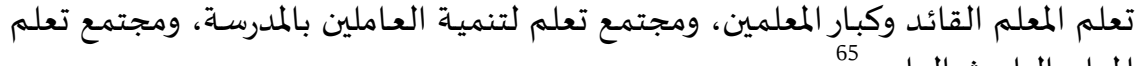

المعلم الباحث العلهي 65

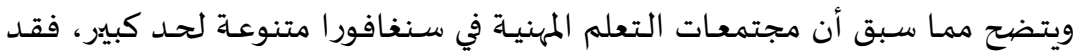

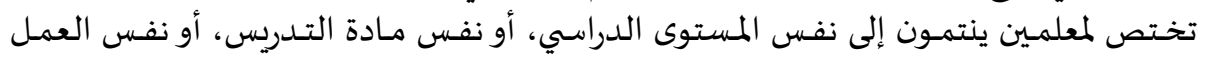

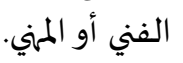

د- إدارة وتقييم مجتمعات التعلم المهنية عبر الإنترنت:

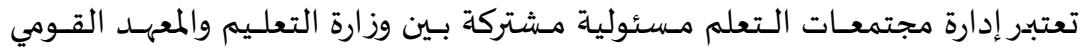

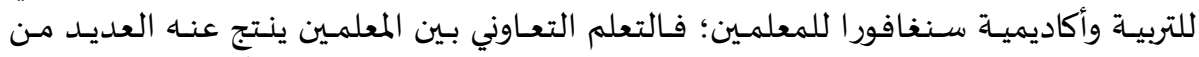

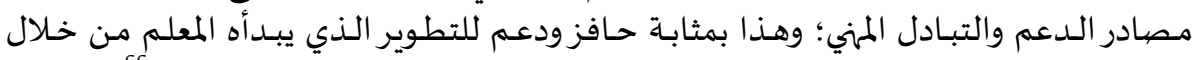

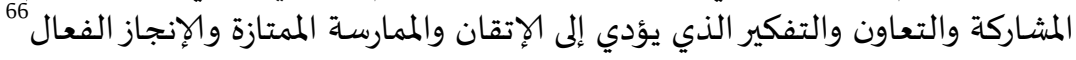

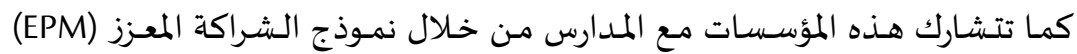
Enhanced Partnership Model 


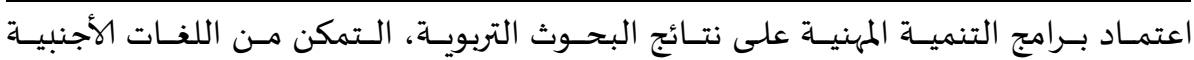

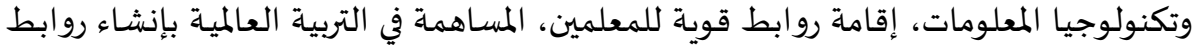

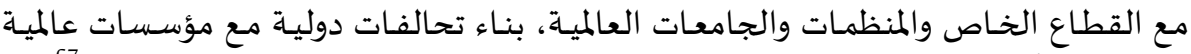

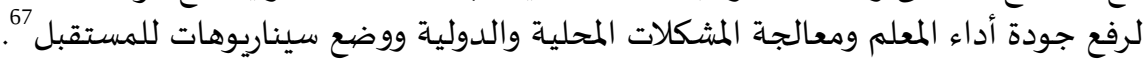

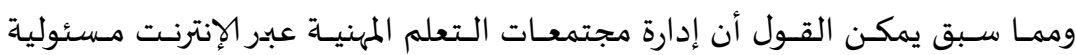

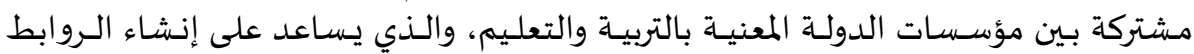
والتحالفات المهنية للمعلمين على المستوى المحلي والقومي والعاليي.

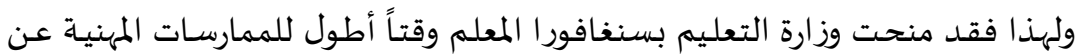

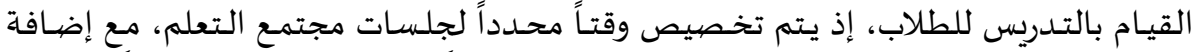

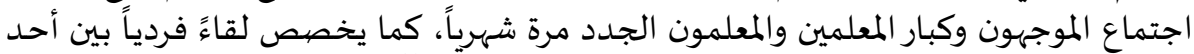

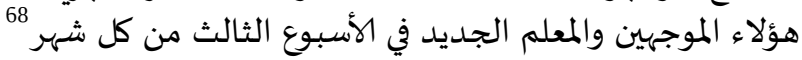

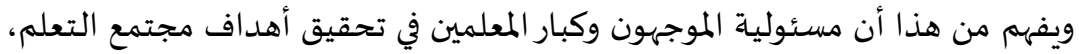

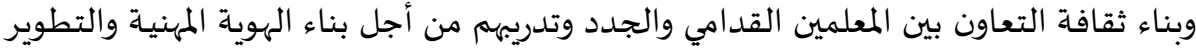

المستمر

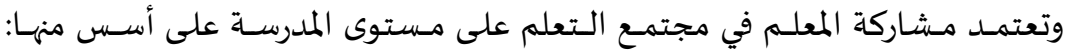

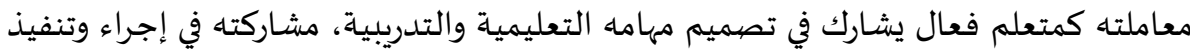

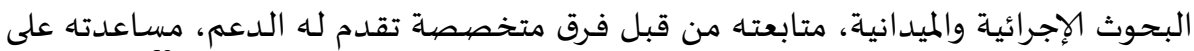

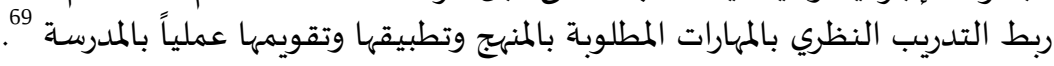

وإضـافة إلى ذلك يـتم تقيـيم أداء مجتمعـات التعلم المهنيـة في سـنغافورا مـن أجـل

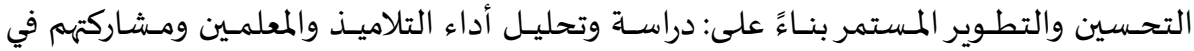

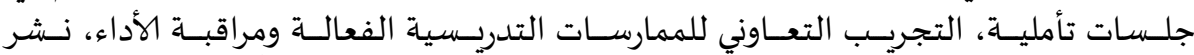

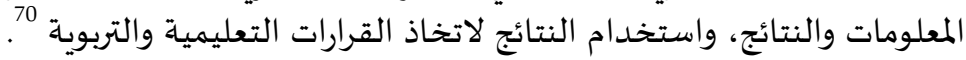

وعليه فيتم مراقبة أداء المعلم من قبل الموجههون وكبار المعلمين خلال مشاركته في جلسات المعات

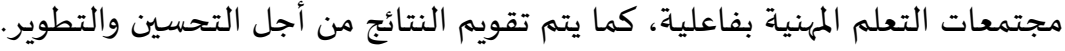

2- ممارسات وأنشطة مجتمعات التعلم المهنية عبر الإنترنت:

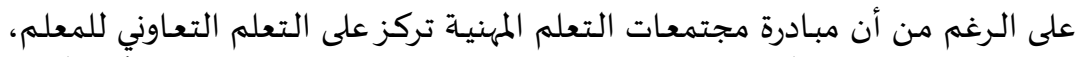

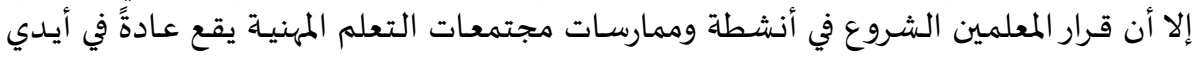

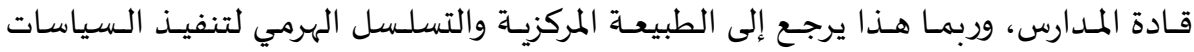

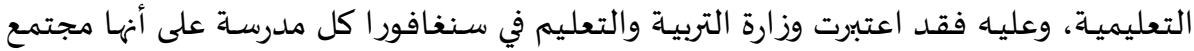
تعلم كبير يتكون من عدة مجتمعات تعلم مهنية فرعية.

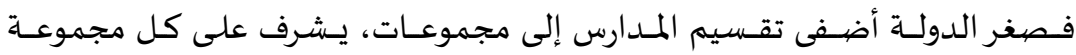

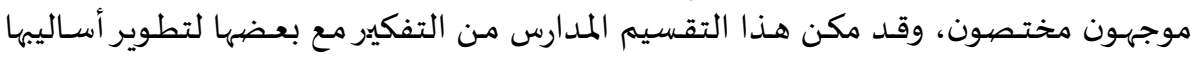

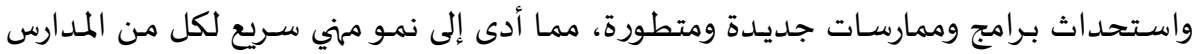

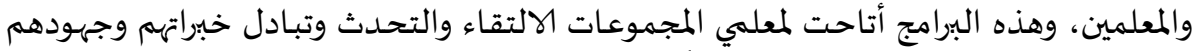

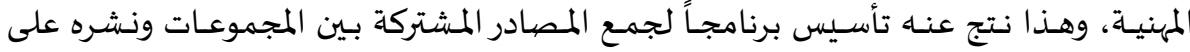


الإنترنت وأطلقوا عليه iSHARE ، ففي خلال الأشهر الثمانية عشرة الأولى لإطلاق البرنامج تم

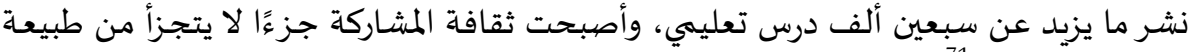

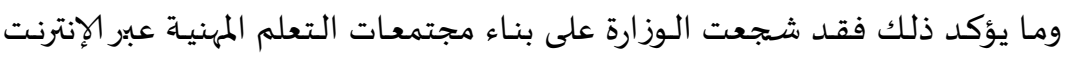

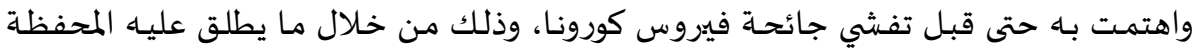

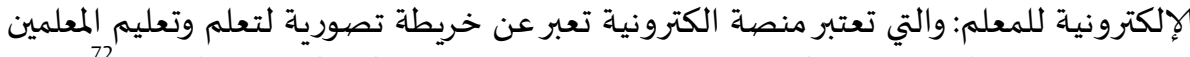

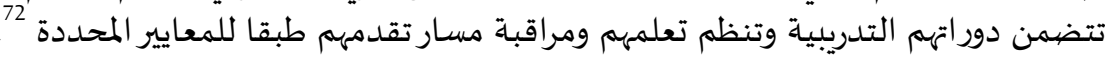

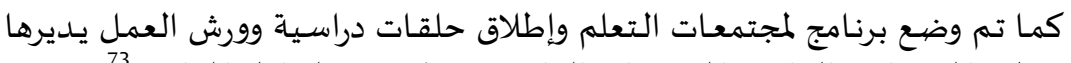

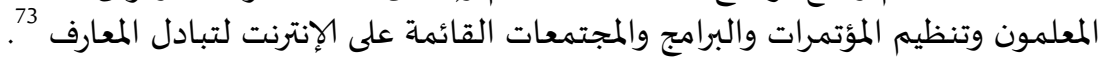

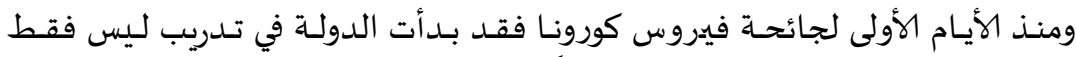

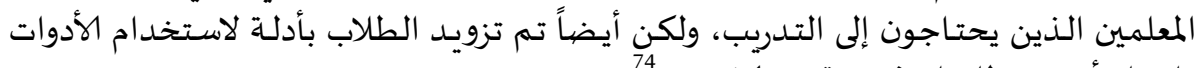
وإعداد أنفسهم للتعلم في بيئة عبر الإنترنت المعند 74

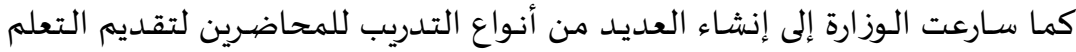

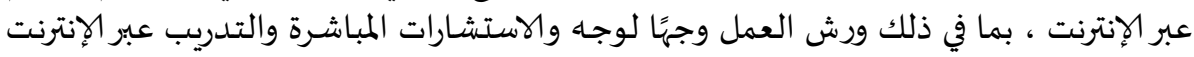

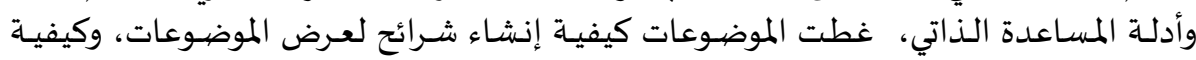

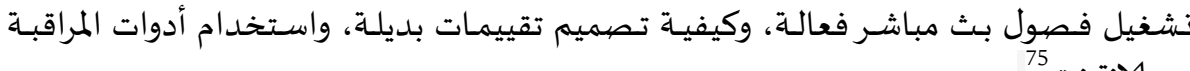

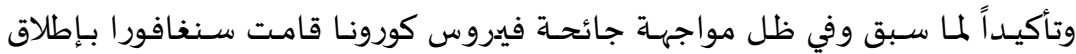

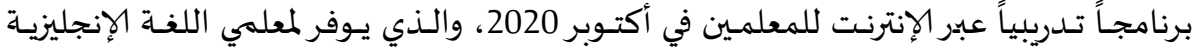

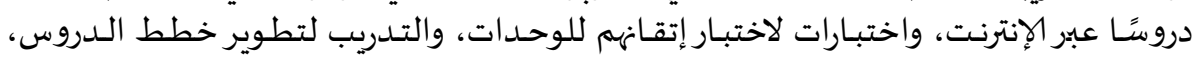

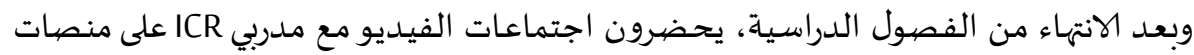

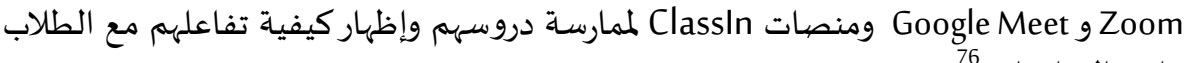
وتلقي التعليقات 76

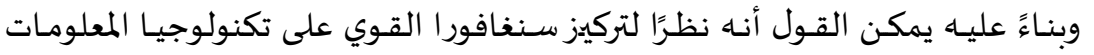

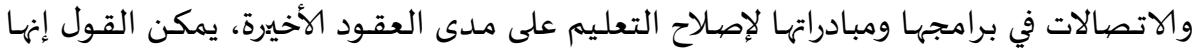

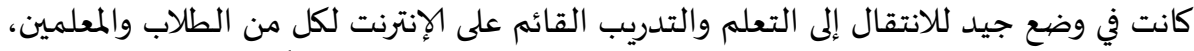

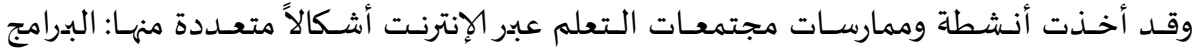

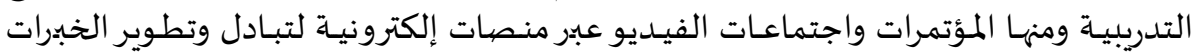

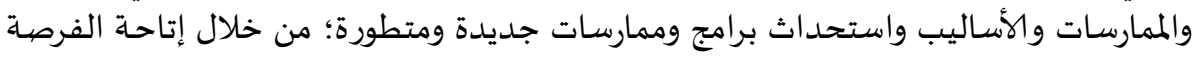
لمعلمي المجموعات الالتقاء والتحدث وتباد وادل الخبرات والجهات وليود المهنية. 
3- إستراتيجيات إدارة مجتمعات التعلم في سنغافورا لمواجهة جائحة فيروس كورونا:

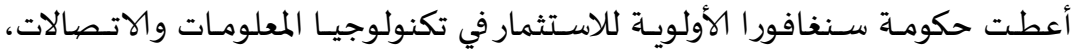

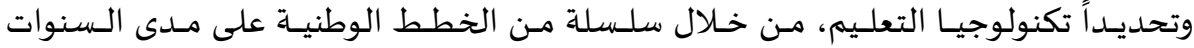

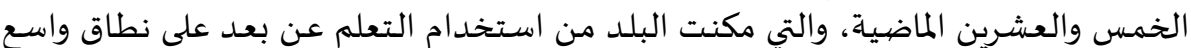

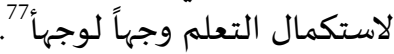

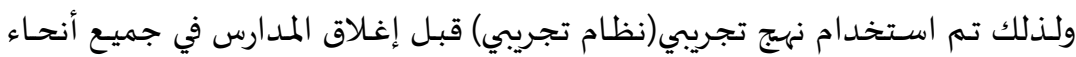

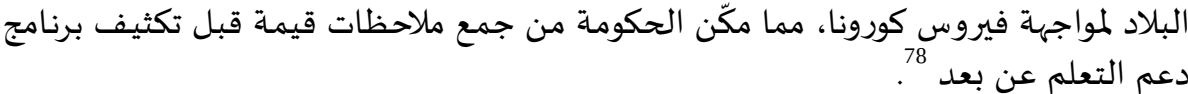
ونتيجـة لـذلك تتنـوع إسـراتيجيات إدارة مجتمعـات التعلم في سـنغافورا لمواجهـة أزمـة

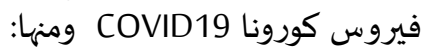

- تعزيز مستوى التأهب مع إبقاء المدارس مفتوحة: ويشمل هذا الأمر الحدد من الاتصال الجسدي عن طريق تقليل الأنشطة الاجتماعية والأنشطة خارج المناهج المنالدراسة،

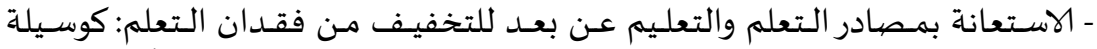

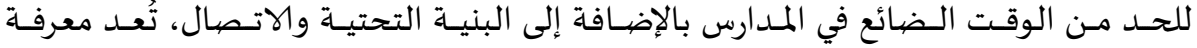

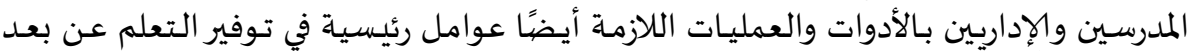
بسنغافورة

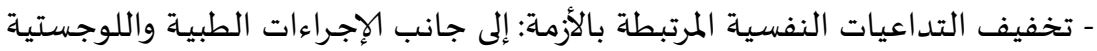

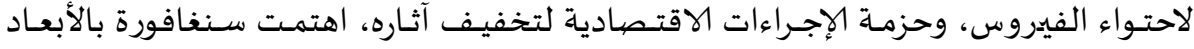

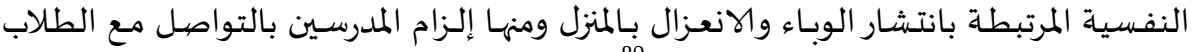

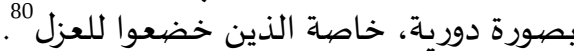

وبالتالي يمكن القول أن سنغافورا أبقت على فتح المدارس مع اتخاذ الإجراءات الطبية المبادية

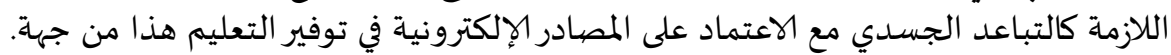

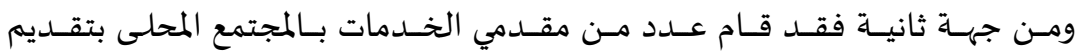

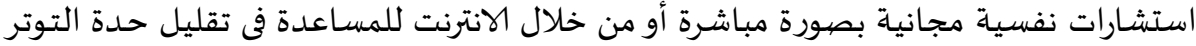

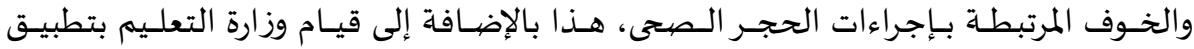

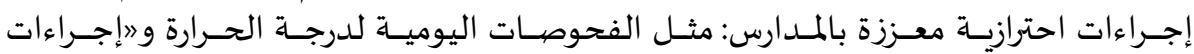

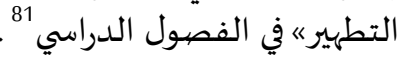

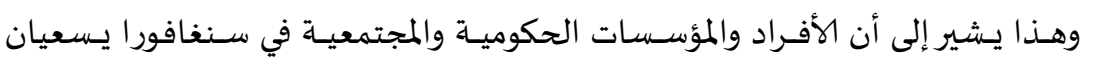
سوياً لتقديم الدعم الممكن واللازم لتخطي عقبة المؤية جائحة فيروس كورونا.

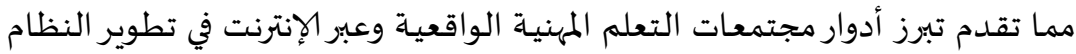

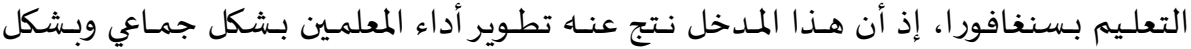

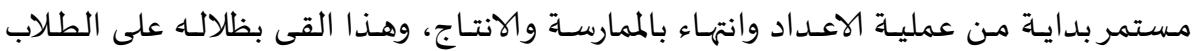

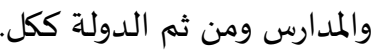


4- القـوى والعوامـل الثقافيـة المؤثرة على مجتمعــات الـتعلم المهنيـة عبر الإنترنـت في

سنغافورا:

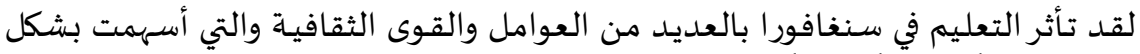

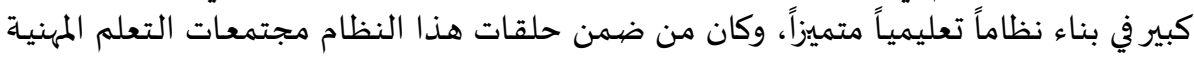
والتي ساعدت المعلمين على إحداث الطفرة في التعليم، ولقد تأثرت هذه المجتمعات النمات المهنية بما

أ- العامل التاريخي والاجتماعي:

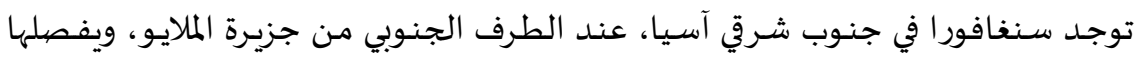

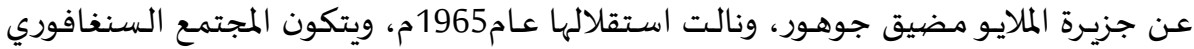

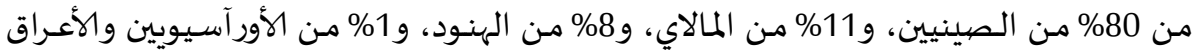

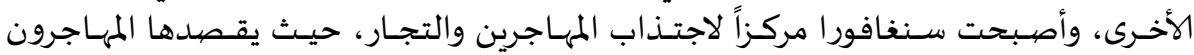

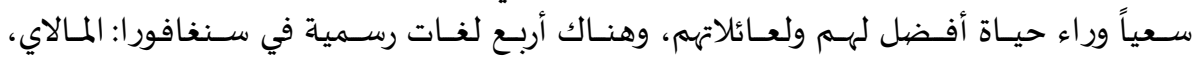

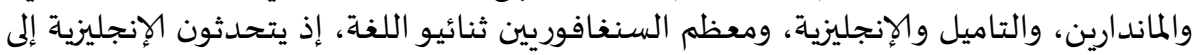

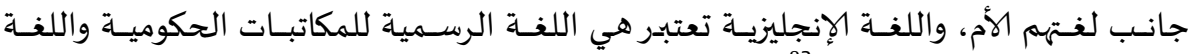
الرئيسية في المدارس والكليات 82

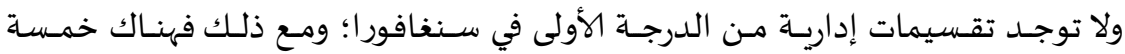

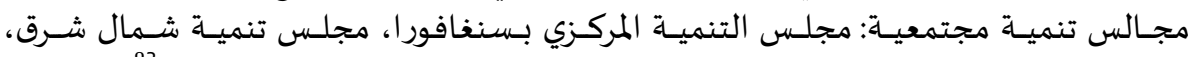

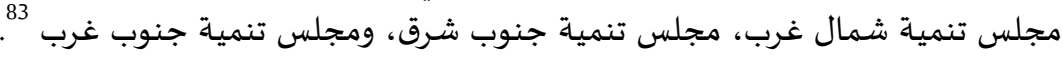

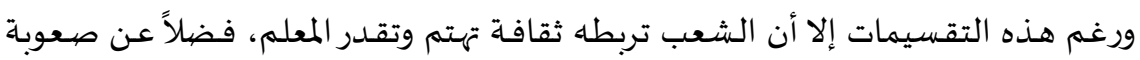

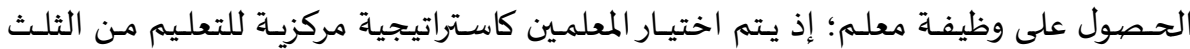

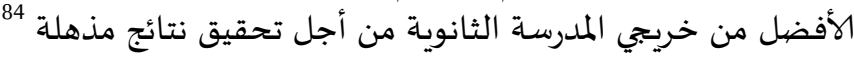

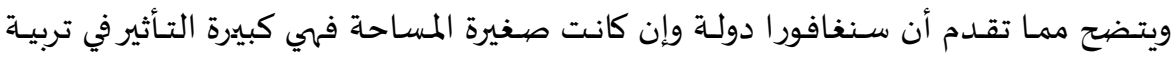

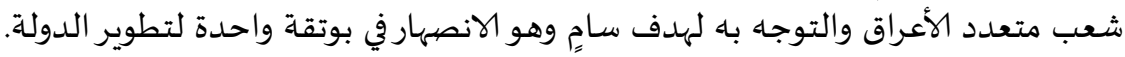

ب- العامل السياسي والاقتصهادي:

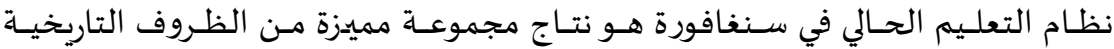

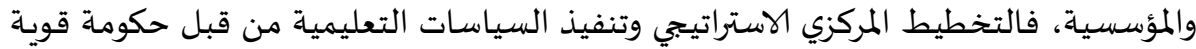

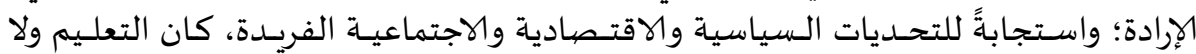

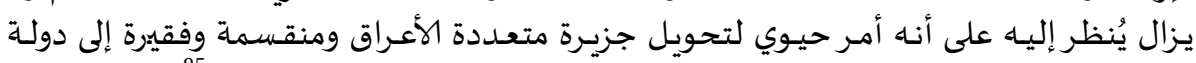

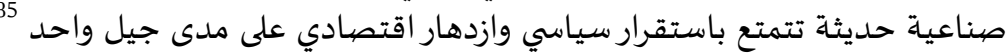

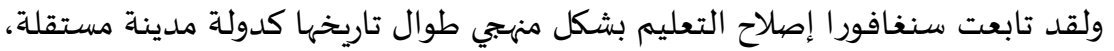

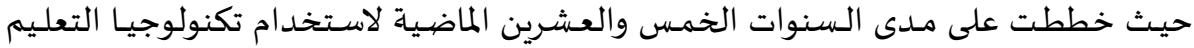

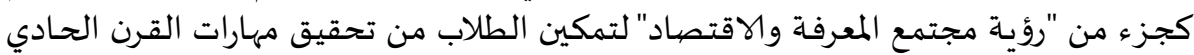

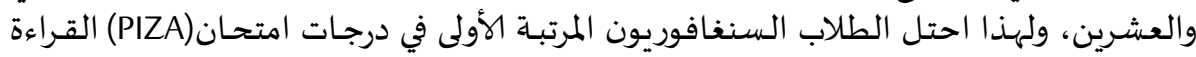


والرياضيات والعلوم في عام 2015 ، وبالإضيافة إلى ذلك قامت وزارئل المارة التعليم بتقليص المنـاهج

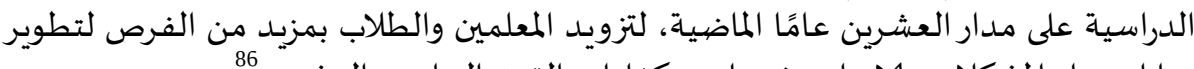

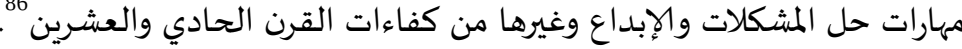

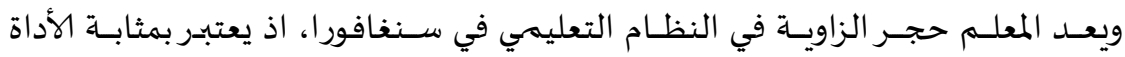

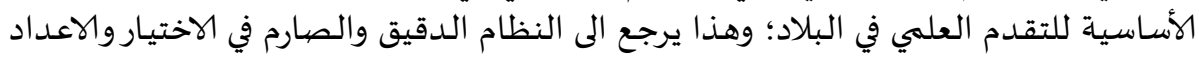

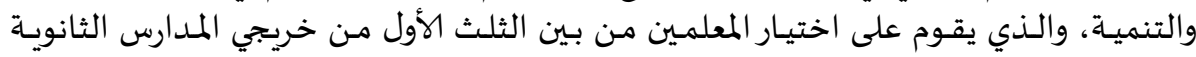

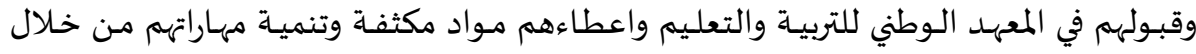

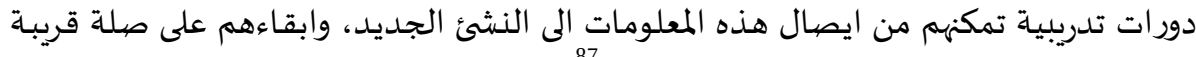
بما يجري من تطورات في تقنية التعليم ومهاراته تونهات

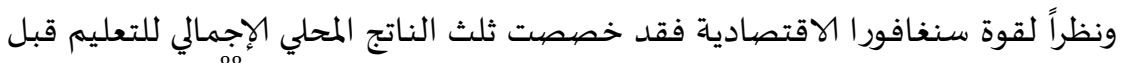

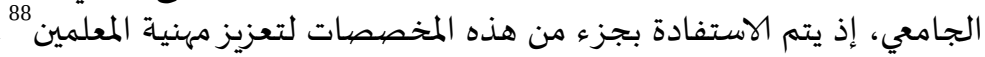

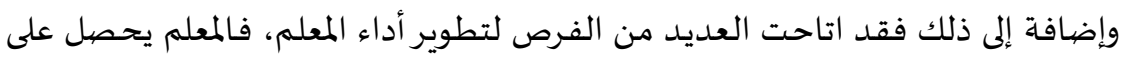

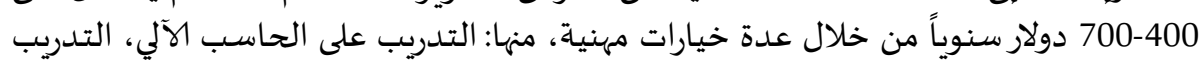

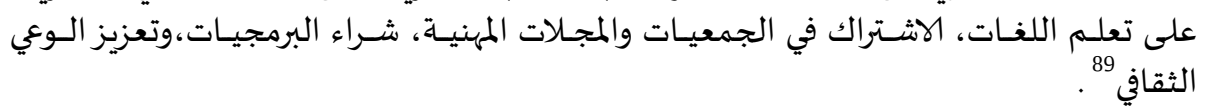

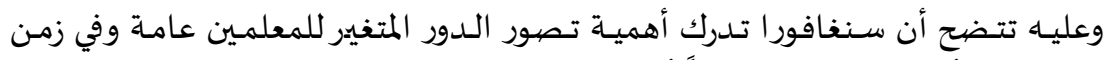

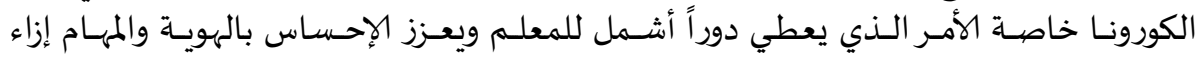

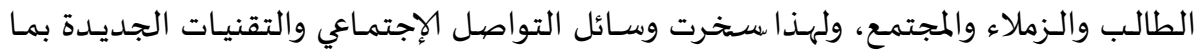

يتناسب مع البيئة التعليمية المتغيرة، بما في ذلك العالم الرقهي وأيضا بيئة الصف التهات التقليدية.

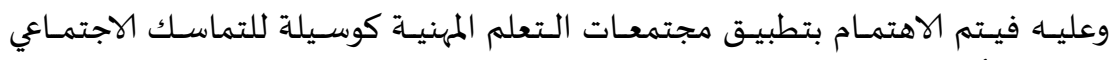
وكمنصة لبناء الأمة، ومن ثم وسيلة لتحقيق التنمية الاقتصادية والاجتماعية بلميلة بالدولة. ثالثاً ملامح مجتمعات التعلم المهنية عبر الإنترنت في كنداء

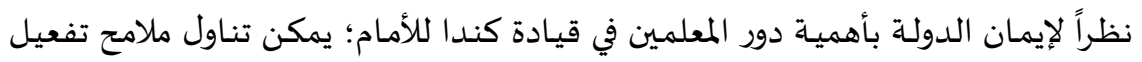

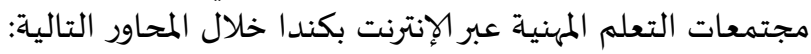
1- طبيعة مجتمعات التعلم المهنية عبر الإنترنت: ويتناول هذا المحور عدة مكونات وعناصر فرعية، وهي كالتالي: أ- فلسفة وأهداف مجتمعات التعلم المهنية عبر الإنترنت :

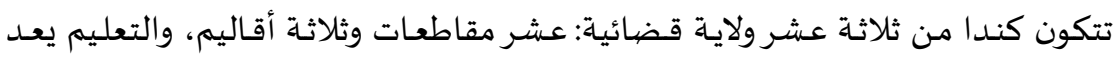

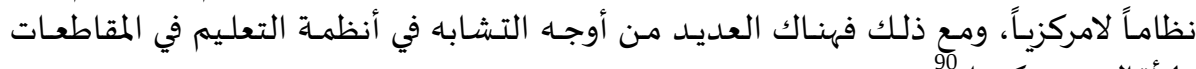
والأقاليم عبر كندا لامركاً،

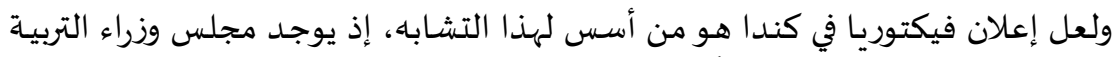

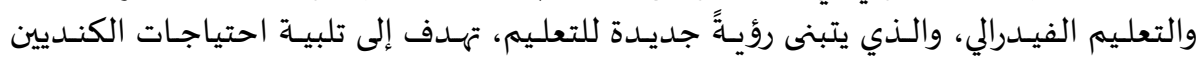

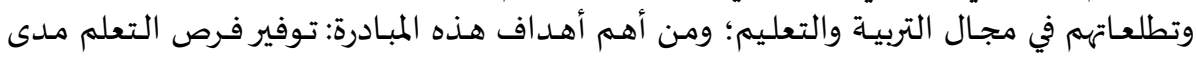


الحيـاة عالي الجـودة للكنديين جميعـاً، في ظل مجتمع مستدام قـادر على تعزيز فرص التطوير الفردي

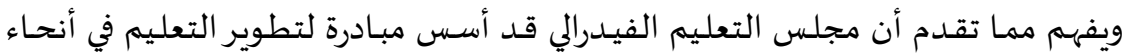

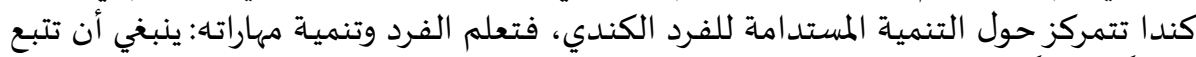
نظاماً متنوعاً ومتكاملاً يسهل الوصول إليه المندا عند الحاجة.

ونتيجة لذلك ظهرت مجتمعات التعلم المهنية بالمقاطعات والأقاليم المختلفة، فمثلاً وعلى المئى

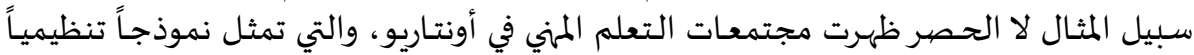

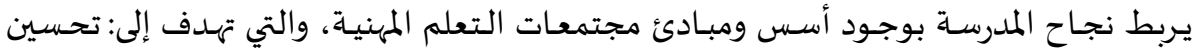

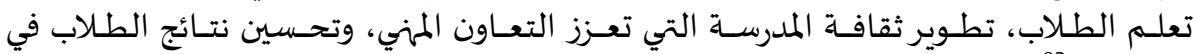
اختبارات

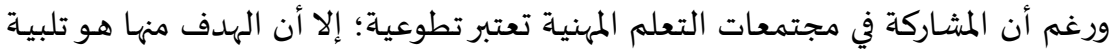

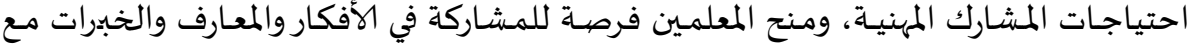

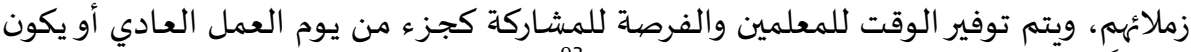

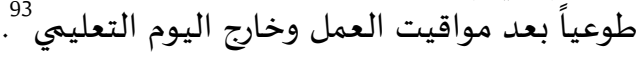

وإضافة إلى ذلك فقد اعتبر اتحاد المعلمين في أونتاريوETFO أن مجتمع التعلم المهني يمثل

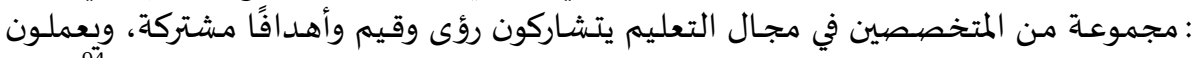

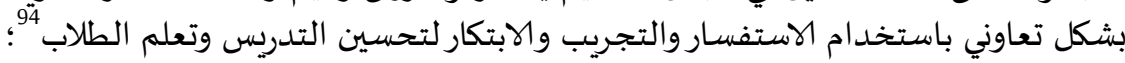
ومما تقدم تتضح معالم فلسفة وأهداف مجتمعات التعلم المهنية عبر الإنترنت في كندا بوصفها مجتمعات تعد وسيلة للمعلمين لتوليد المعرفة فيما يتعلق بالتعليم والتعلم.

$$
\text { ب- مبادئ ومرتكزات مجتمعات التعلم المهنية عبر الإنترنت : }
$$

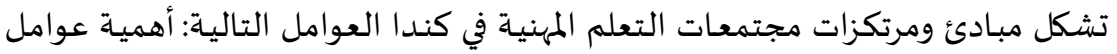

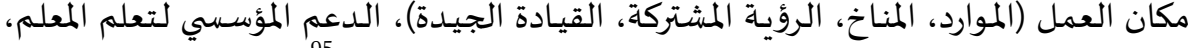

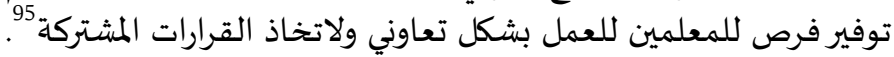

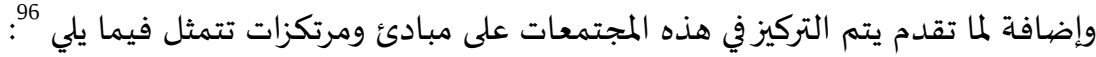
- التعلم المني المتماسك، بمعنى التركيز على الاحترام والمسؤولية والنتائج.

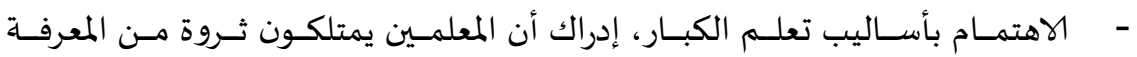

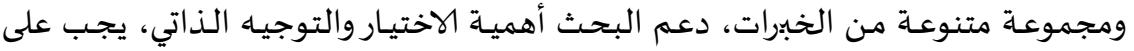

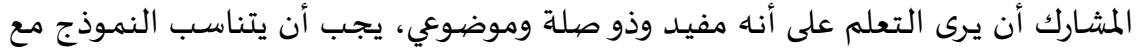

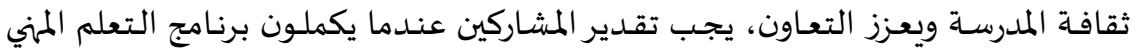




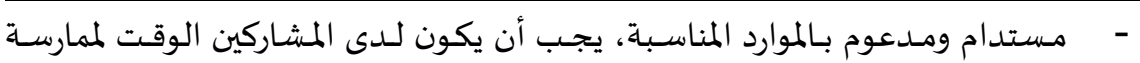

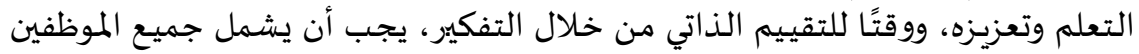
الذين يدعمون تعلم الطلاب.

المعلمين.

وفي ذات الـسياق يقـوم اتحـاد المعلمـين في أونتـاريو ETFO بتطــوير سياسـة محسـددة

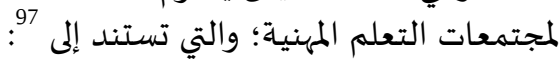
- نموذج صنع القرار المشترك القائم على الأدلة، الزمالة واحترام مهنية الأعضاء واستقلاليتهم. - المشاركة في مجتمعات التعلم المهنية_PLC طوعية لتعزيز تمكين المعلمين وتطوير القيادة. - التركيز على جميع مجالات المنهج، مع التركيز على تنمية الطفل ككل.

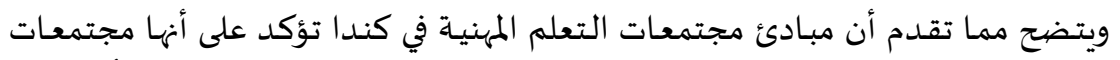

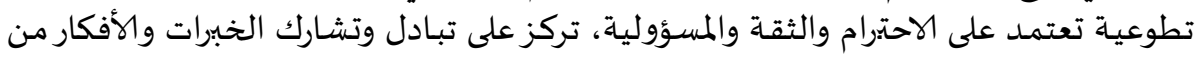
أجل تحقيق هدف مشترك وهو تنمية الطلاب والمعلمين.

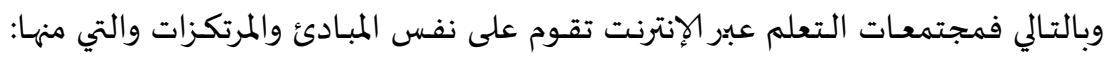

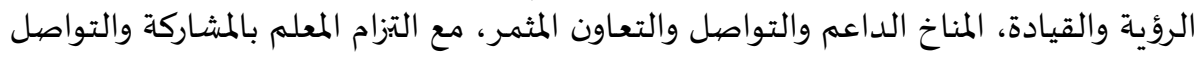
واحترام الآخرين.

\section{ج- تصنيفات وأنواع مجتمعات التعلم المهنية عبر الإنترنت :}

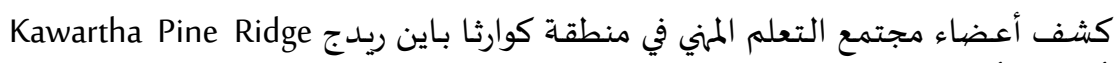

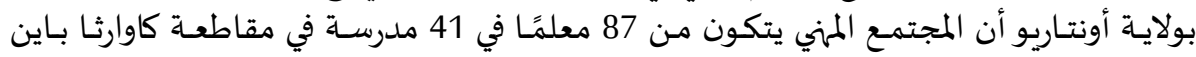

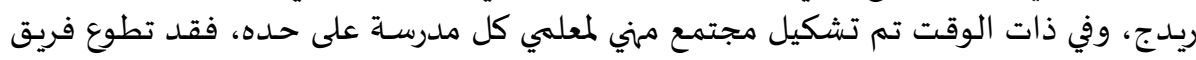

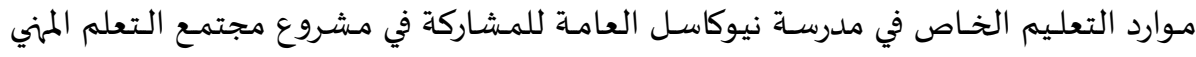

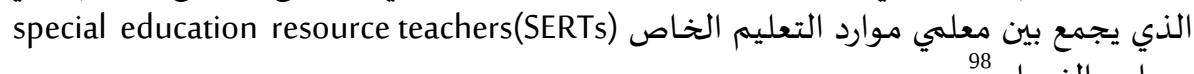

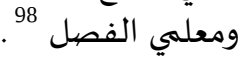

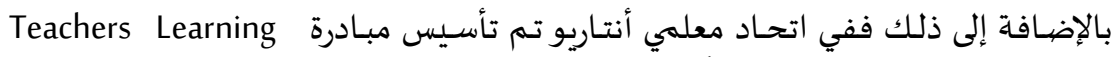
Together (TLT

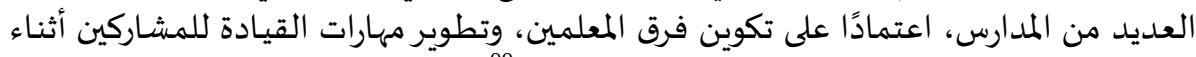

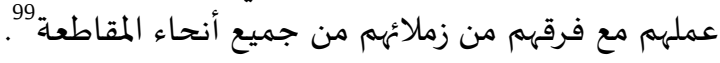

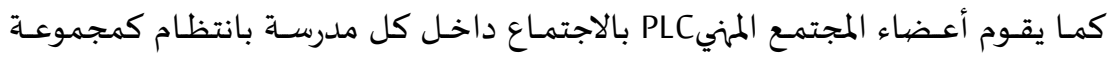

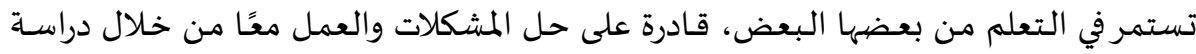

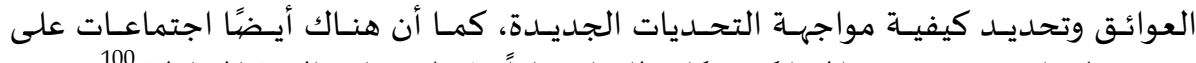

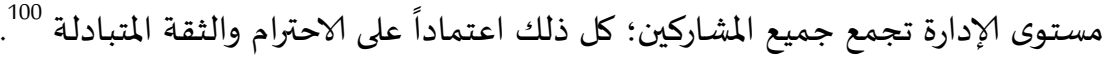

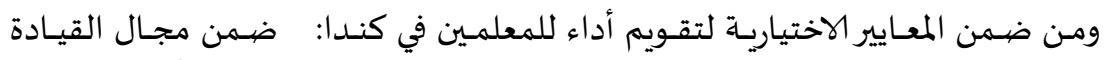

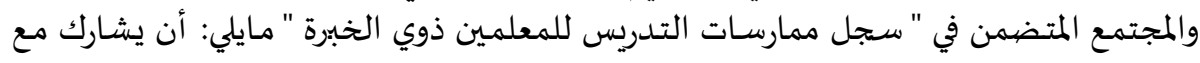


الزملاء في التعلم المكتسب من خلال المشاركة في مبادرات على مستوى النظام التعليمي بالدولة

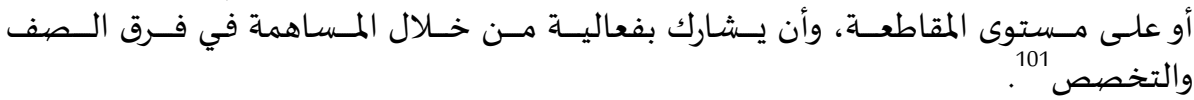

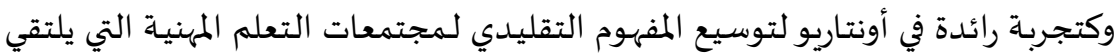

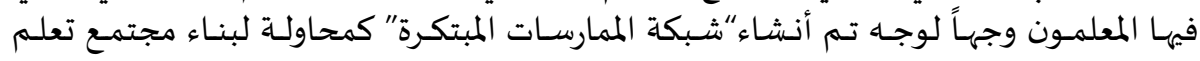

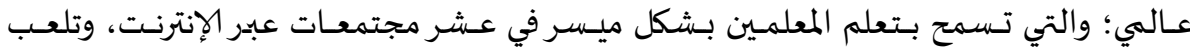

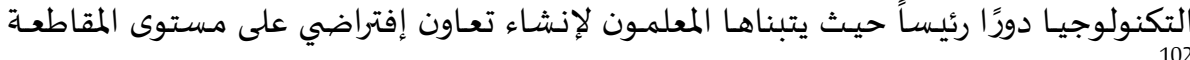

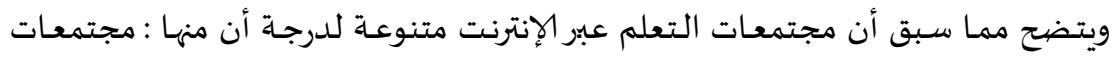

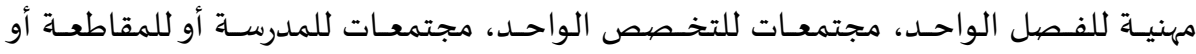
الدولة ككل، ومجتمعات عالمية. د- إدارة وتقييم مجتمعات التعلم المهنية عبر الإنترنت :

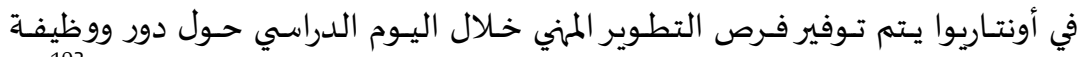

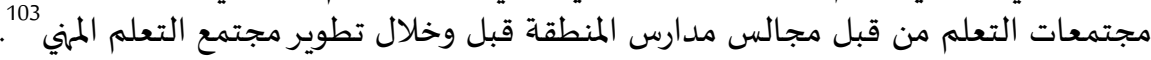

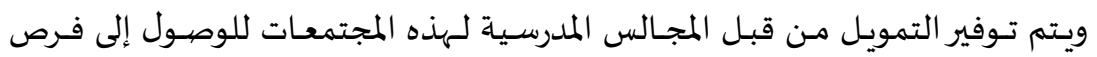

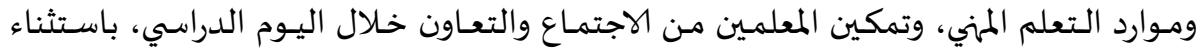

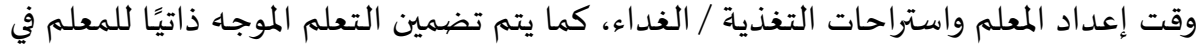

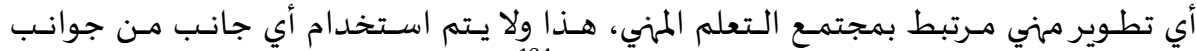
مشاركة المعلم في هذه المجتمعات لتقييم أنعلم ألماء المعلم 104.

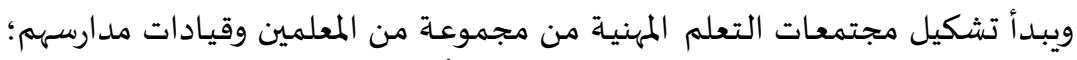

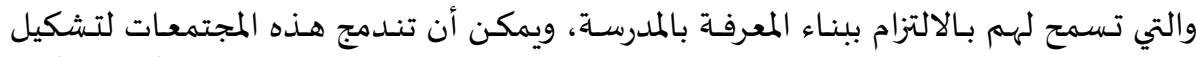

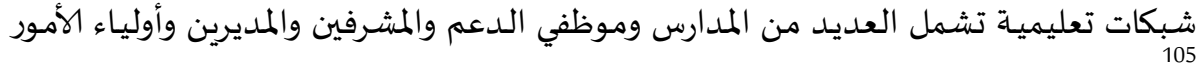

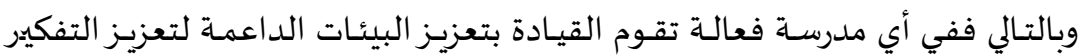

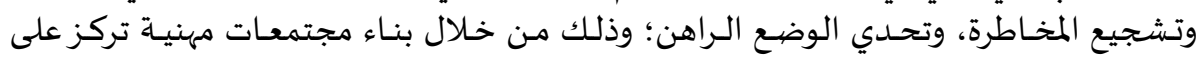

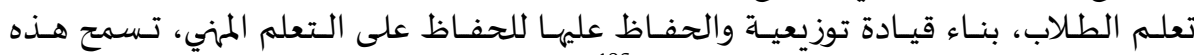

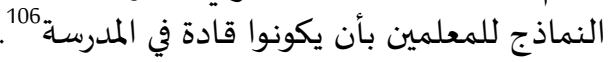

ويقدم مجلس إدارة المدرسة ومجلس إدارة المنطقة الدعم لمجتمعات التعلم، فمجلماتس

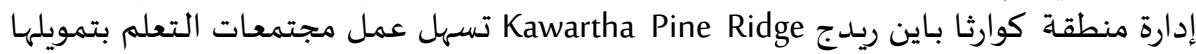

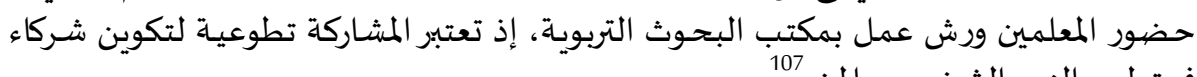
في تطوير النمو الشخصي والمشني 107

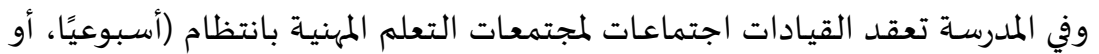

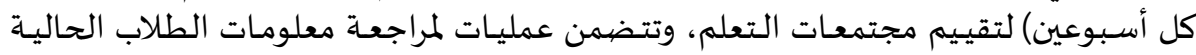




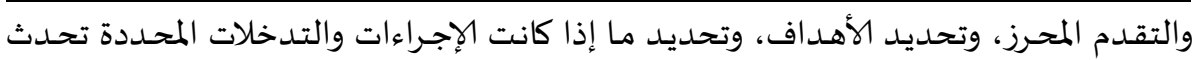

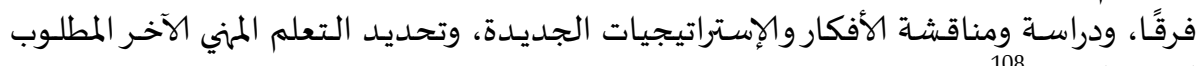
لدعم النجاح فرداسل

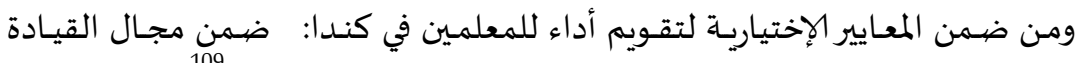

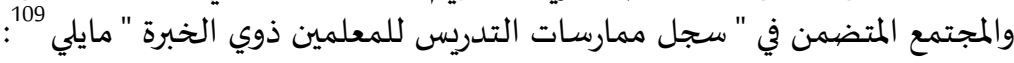

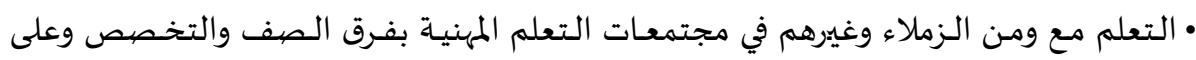
مستوى النظام التعليمي بالدولة أو بالمقاطعة. • يعمل بشكل تعاوني مع الزملاء لحل هموم الطلاب والفصول الدراسية والمدرسة.

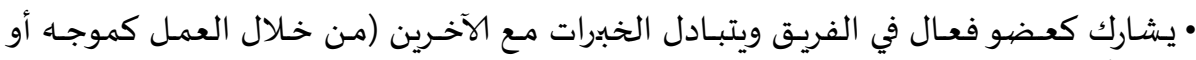

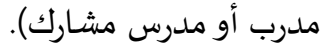
• يشارك بفعاليـة في اللجان من خلال تنظيم الأنشطة المدرسية (مبـادرات المدرسـة / الرعيـة،

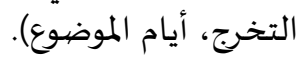

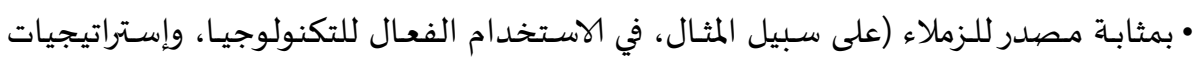
التقييم، وإدارة الفصل الدراسي).

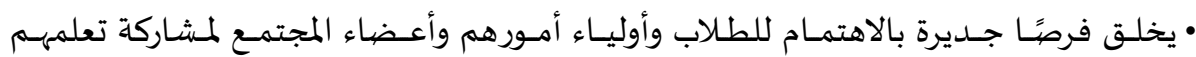

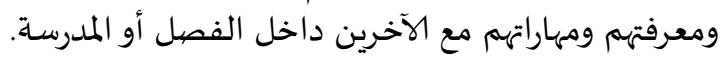

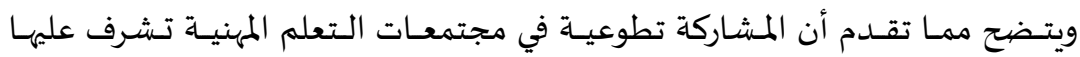

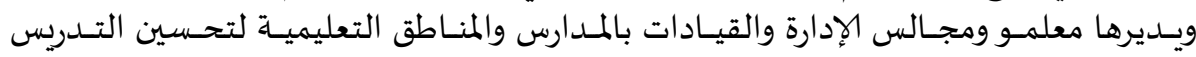

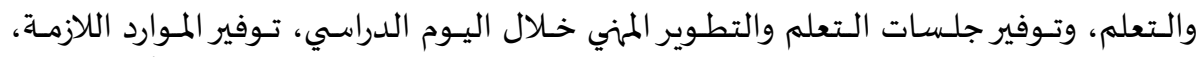

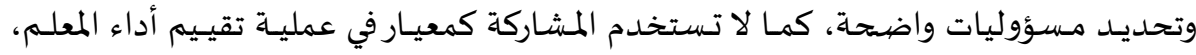

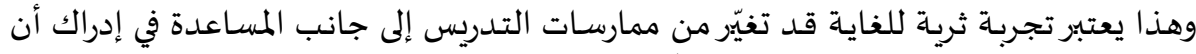

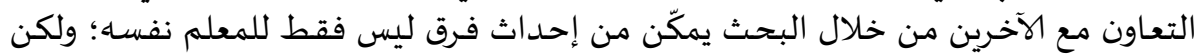

الأهم من ذلك لطلابه.

\section{2- ممارسات وأنشطة مجتمعات التتعلم المهنية عبر الإنترنت:}

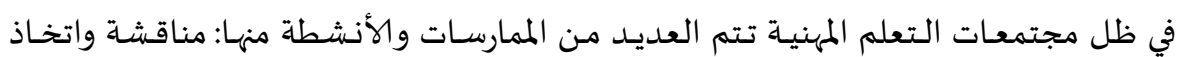

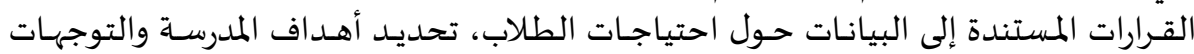

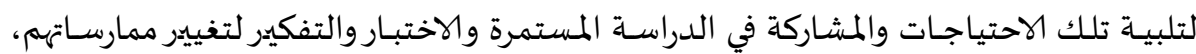

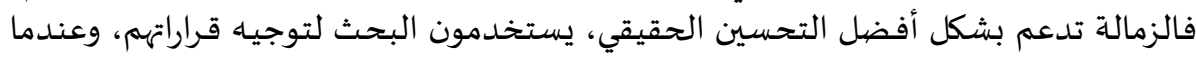

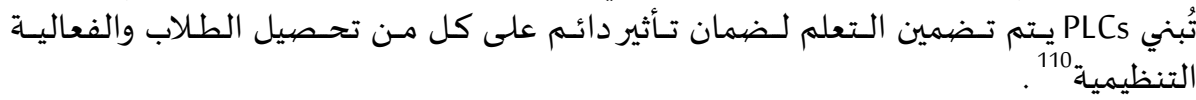

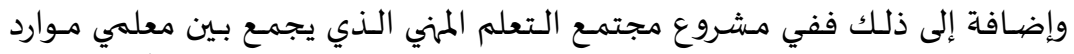

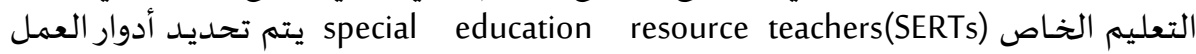

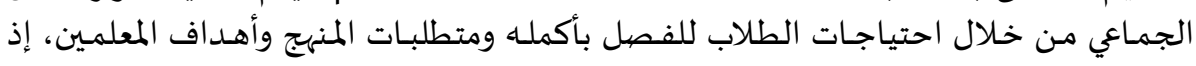


تعمل مجتمعات تعلم SERT مع جميع الطلاب في الغرفة وتتقاسم المسؤولية عن الطلاب ذوي

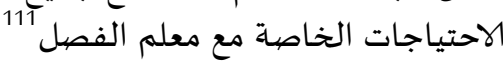

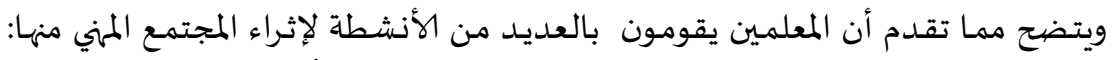

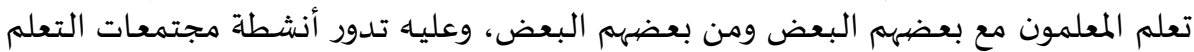

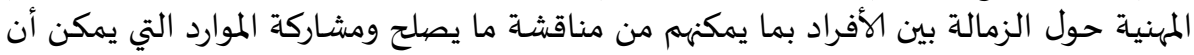

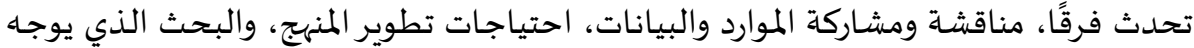

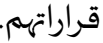

وبفضل مبادرة "تعلم المعلمين معاً" TLT فقد استفاد الطلاب من العمل الذي قام التعام بـاه

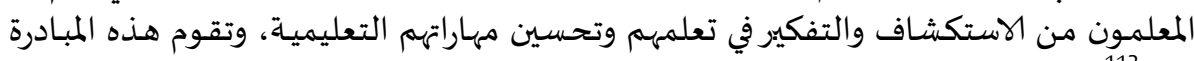
على :

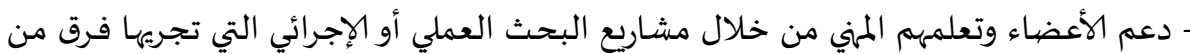

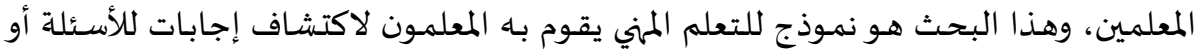

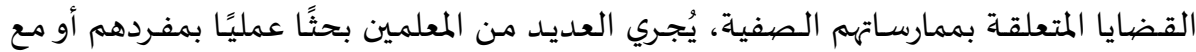

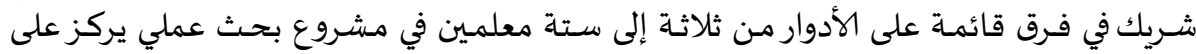

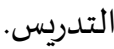

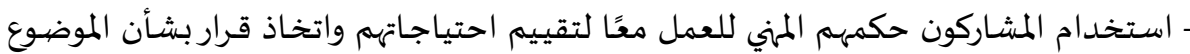

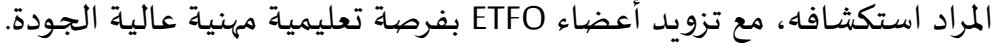

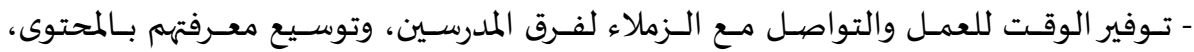

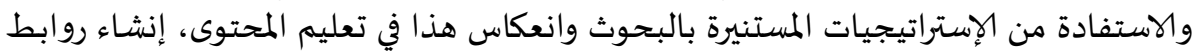

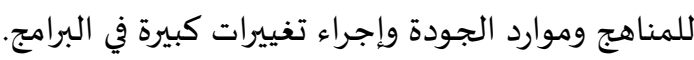

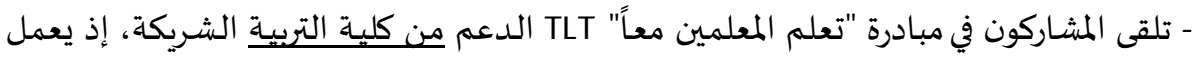

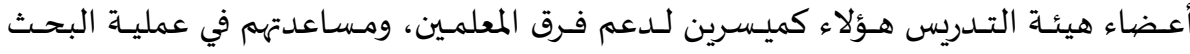

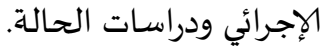

وأضف إلى هذه المبادرة فإن برنامج تعلم المعلمين والقيادات ( Teacher Learning and ذوي (TLLP) (Leadership Program

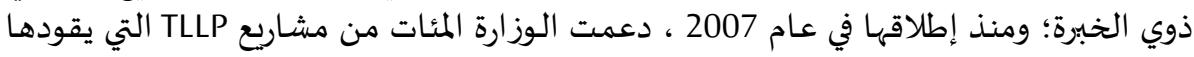

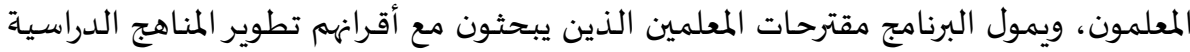

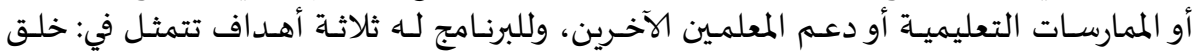

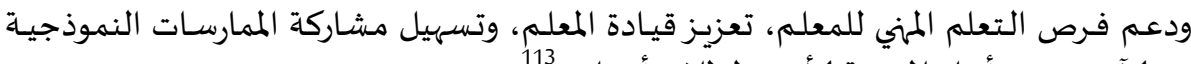
مع الآخرين من أجل المنفعة المأوسع لطعلاب أونتاريو تعزئ.

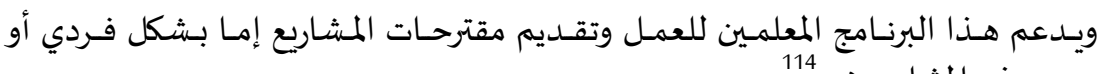

كفريق؛ ومن هذه المشاريع هي

- دراسة الدرس وإنشاء مورد إلكتروني يمكن مشاركته على مستوى المقاطعة. 
- بحوث عملية في استراتيجيات الفصل المبتكرة ونشر النتائج في مجلة مهنية.

- تعميق ومشاركة خبرات التدريس (مثل مهارات الرياضيات).

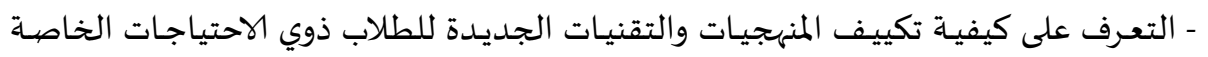
وفتح الفصل الدراسي أمام المعلمين الآخرين في المدرسة أو المنطقة التعليمية.

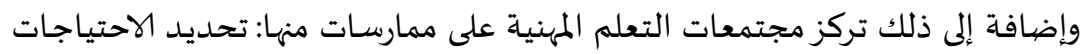

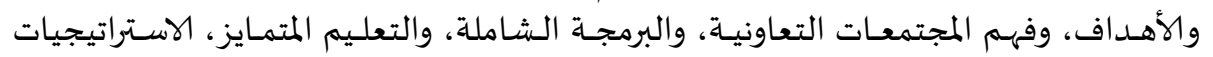

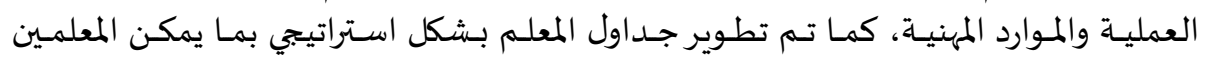

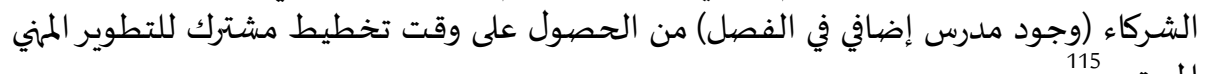

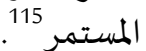

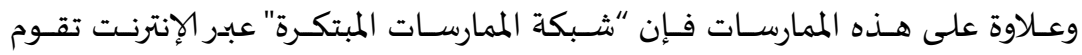

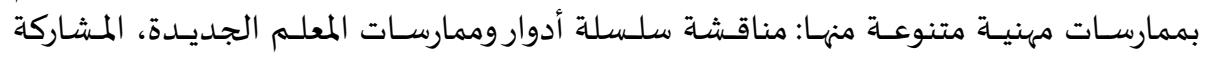

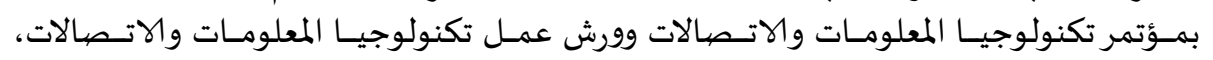

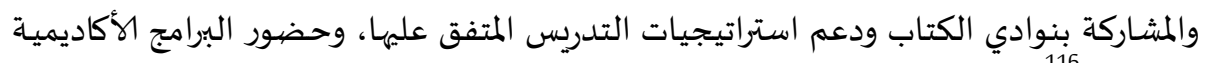
الصيفية

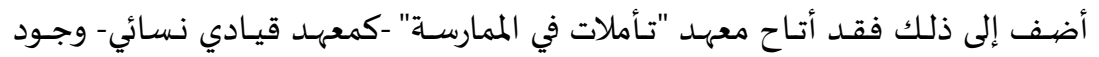

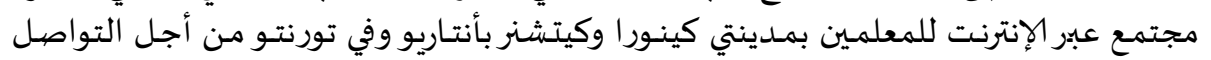

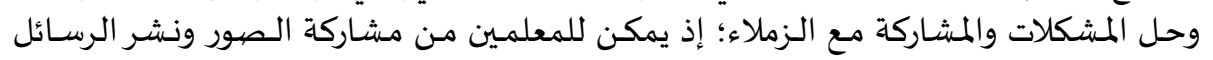

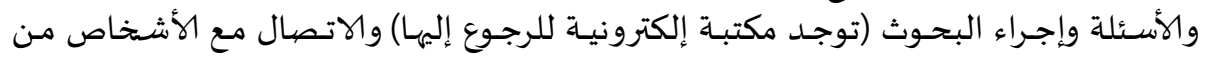

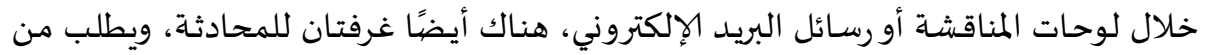

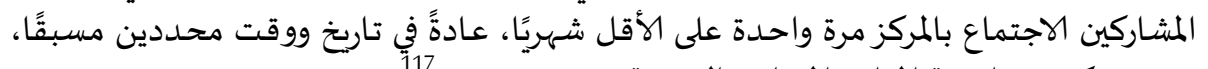

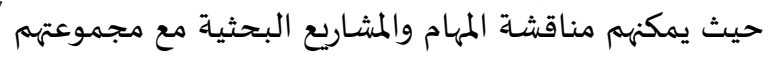

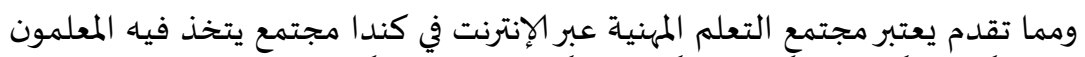

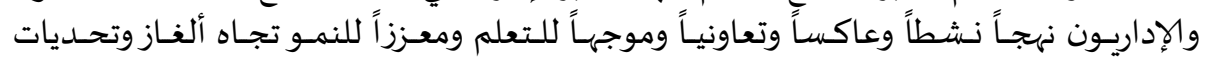

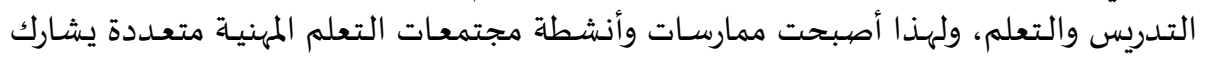
فيها جميع الموظفون بالمدارس.

\section{3- إستراتيجيات إدارة مجتمعات التعلم المهنية لمواجهة جائحة فيروس كورونا:}

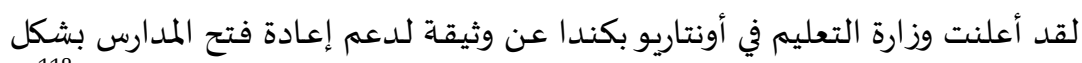

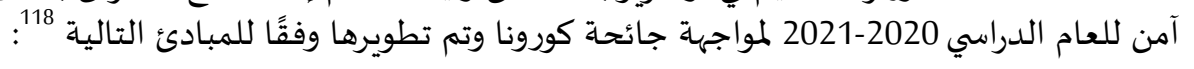

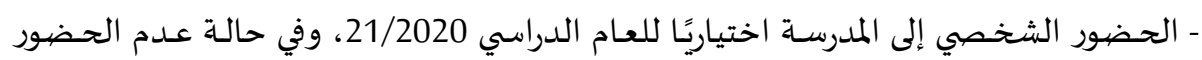

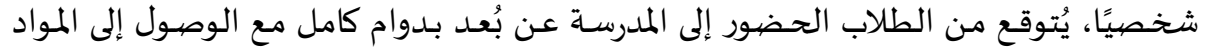
التعليمية المنشورة عبر الإنترنت لدعم فرص المر التعلم المتزامن وغير المتزامن.

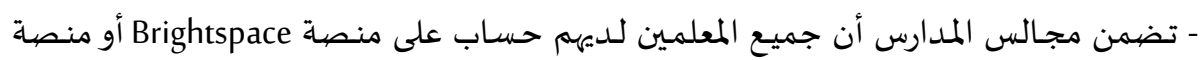

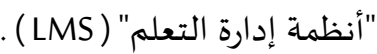




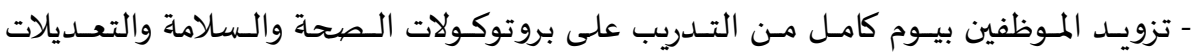

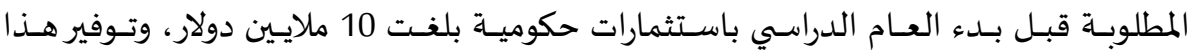
التدريب لجميع الموظفين بما في ذلك المعلمين. - يجب أن يكون المعلمون مستعدين لتحميل موارد التعلم في نظام إدارة التعلم

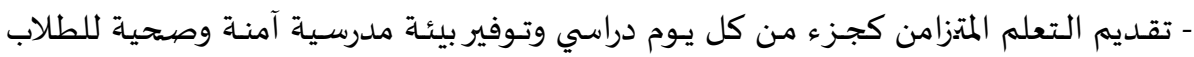

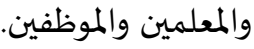
- توفير تعليم عالي الجودة باستمرار لكل طالب في أونتاريو. ـ معالجـة الفجـوات المحتملـة في تعلم الطلاب والصححة العقليـة والرفـاه، الناشـئة عـن إغـلاق

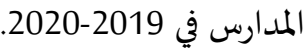
ــ الحفاظ على اتصالات وثيقة واحترام آراء وسـلطة الوالدين وتقليل الحـواجز التي تحـول دون

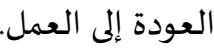

- دعم حكومة أونتاريو إعادة فتح المدارس باستثمارات 309 ملايين دولار لضمان عودة آمنة.

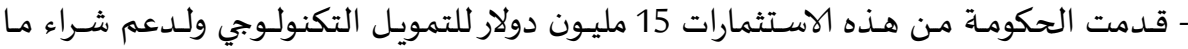
يصل إلى 35000 جهاز لطلاب أونتاريو لدعم تعلمههم المتزامن داخل الماردات المدرسة وخارجها. - تقديم المواضع التعاونية افتراضيًا حيثما كان ذلك ممكن.

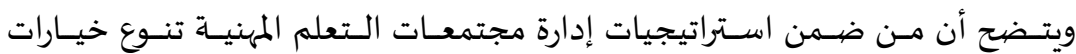

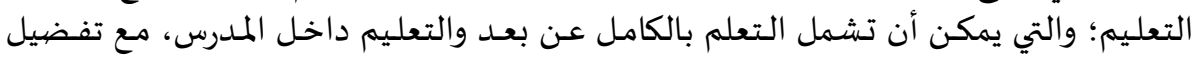

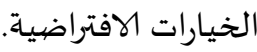

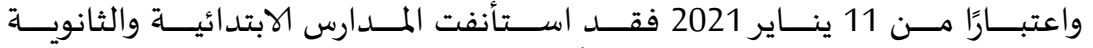

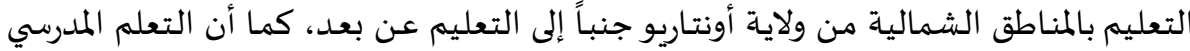

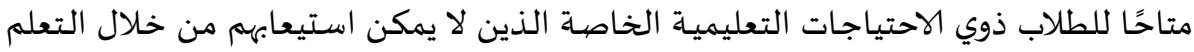

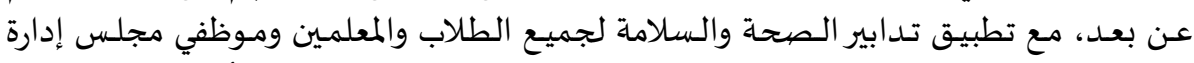

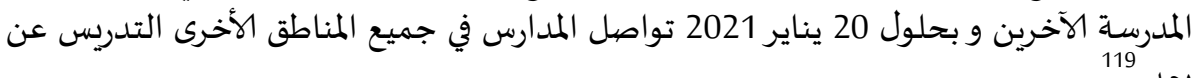

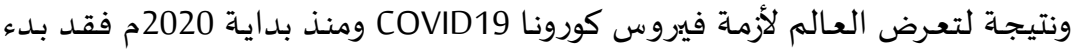

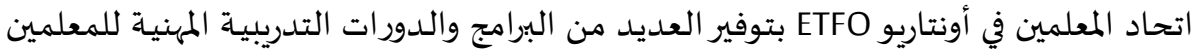

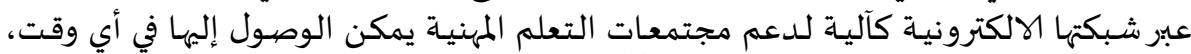

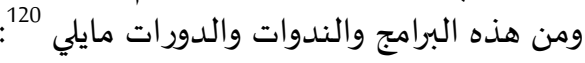

- ندوة عبر الإنترنت عن الصحة العقلية: أهمية الحفاظ على قدرتك على الصمود - 17 يونيو - تعزيز العلاقات في برنامج رياض الأطفال أثناء التعلم عن بعد، ندوة عبر الويب 11 يونيو - فهم العنصرية ضد السود في التعليم في أونتاريو، ندوة عبر الويب 10 يونيو. 
- المرأة في العمل: التواصل وتطوير رسالتك، ندوة عبر الإنترنت من جزأين 1 و 4 يونيو.

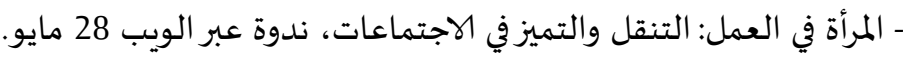
- التعلم الممني المستمر (CPL)، ندوة عبر الويب في 27 مايو. - دعم الطلاب في التعلم عن بعد، ندوة عبر الويب في 13 مايو.

- المرأة في العمل: القوى التي تعمل ضد النساء الساعيات إلى القيادة، ندوة الإنترنت 21 مايو لمائ

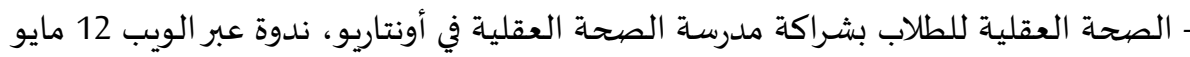
- التنقل في التعليم الخاص من خلال التعلم عن بعد، ندوة عبر الويب 11 مايو. ـ قضايا حقوق الملكية الناشئة في عالم COVID-19. - دعم الفنون الابتدائية من خلال التعلم عن بعد، ندوة عبر المبائه الميب في 7 مايو. - قائمة مرجعية لمعلم أصول التدريس ذات صلة بالثقافة ومتجاوبة، مورد عبر الإنترنت. - تعزيز موارد الرياضيات والعلوم وتغير المناخ للمعلمين وأولياء الأمور عبر الإنترنت. - دمج التربية البدنية في التعلم عن بعد، ومن خلال البث الشبكي.

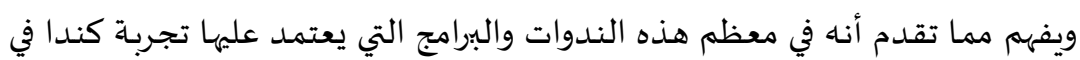

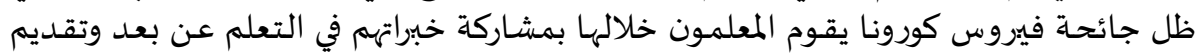

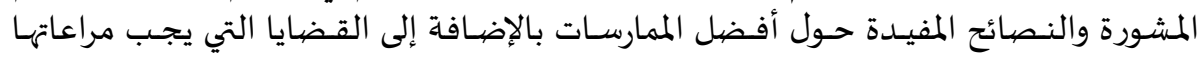

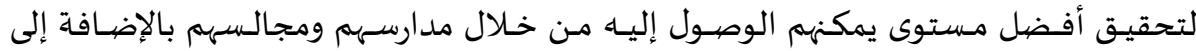

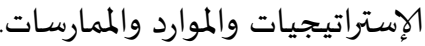

\section{4-القوى والعوامل الثقافية المؤثرة على مجتمعات التعلم المهنية عبر الإنترنت في كندا:}

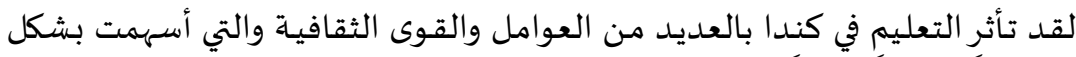

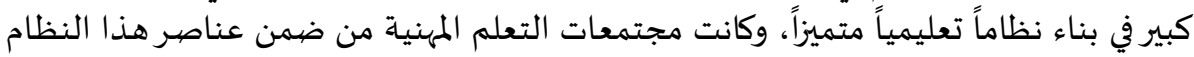

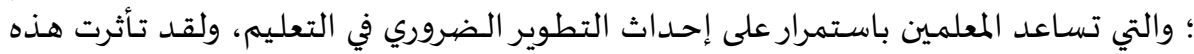

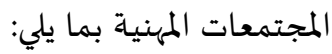

\section{أ- العامل التاريخي والاجتماعي:}

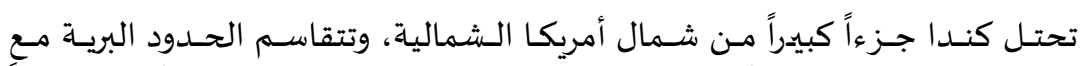

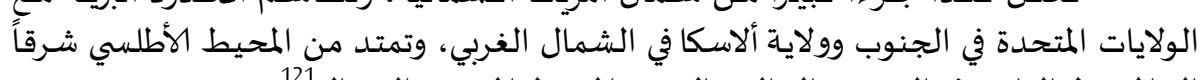

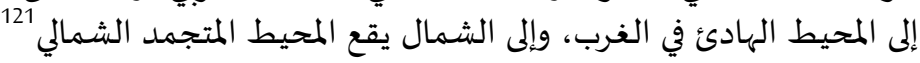

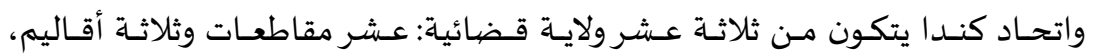

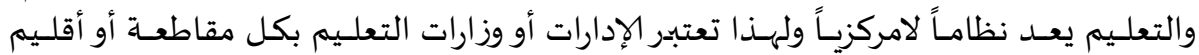

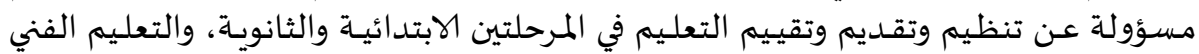

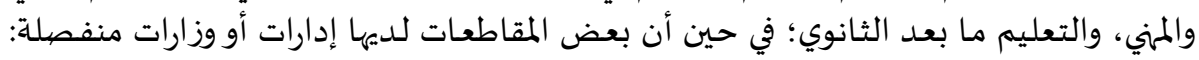


واحدة مسؤولة عن التعليم الابتدائي والثانوي والأخرى للتعليم ما بعد الثانوي والتدريب على

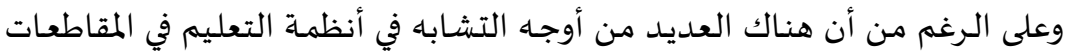

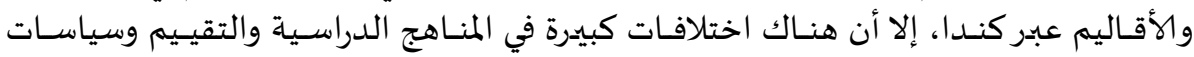

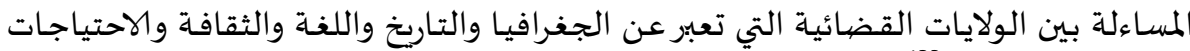
المتخصصية للسكان المولانيات 123.

و رغم أن كندا تمتلك مزيجًا من جنسيات وثقافات مختلفة، فالدستور يكفل حمايتها

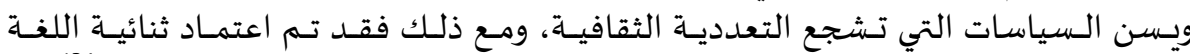

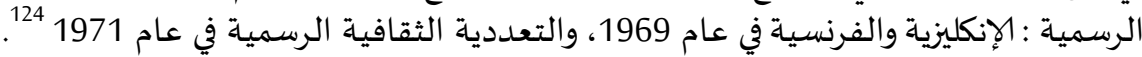

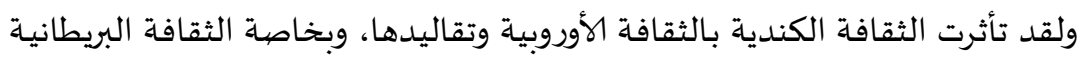

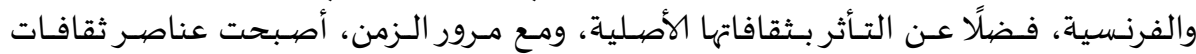

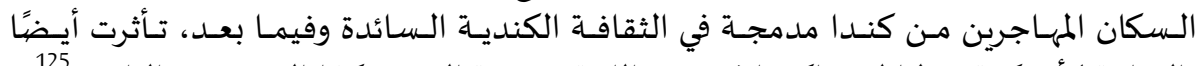

بالثقافة الأمريكية، نظرًا لاشتراكهما في نفس اللغة، ودرجة في الثقافة القرب وكذا الهرا الهجرة بين البلدين

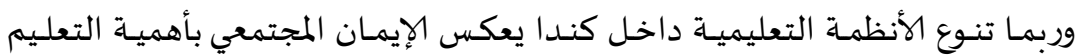

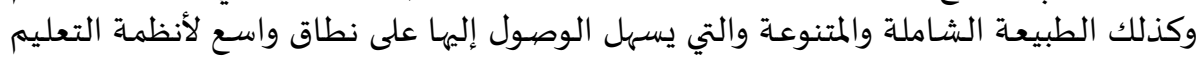

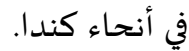

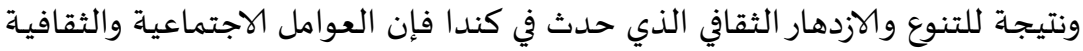

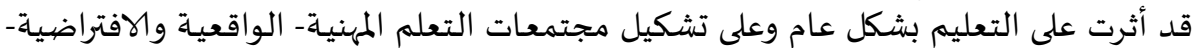

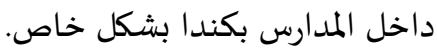
ب- العامل السياسي والاقتصادي:

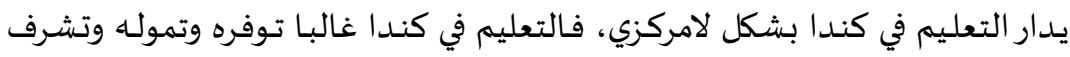

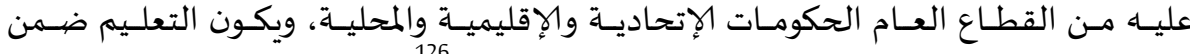
اختصاص مجالس المحافظات وتشرف المقاطعة على المنهج

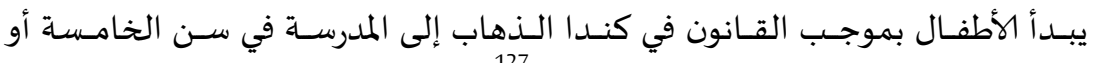

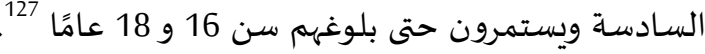

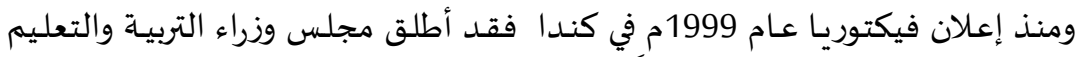

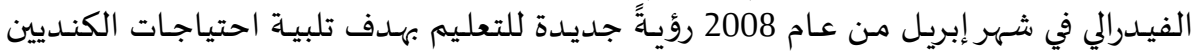

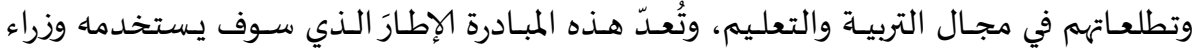

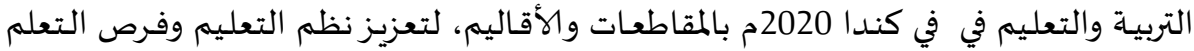

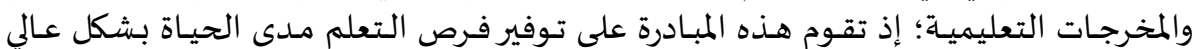

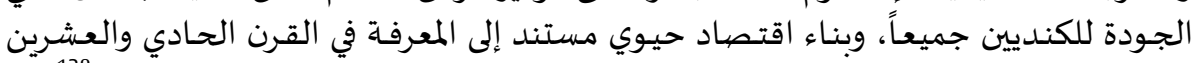

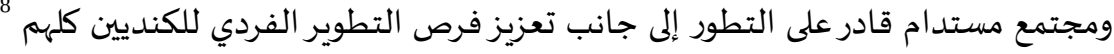




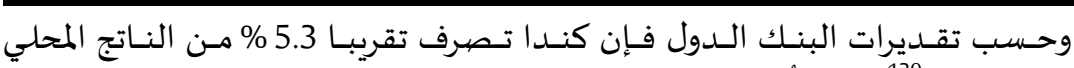

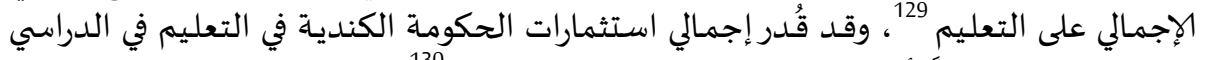
2019-2018 ، شاملاً رأس المال البشري بندو 26 مليار دولار 130

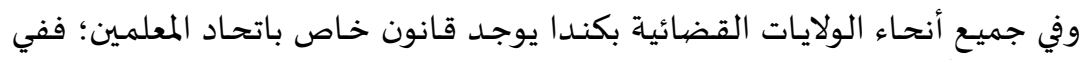

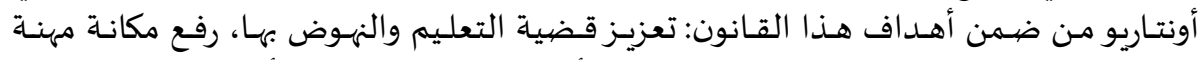

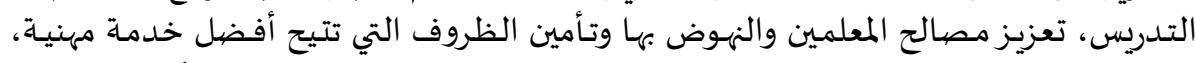
إثارة وزيادة الاهتمام العام بالشؤون التعليمياة، والتعاون مع منظمات التهات المعلمين الأخرى في جميع أنحاء العالم 131

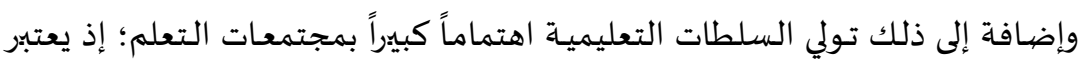

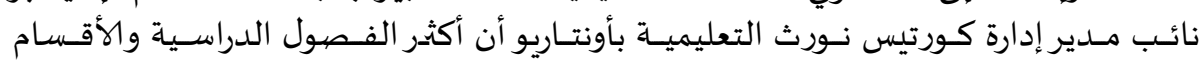

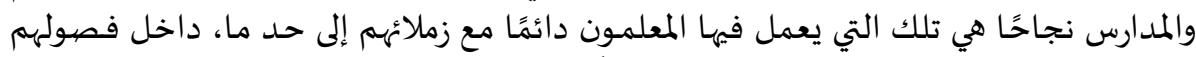

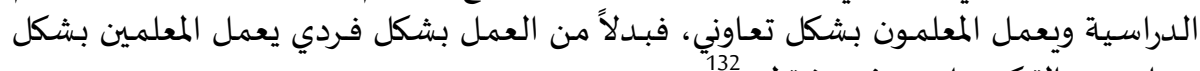

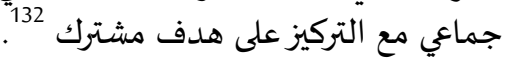

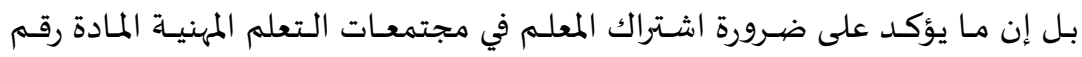

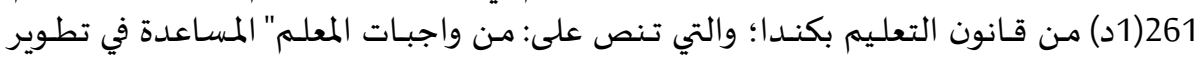

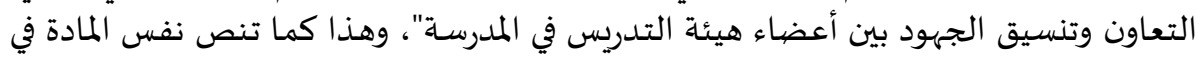

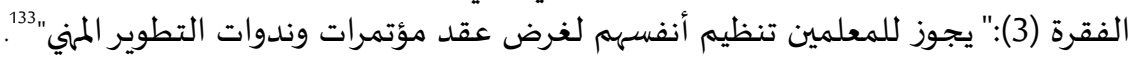

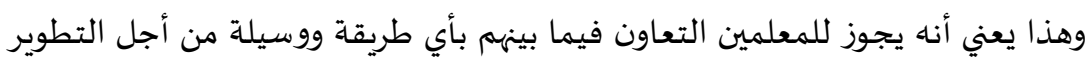

$$
\text { والتعاون وتنسيق الجهود في المدرسة. }
$$

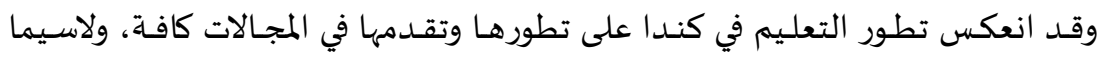

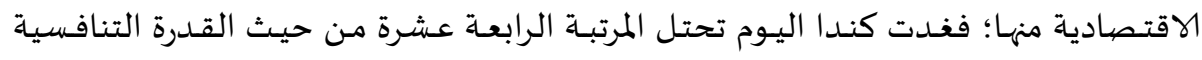

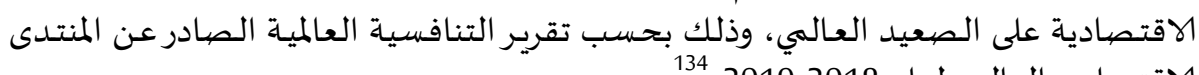

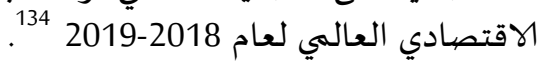

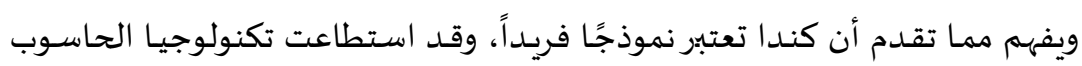

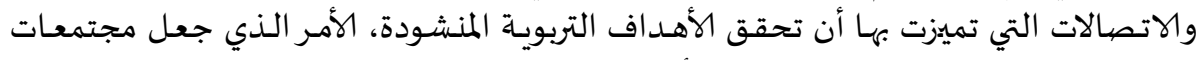

التعلم المهنية الواقعية والافتراضية فيها أمرًا حتميًا ضروريًا. 
رابعاً: تحليل مقارن لمجتمعات التعلم المهنية عبر الإنترنت في سنغافورا وكندا:

من العرض السابق لمجتمعات التعلم المهنية بالخبرتين يمكن عرض التحليل المقارن كما

يلي:

1- طبيعة مجتمعات التعلم المهنية عبر الإنترنت:

ويتناول هذا المحور عدة مكونات وعناصر فرعية، وهي كالتالي:

أ- فلسفة وأهداف مجتمعات التعلم المهنية عبر الإنترنت :

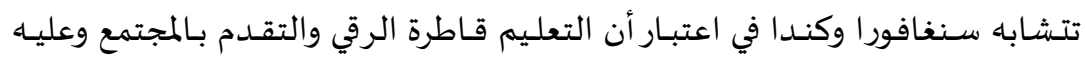

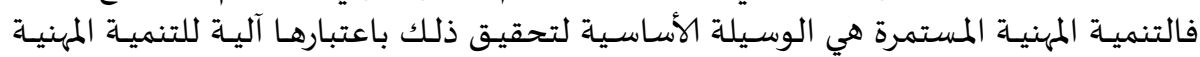

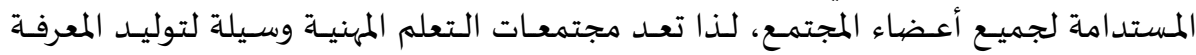

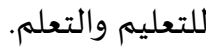

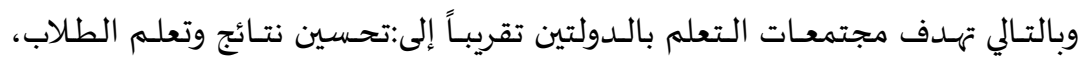

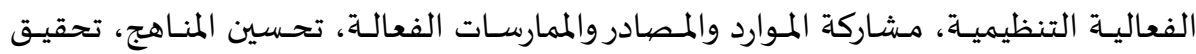
أهداف الوزارة والمجتمع والمدرسة والمعاركة المواردمالمين.

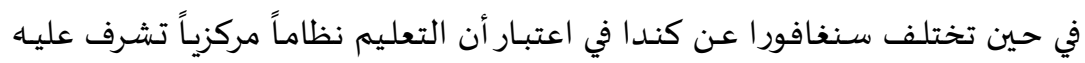

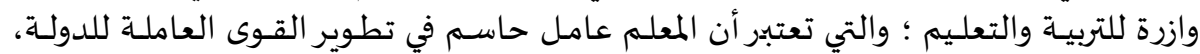

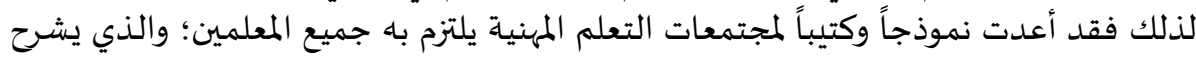

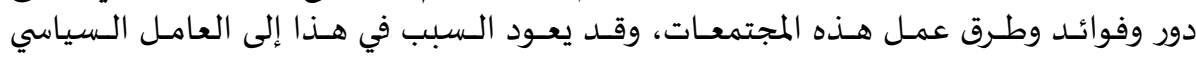

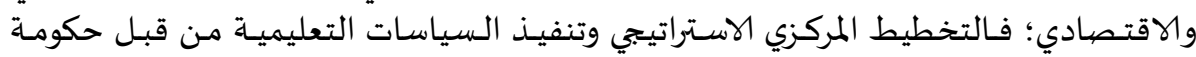
قوية الإرادة كما تعتبر أن الأداة المأساسية للتقدم العادي وتلفي في البلاد هي التعليم والتعلم.

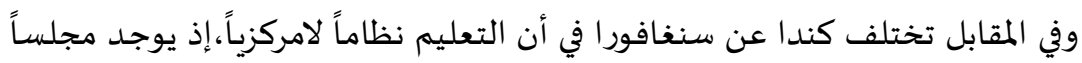

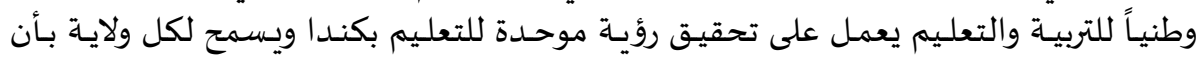

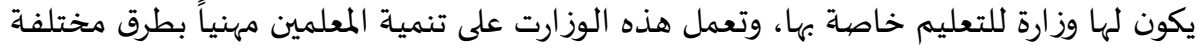

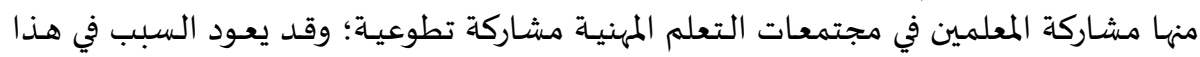

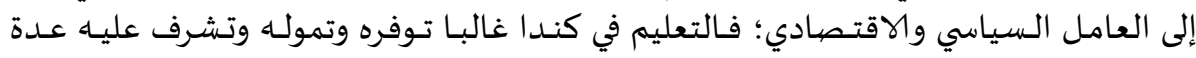

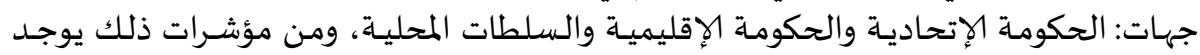

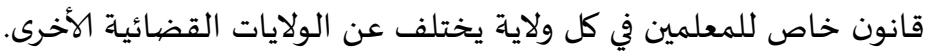

$$
\text { ب- مبادئ ومرتكزات مجتمعات التعلم المهنية عبر الإنترنت : }
$$

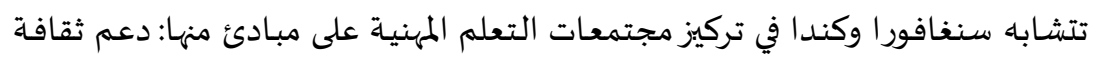

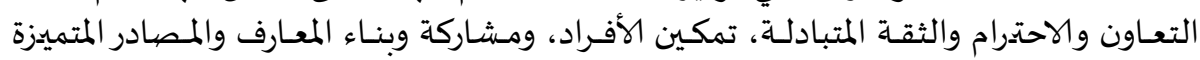
وممارستها باتقان وتحقيق الانجاز الفعال. 


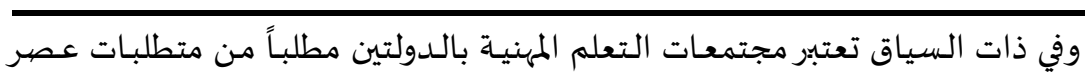

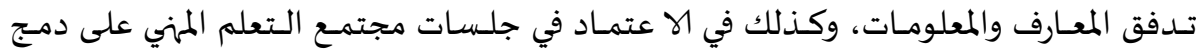
التنمية المهنية المرتكزة على نتائج البحوثوث التربوفية.

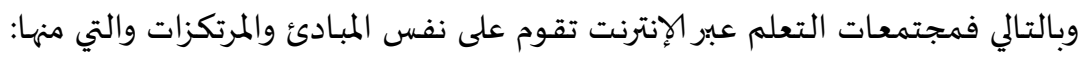

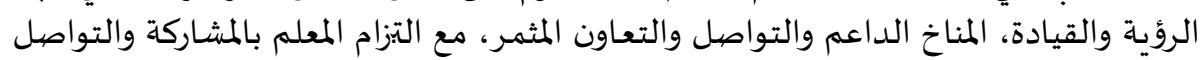

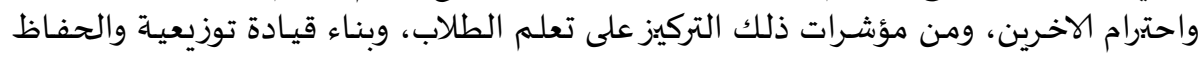
علهيا للحفاظ على التعلم المهني.

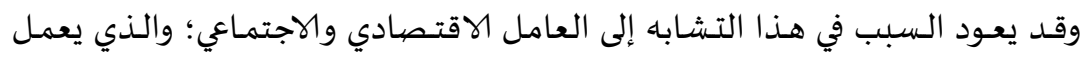

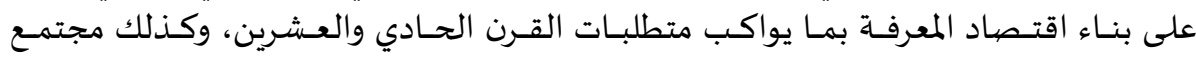

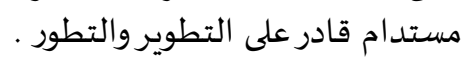

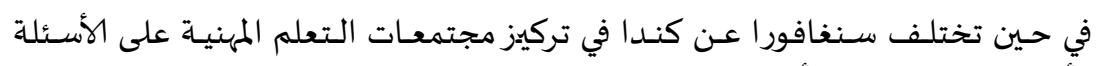

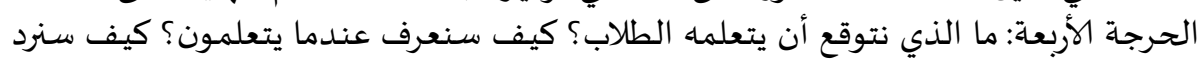

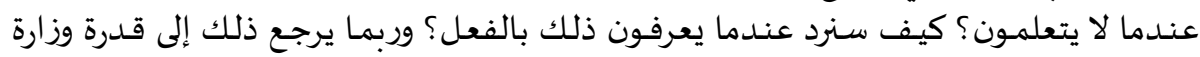

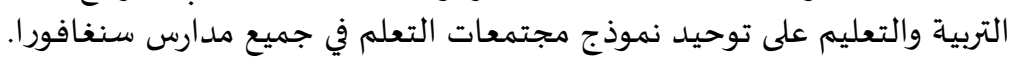

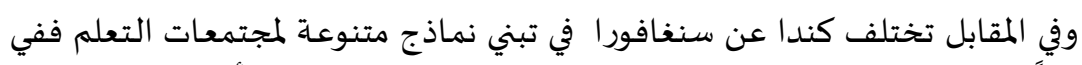

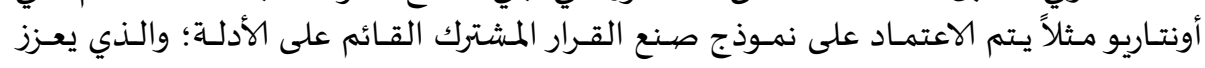

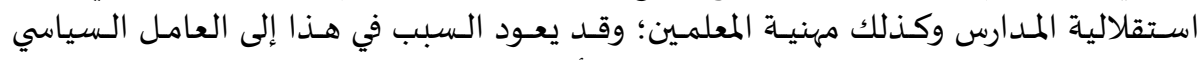

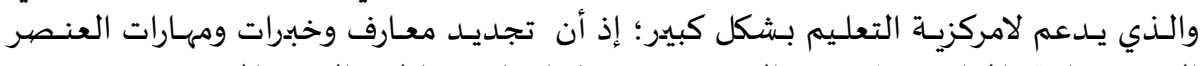

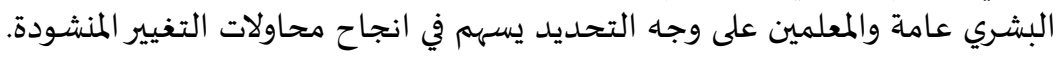

$$
\text { ج- تصنيفات وأنواع مجتمعات التعلم المهنية عبر الإنترنت : }
$$

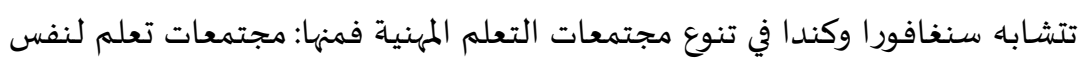

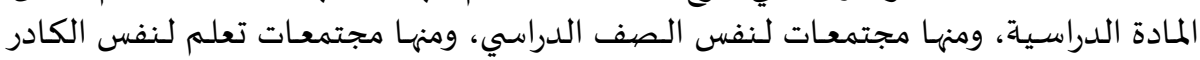

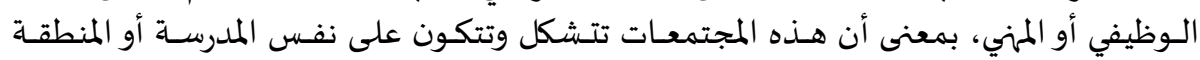

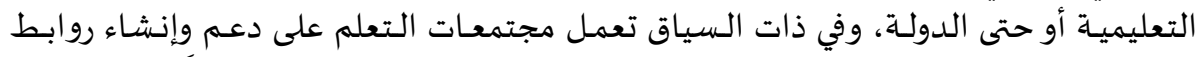

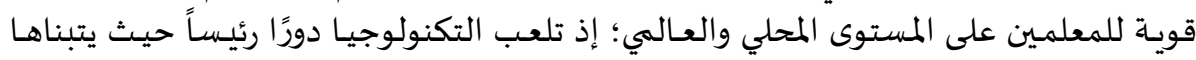

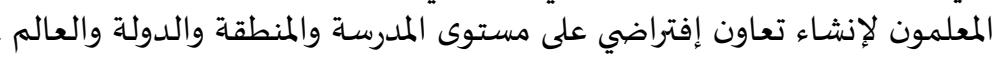

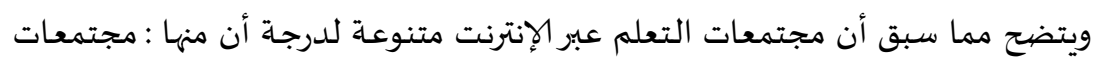

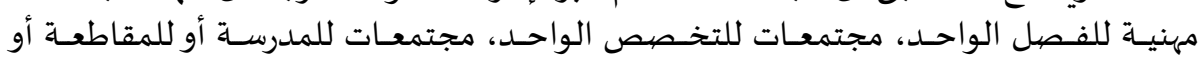
الدولة ككل، ومجتمعات عالمية.

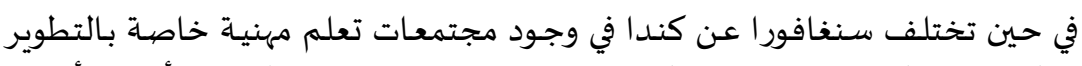

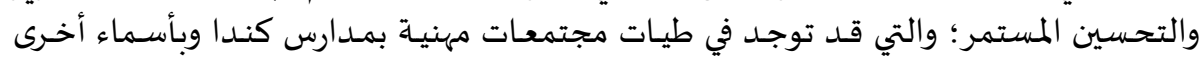

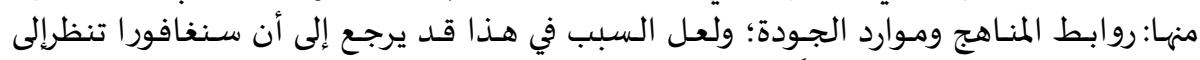

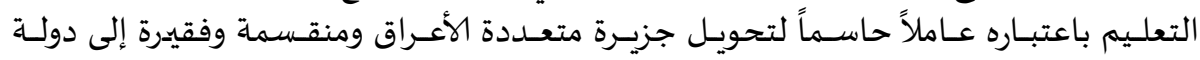

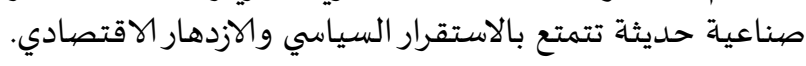




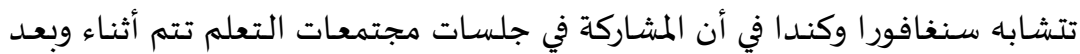

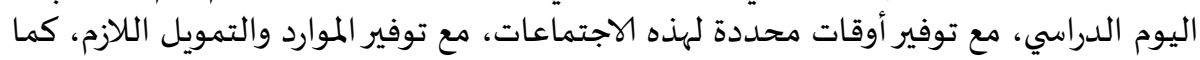

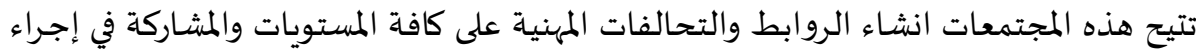
الأبحاث العلمية الإجرائية ومناقشة وتبادل المبادل وممارسة نتائجها المتميزة.

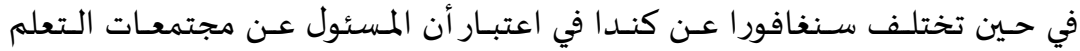

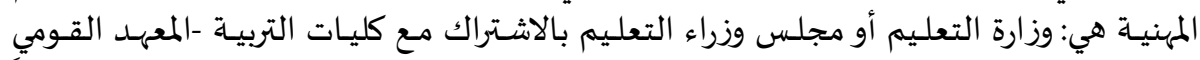

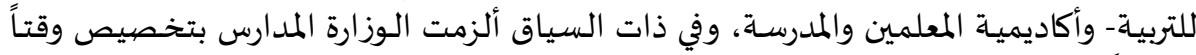

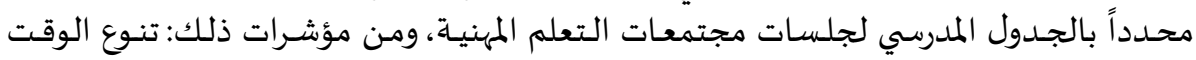

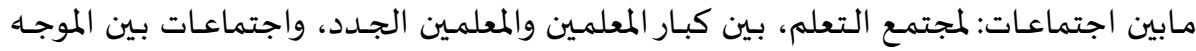

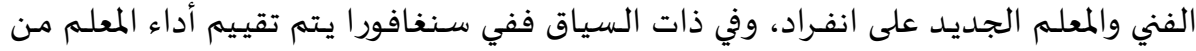

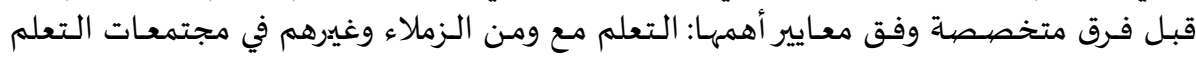
المهنية ومشاركته في البحوث الإجرائية بفاعلية.

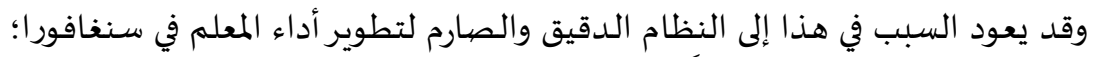

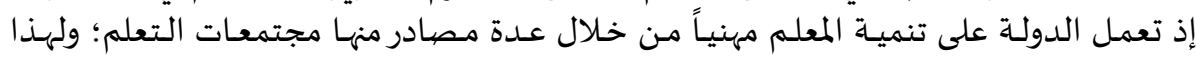

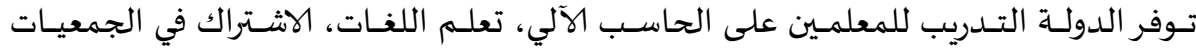

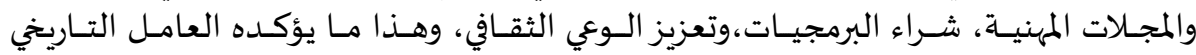

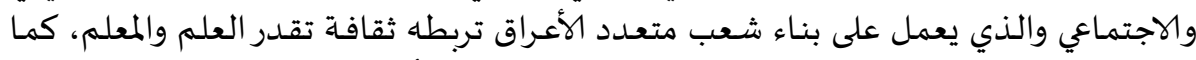

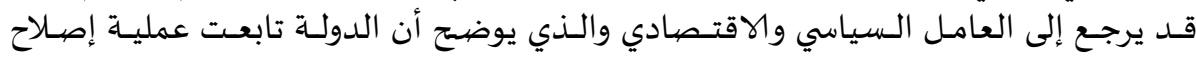

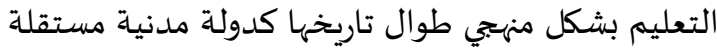

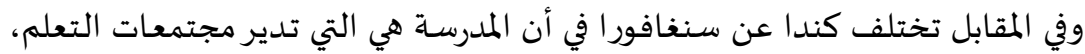

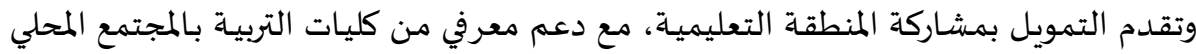

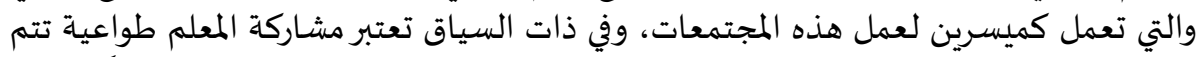

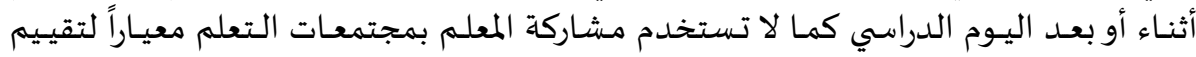

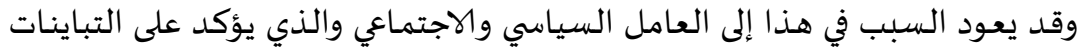

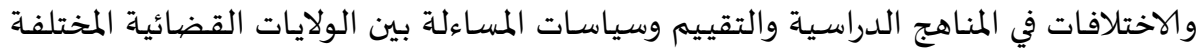

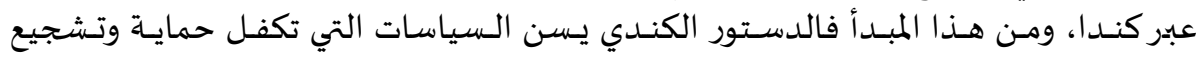

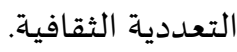

2- ممارسات وأنشطة مجتمعات التعلم المهنية عبر الإنترنت:

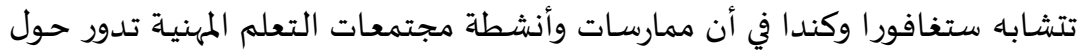

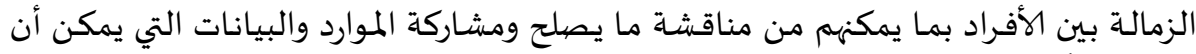

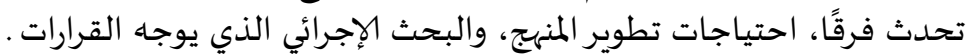


وفي ظل هذه الظروف تدعم هذه الممارسات توفير فرص التعلم المنفي للمعلم، وتعزيز الماتيز

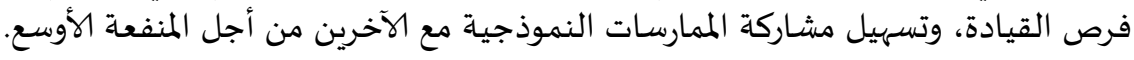

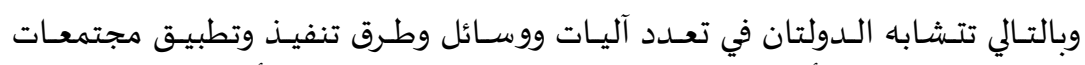

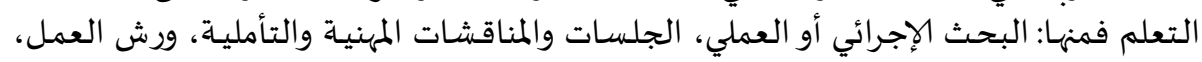

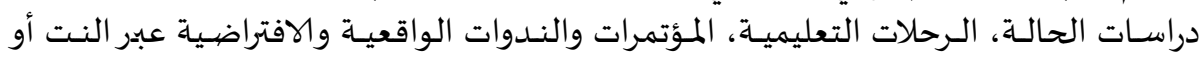
شبكة المعلمين الخاصة.

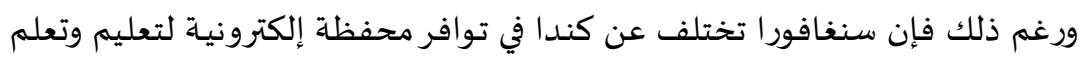

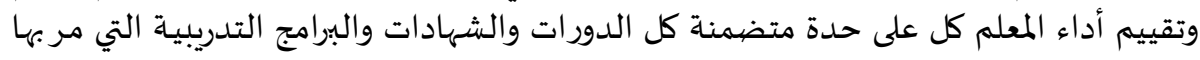

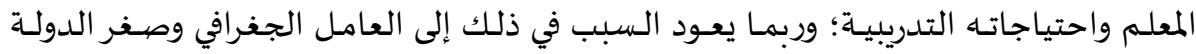

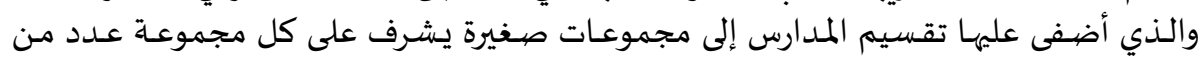

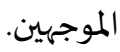

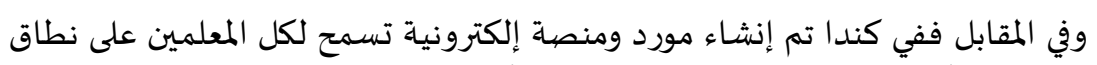

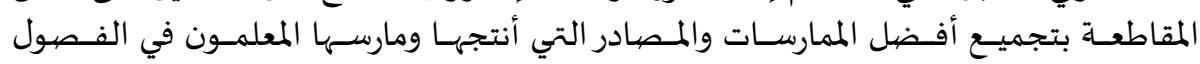
الدراسية، ليستفيد منها ويتبادلها جميع المعلمون على نطار المياق مجتمع التعلم.

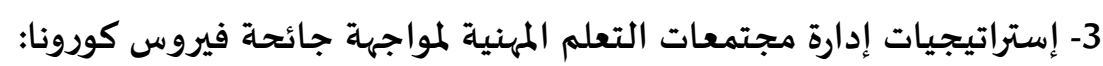

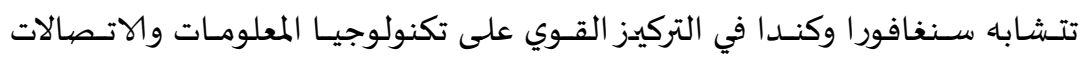

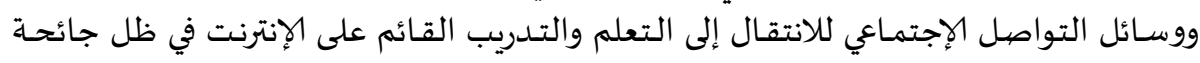

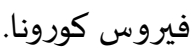

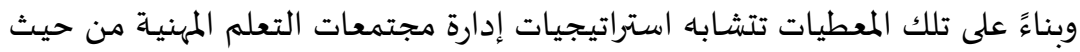

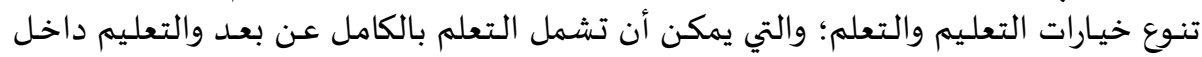

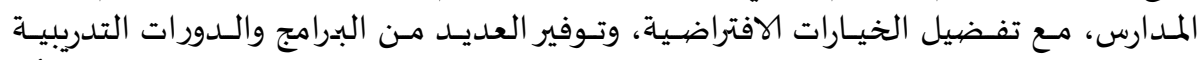

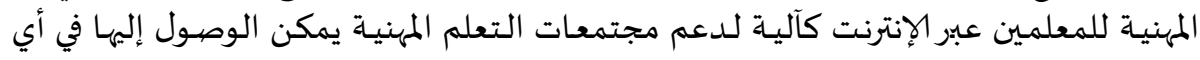

وتختلف سـنغافورا عن كندا في قيام مقدمو الخـدمات بـالمجتمع المحلى وغيرهـا من

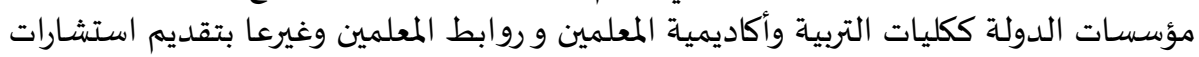

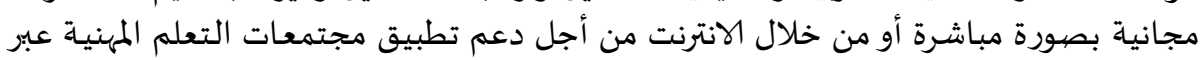

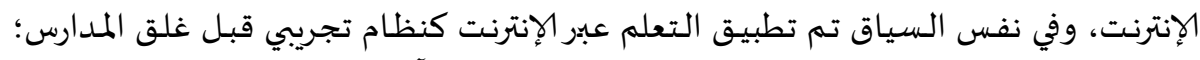

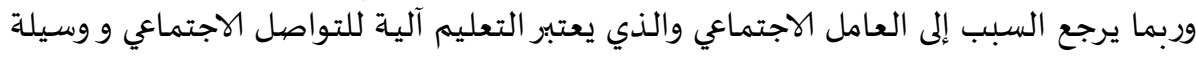

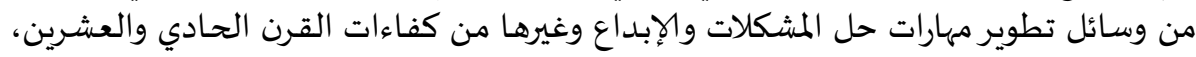

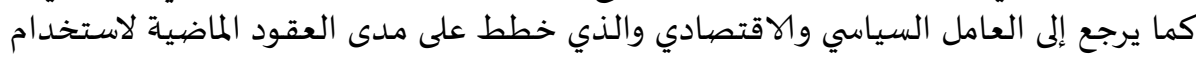

تكنولوجيا التعليم كجزء من "رؤية مجتمع المعرفة والميادي والاقتصياد".

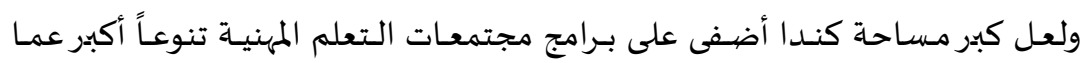

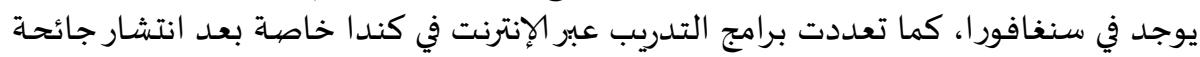

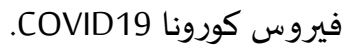




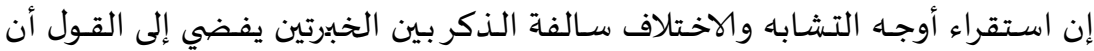

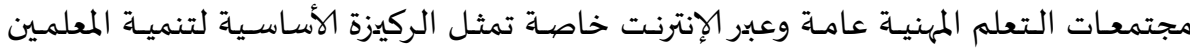

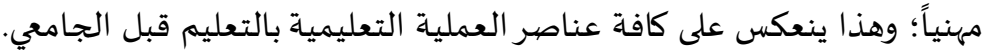

خامساً: واقع مجتمعات التعلم المهنية عبر الإنترنت بالتعليم قبل الجامعي في مصر: يمكن تنـاول ملامح تفعيل مجتمعات التعلم المهنيـة عبر الإنترنت بمصر خـلال المحاور

1- 1 طبيعة مجتمعات التعلم المهنية عبر الإنترنت:

ويتناول هذا المحور عدة مكونات وعناصر فرعية، وهي كالتالي:

أ- فلسفة وأهداف مجتمعات التعلم المهنية عبر الإنترنت :

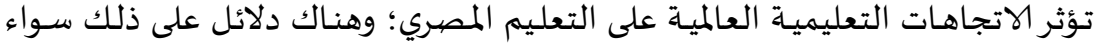

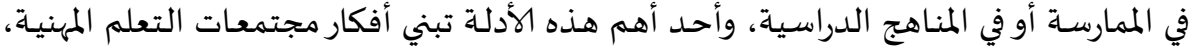

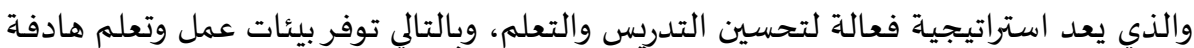

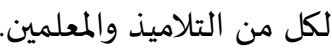

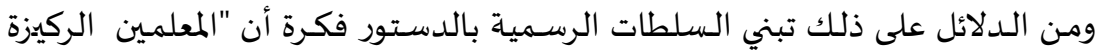

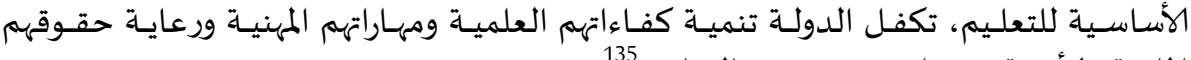

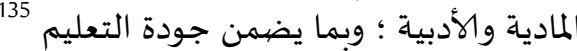

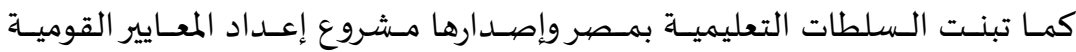

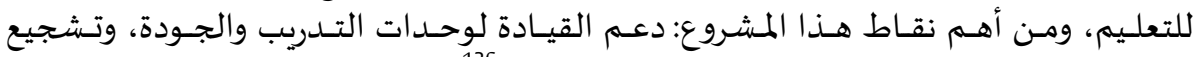

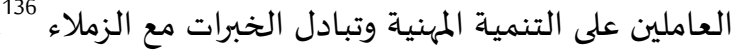

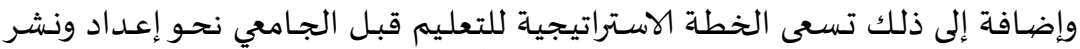

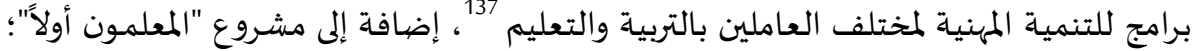

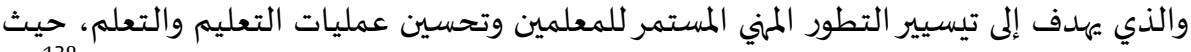

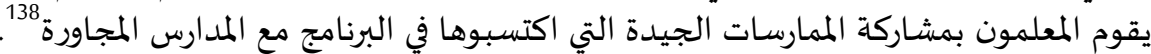

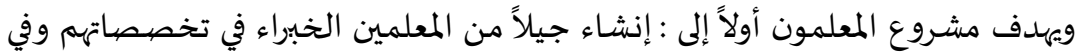

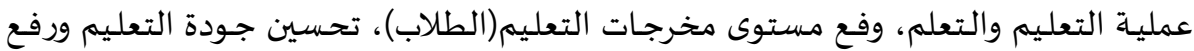

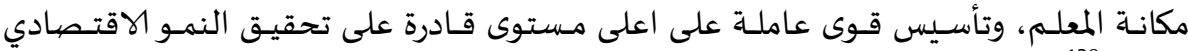
للدولة 139

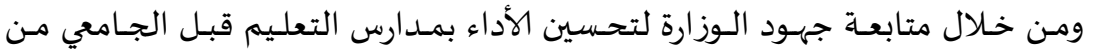

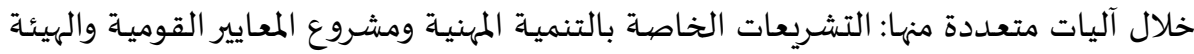

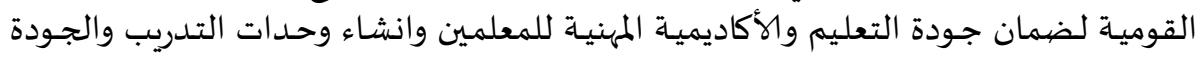

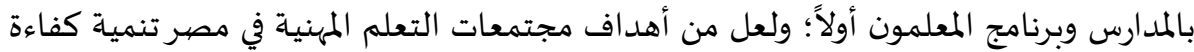

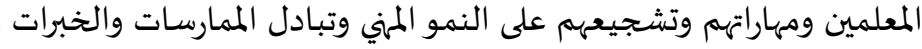


ورغم هذه الجهود فهناك بعض المشكلات التي تحول دون نجاح تنفيذ التنمية المهنية؛

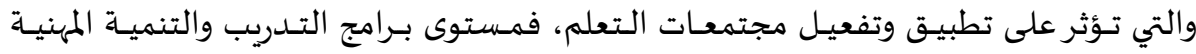

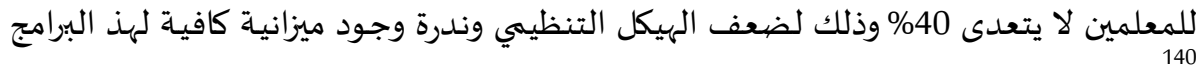

\section{ب- مبادئ ومرتكزات مجتمعات التعلم المهنية عبر الإنترنت :}

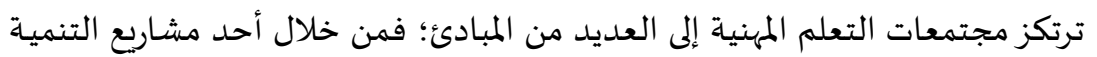

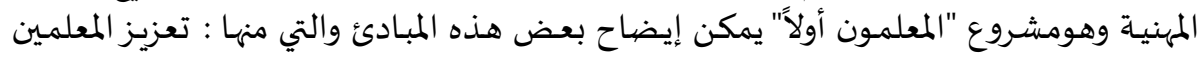

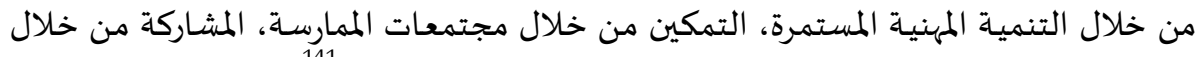

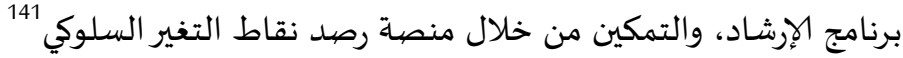

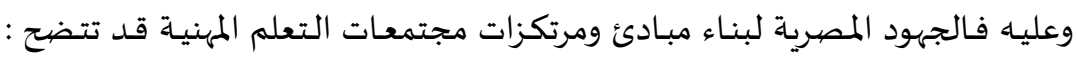

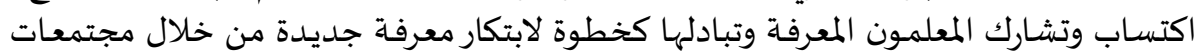

التعلم.

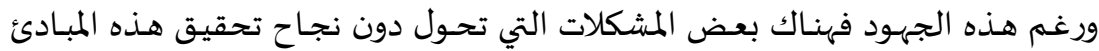

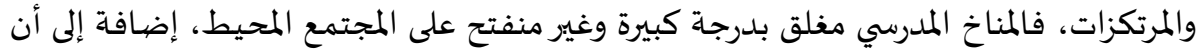

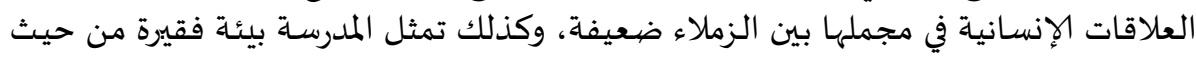

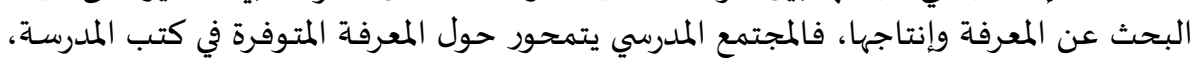

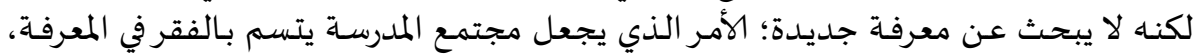

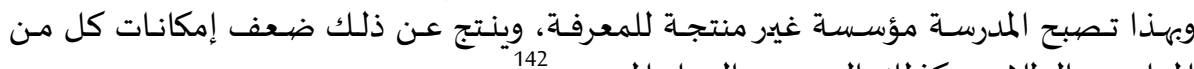
المعلمين والطلاب، وكذلك إلى جمود العمل المدرسي لمعيد 142

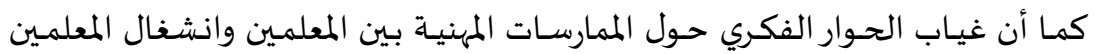

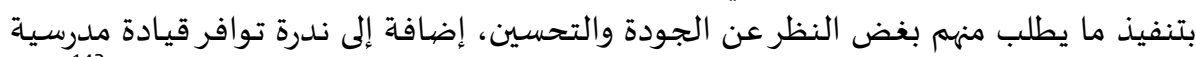

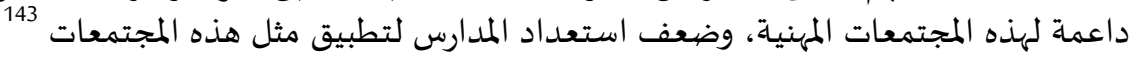

$$
\text { ج- تصنيفات وأنواع مجتمعات التعلم المهنية عبر الإنترنت : }
$$

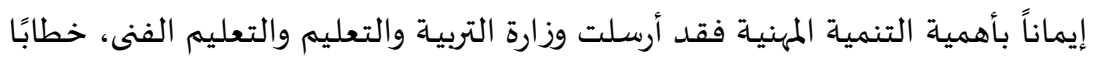

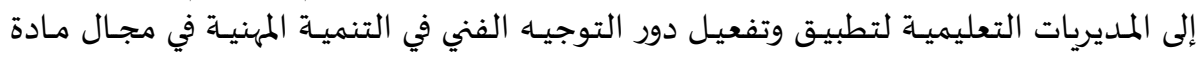

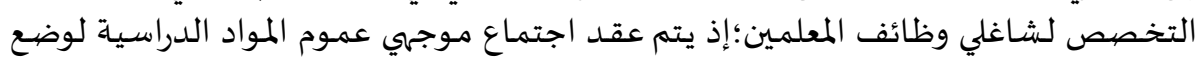

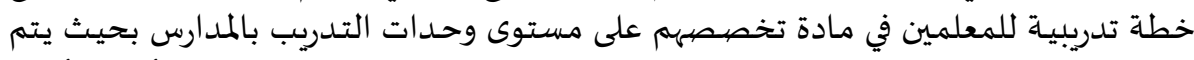

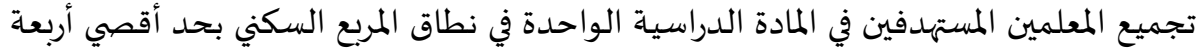

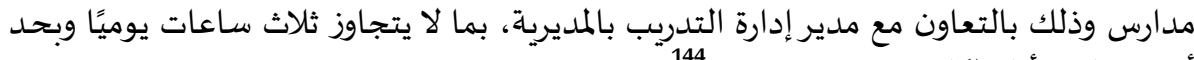

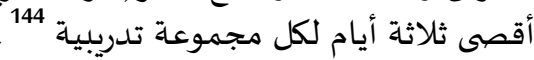

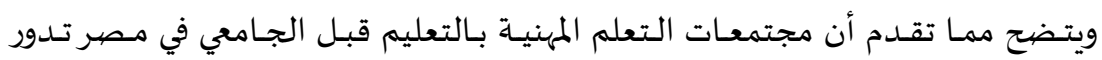

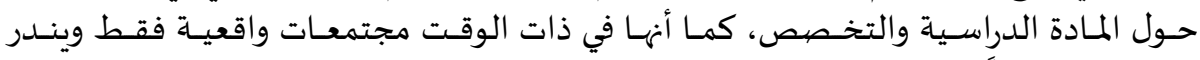

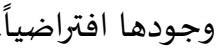


د- إدارة وتقييم مجتمعات التعلم المهنية عبر الإنترنت :

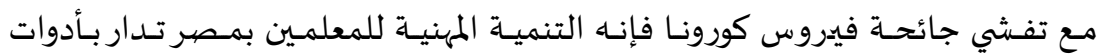

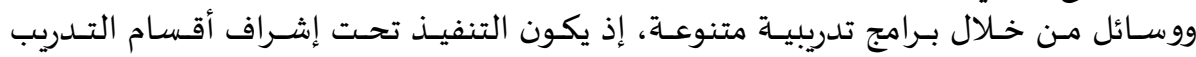

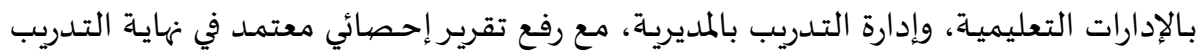

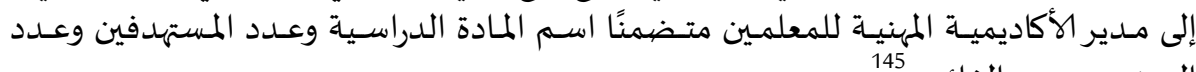

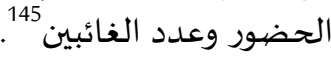

ويتضح مما تقدم أن التنمية المهنية للمعلمين (ومنها مجتمعات التعلم المهنية) في مصر تديرها وتقوم بها أقسام ووحدات ومديريات التدريب بالتعاون مع الأكاديمية المهنية للمعلمين. لمعين.

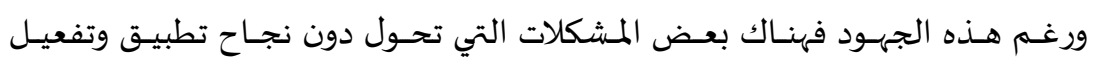

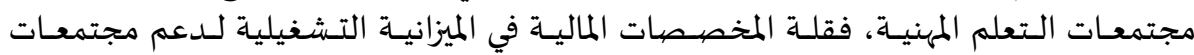
التعلم، وكذلك ضعف الإمكانيات المادية بمدارس التعليم قبل الجامعي.

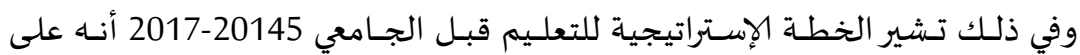

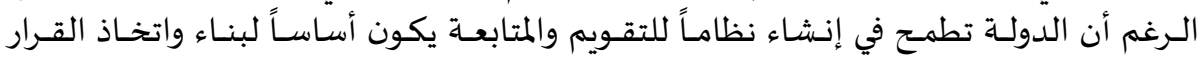

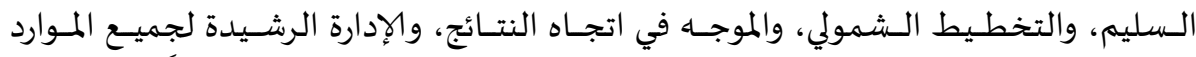

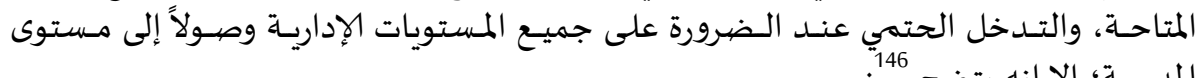

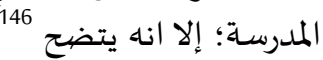
- غياب ثقافة القياس والتقويم والفهم المشترك الواحد بين العاملين بالمجال التربوى، - - تدنى مستوى جودة برامج التدريب المرتبطة برفع الكفاءة المهنية للمعنيين، و و - غياب المقياييس المقننة لقياس مختلف جوانب شخصية الفرد . 2- ممارسـات وأنشطة مجتمعات التعلم المهنية عبر الإنترنت:

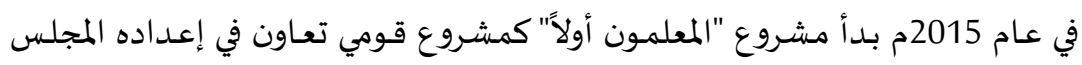

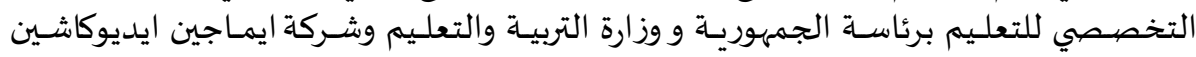
Imagine Education

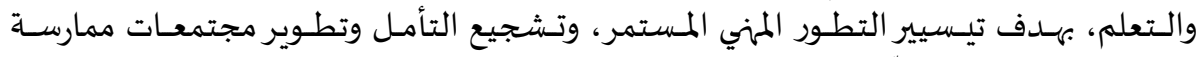

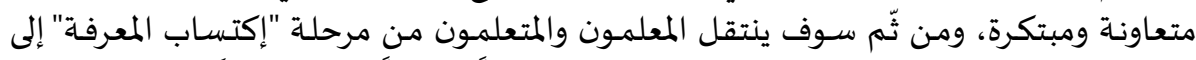

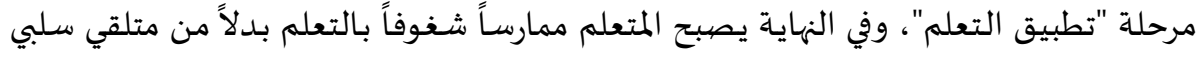

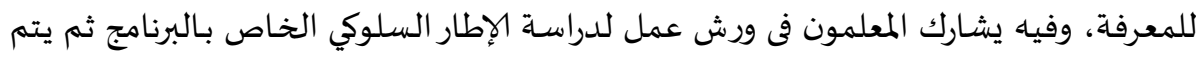

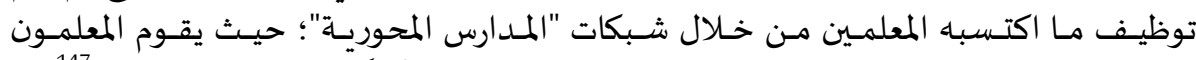

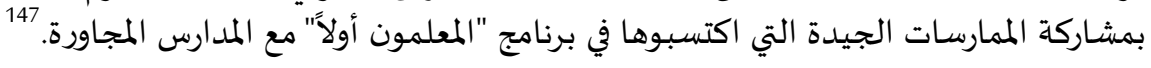

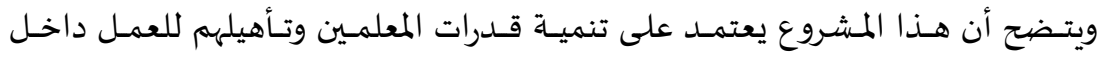

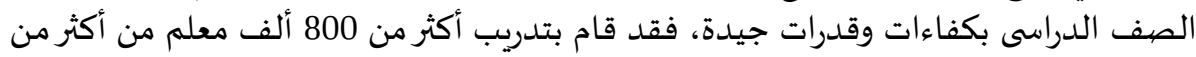

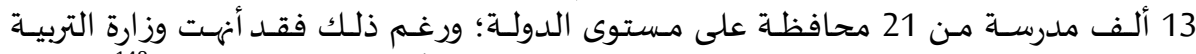

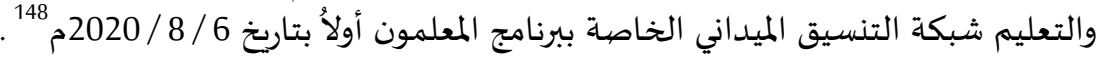




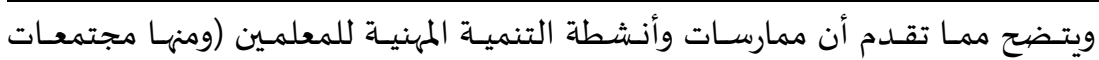

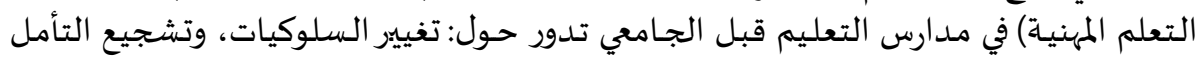
والتعاون من خلال ورش العمل والبرامج التدريبية.

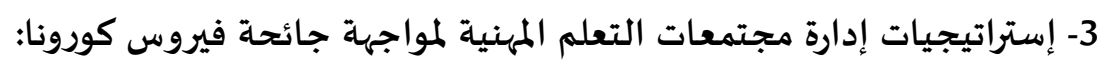

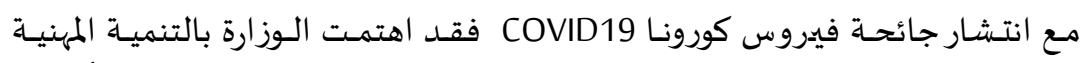

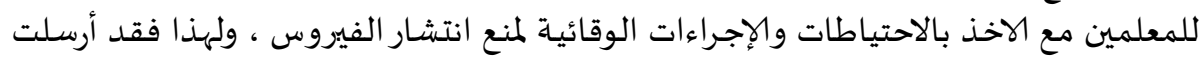

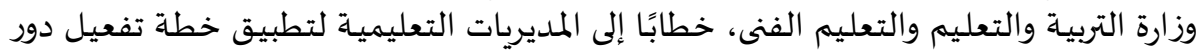

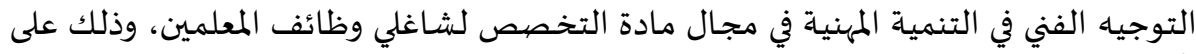

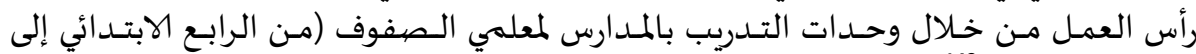
الثالث الإعدادي)

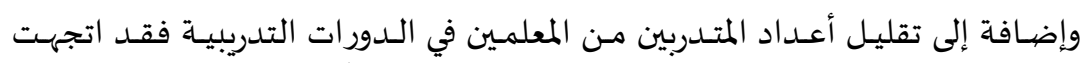

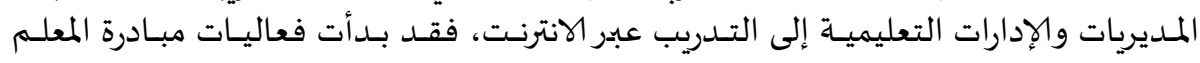

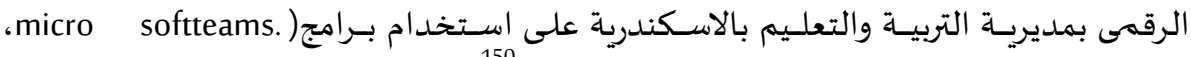
(Edomodo

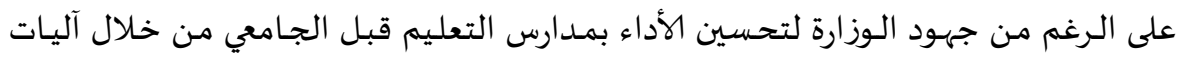

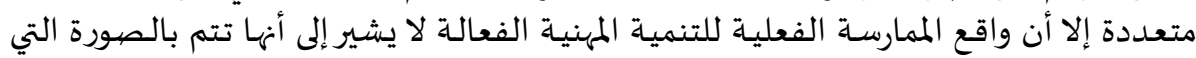

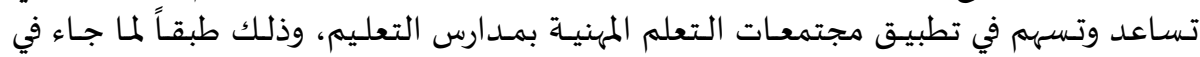

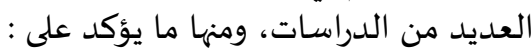

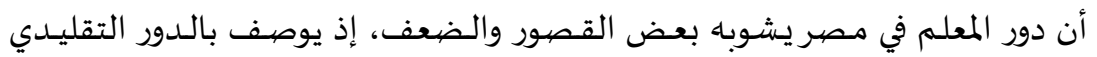

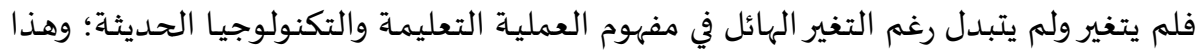

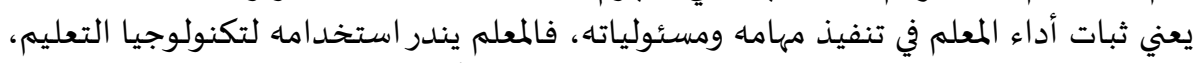

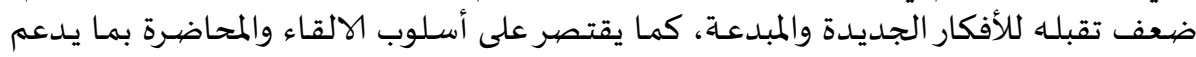

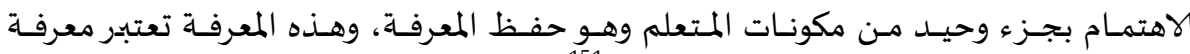

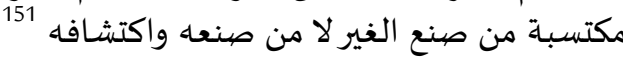

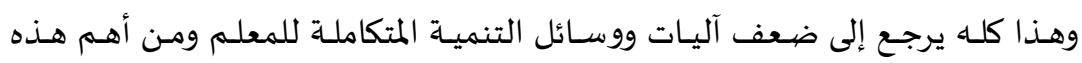
الوسائل والآليات مجتمعات لئه التعلم المهنية .

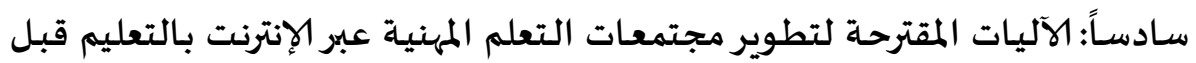

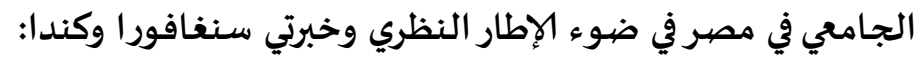

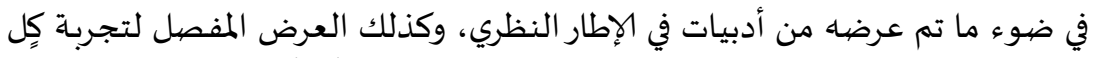

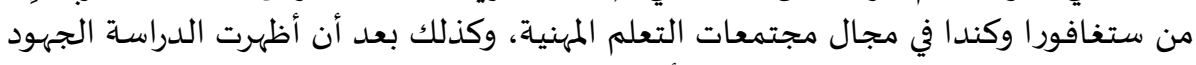

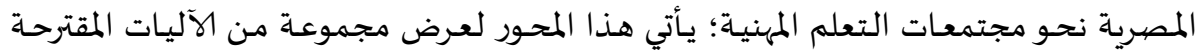

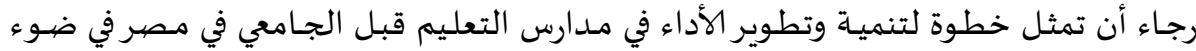
خبرة دولتي المقارنة ) ستغافورا وكندا.

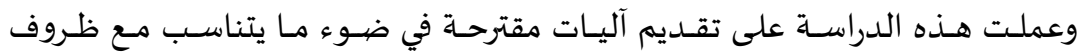

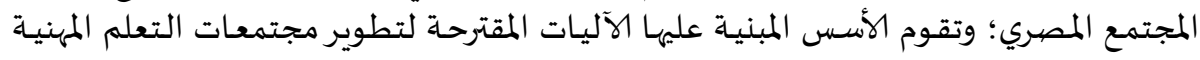




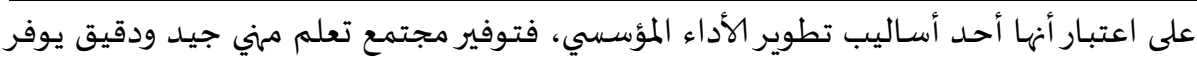

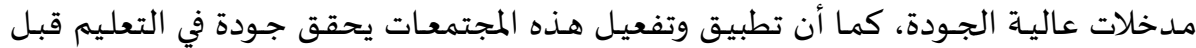

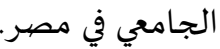

$$
\begin{aligned}
& \text { وفي ضوء ما تقدم تتضح معالم الأليات المقترحة حسب ما يلي : } \\
& \text { 1- طبيعة مجتمعات التعلم المهنية عبر الإنترنت: } \\
& \text { ويتناول هذا المحور عدة مكونات وعناصر فرعية، وهي كالتالي: } \\
& \text { 1-1-1 فلسفة وأهداف مجتمعات التعلم المهنية عبر الإنترنت : }
\end{aligned}
$$

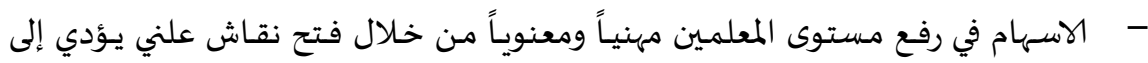

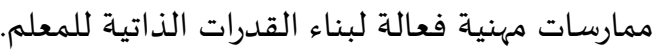

- - - مطوير خبرات ومهارات ومعارف الزملاء والطلاب من خلال غرس فكرة المشاركة. - - - تلبية احتياجات المعلمين والطلاب وتطوير وتحسين أدائهم باستمرار. - - مشاركة الرؤى والقيم والأهداف والتأكيد على ثقافة التعاون والتشـارك الداعم. - - دعم مهارات القرن الحادي والعشرين في التعليم والتعلم؛ وذلك من خلال مساعد ة

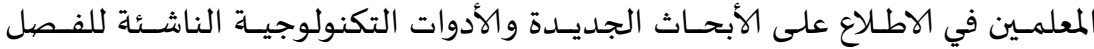

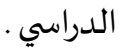

- - - إعطاء المعلمين الفرصة لممارسة القيادة مع تطوير وتحسين خبراتهم ومهاراتهم وتحقيق

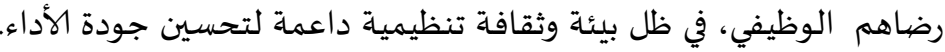

توفير نظرة مختلفة للمعلمين على ما يمارسه معلمو المدارس والمدن والدول الأخرى .

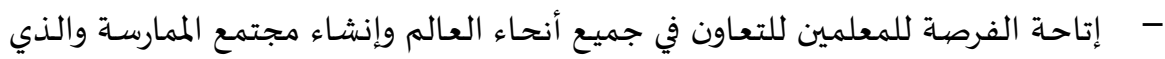
يتجاوز جدران الفصل الدراسي بكثير.

\section{2-1- مبادئ ومرتكزات مجتمعات التعلم المهنية عبر الإنترنت :}

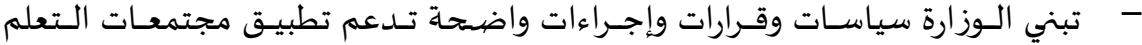

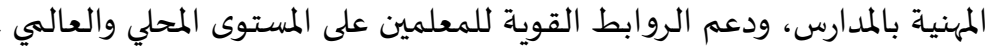

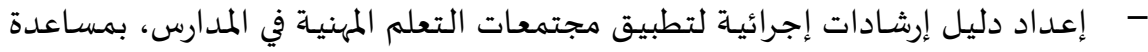

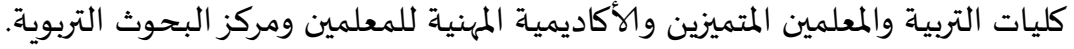
- - الاعتمـاد على نمـوذج لمجتمعـات الـتعلم يشجع العمل والثقافـة التعاونيـة والاحتـرام

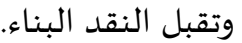


- - مالقيادة الداعمة والمناخ التنظيمي المناسب لتبادل القيادة بين أعضاء المجتمع الواحد. - - مككين المعلمين والطلاب من خلال الاحترام والمسئولية ونتائج العمل.

- - ارتباط نموذج مجتمعات التعلم المهنية بالرؤية التربوية للوزارة والمدرسة. - بناء مجتمع التعلم لتحقيق أهداف محددة للطلاب والمعلمين والمجتمع المدرسي. - استخدام وتفعيل وسائل التكنولوجيا الحديثة من حواسيب وأجهزة ذكية. - - - توفير الموارد والإمكانيات اللازمة للعمل على نشر ثقافة مجتمعات التعلم بالمدرسة. - - - إعداد وتنفيذ برنامج تدريبي لتدريب المعلمين يتوائم مع إرشادات الوزارة حول تطبيق

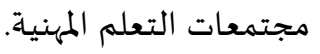

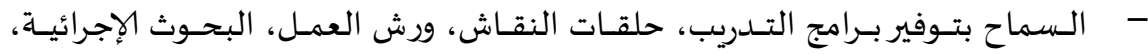

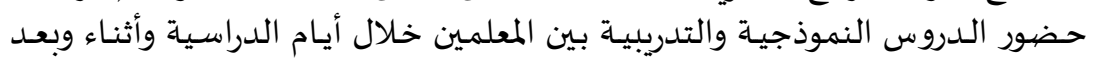
ساعات العمل؛ وذلك كآلية لتطبيق مجتمع التعلم المهني والفعال.

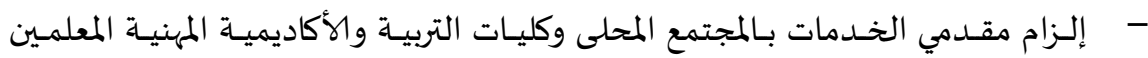

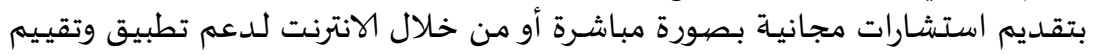
أداء مجتمعات التعلم المهنية عبر الإنترنت.

- - ـوفير المكان والوقت المناسب واللازم للمعلمين وعقد اللقاءات والاجتماعـات الدوريـة

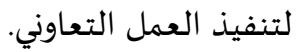

3-1-1 تصنيفات وأنواع مجتمعات التعلم المهنية عبر الإنترنت :

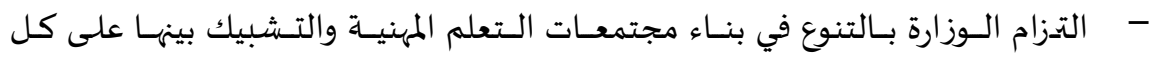
المستويات بالمدرسة والإدارة والمحافظة والدولة بل بل والعالم ؛ وذلك من خلال:

$$
\begin{aligned}
& \text { - - توفير وتفعيل مجتمعات تعلم مهنية للمواد والتخصصات العلمية. } \\
& \text { - - توفير وتفعيل مجتمعات تعلم مهنية للتطوير التربوي والإداري. } \\
& \text { - - } \\
& \text { - - مفير وتفعيل مجتمعات تعلم مهنية للتطوير التكنولوجي. } \\
& \text { 1-4-1 إدارة وتقييم مجتمعات التعلم المهنية عبر الإنترنت : }
\end{aligned}
$$

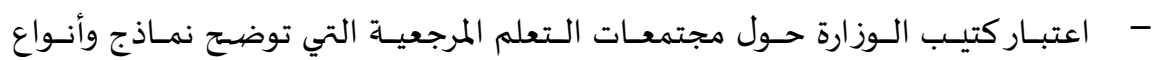

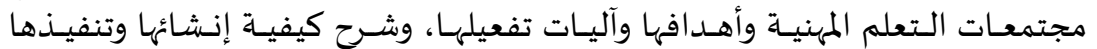

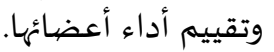




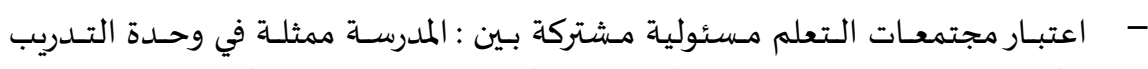

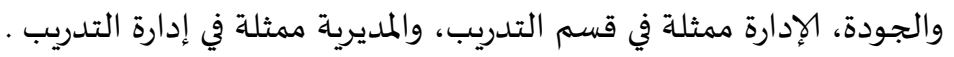

- - تمكين أفرع الأكاديمية المهنية للمعلمين بالمحافظات بالإشراف وتقييم أداء مجتمعات التعلم في نطاقها.

- - تيسيير مشاركة كليات التربية بالمجتمع المحلي لدعم مجتمعات التعلم المهنية . توفر الوزارة الدعم المالي والفني للمجتمعات المهنية مع السماح للمجتمع المحلي بالقيام

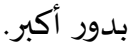
- - السماح للمعلمين على إنشاء روابط وتحالفات مهنية ودعم هذه الروابط. إلزام القيادات المدرسية بتوفير وقت لجلسات مجتمعـات التعلم أثناء اليوم الدراسي مع تخفيف الحمل التدريسي الملقى على المعلمين.

- - إلزام القيادات المدرسية والإثـراف الفني بالاجتماع مع مجتمعات التعلم كل في مجال التمال عمله لمناقشة الأهداف والإجراءات المطلوبة لتحقيق التميز في التعليم والتعلم . - - متابعة اجتماع الموجهون وكبار المعلمون مع المعلمين الجدد مرة شهرياً فردياً وجماعياً. - - متابعة وتقييم مدى التزام مديري المدارس بتنفيذ القرارات الخاصية بمجتمعات التعلم المهنية بالمدارس. - - متابعة ومراقبة الدعم المؤسسي لمجتمعات التعلم المهنية. - - تكريم وتقدير المدارس وفرق العمل المتميزة في نشر وتطبيق مجتمعات التعلم المهنية. - - - تعميم التجارب المتميزة في مجال تطبيق مجتمعات التعلم المهنية بين المدارس. - - تعديل تقرير كفاية المعلم ليتضمن مشاركة المعلم في مجتمعات التعلم المهنية بفاعلية.

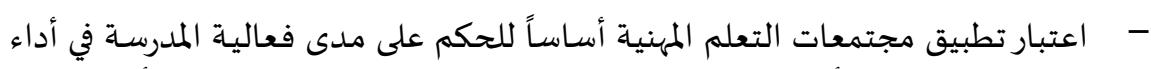

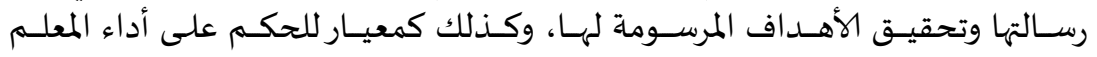

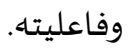

\section{2- ممارسات وأنشطة مجتمعات التعلم المهنية عبر الإنترنت:}

- - إلزام الـوزارة المعلمين بالتسجيل في بنك المعرفة للاستفادة المعنيـة كما هو الحسال في حساب المعلم على موقع الأكاديمية المهنية للمعلمين. 


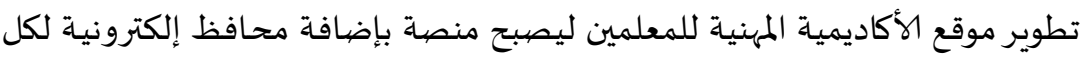

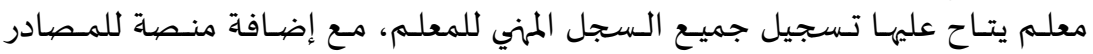

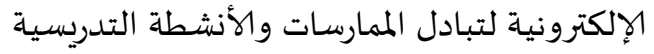

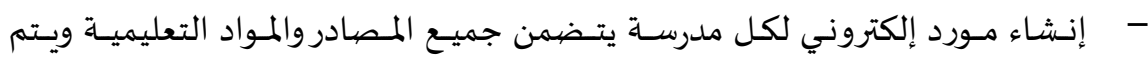
تحديثه باستمرار.

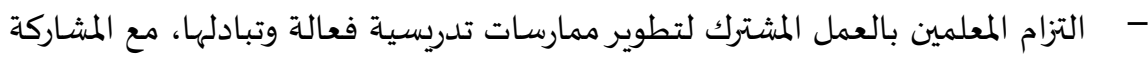
في البحوث الإجرائية ونشر نتائجها.

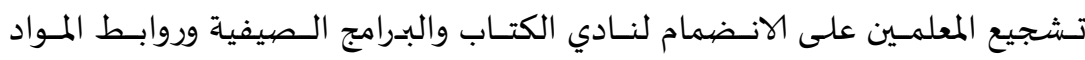

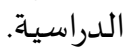

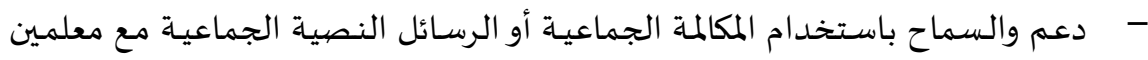
آخرين في المدرسة وخارجها لمناقشة موضوع يخص المكاحة التعليم والتعلم.

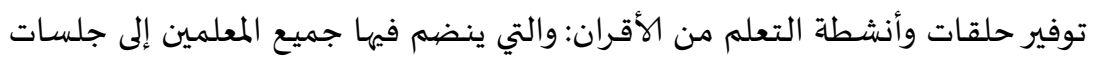

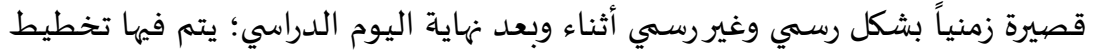

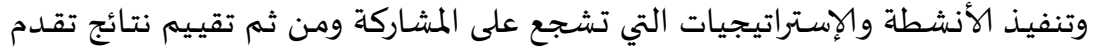
التعلم بين جميع الطلاب.

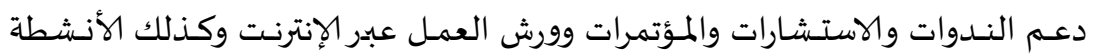
البحثية عن بُعد عبر الإنترنت من المنزل.

ممارسة وتنفيذ أبحاث إجرائية من وعلى أرض الواقع بالمدارس والاستفتفادة منهـ المنا بشكل عملي. تنظيم جدول دراسي يعزز التعلم الفعال القائم على الأنشطة المهنية المشتركة. - - موظيف تقنية المعلومات والاتصالات لدعم عملية التعلم المني والجماعي. - - تـشكيل فـرق لمجتمعـات الـتعلم المهنيـة حسب التخصـصـات أو المرحلـة أو الـصف

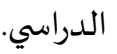

- - عقد ورش عمل لصياغة رؤية مشتركة لمجتمع التعلم منبثقة من رؤية المدرساة. - - عقد اجتماعات دورية مع الفرق لمراجعة الرؤية ومدى مواءمتها للمستجدات التربوية. - - - تنفيذ ومتابعة أنشطة مجتمعات التعلم المهنية بناءً على المواد المتفق عليها.

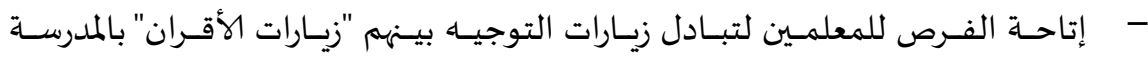
والمدارس المجاورة والمتميزة. - - السماح بتطبيق المعارف الجديدة ومشاركة نتائجها بين المعلمين. 


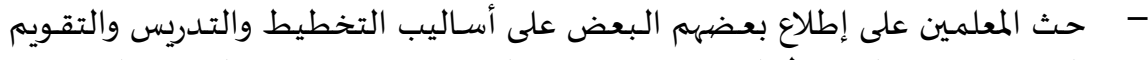

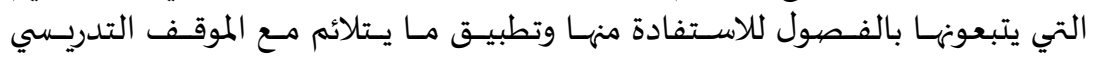

$$
\text { والتعليمي. }
$$

$$
\begin{aligned}
& \text { - - احتفاء المدرسة مع أعضاء مجتمع التعلم بنجاح الممارسات المهنية. }
\end{aligned}
$$

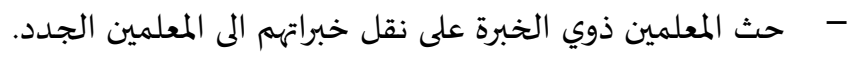

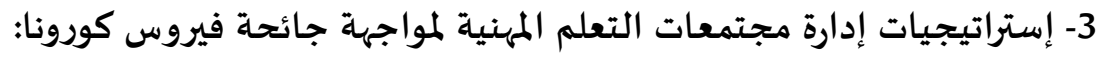

- اهتمام الدولة بالتطوير التكنولوجي الحقيقي من خلال الاستثمار في تكنولوجيا التعليم لمواكبة العصر. الدولة بالت

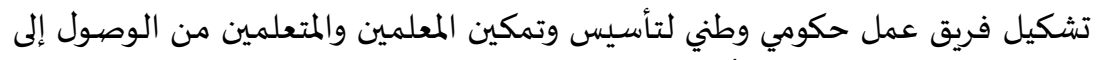

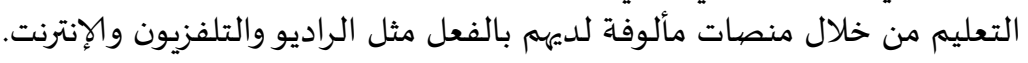

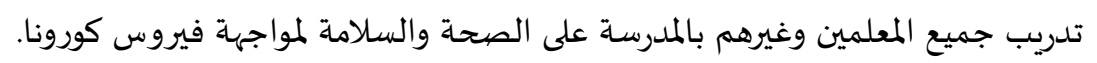

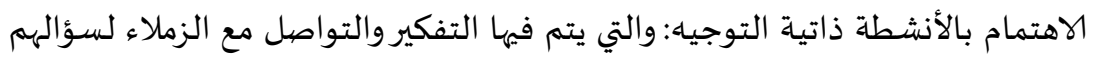

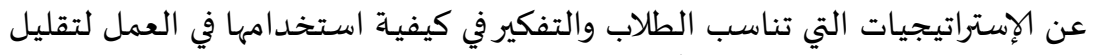
الضغط والتوتر ولزيادة كفاءة الأداء.

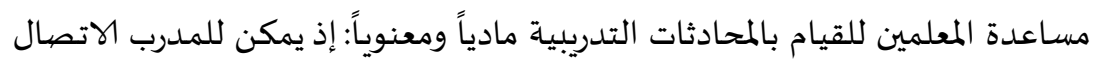

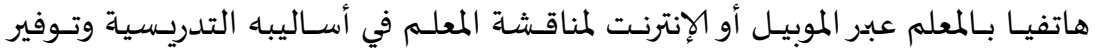

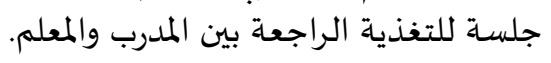

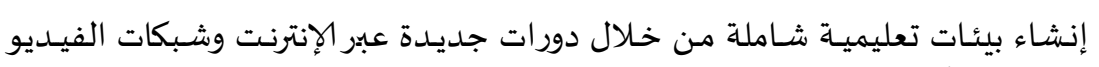

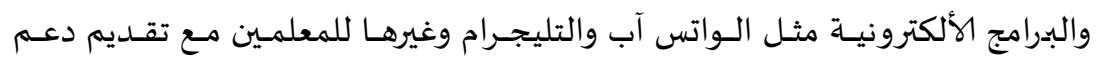
إضافي لتطويرهم من الناحية المهنية.

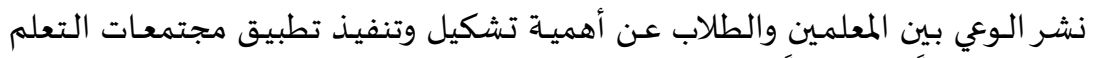

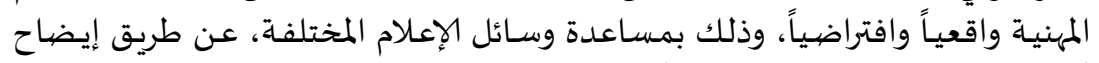

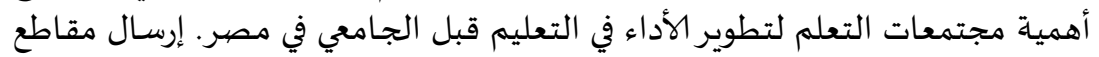

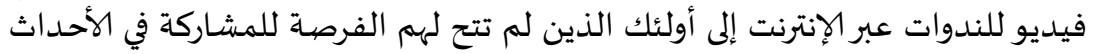
مباشرة

زيادة المنصات التعليمية الإلكترونية والدروس المتلفزة كماً وكيفاً.

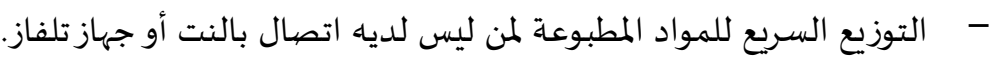

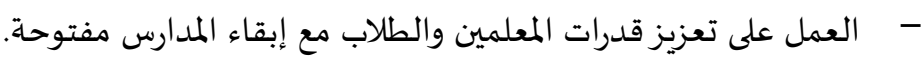


- - الـسماح للمنظمهات المجتمعيـة بتقـديم الــدعم المـادي والفني لتخفيـف التــداعيات النفسية لفيروس كورونا.

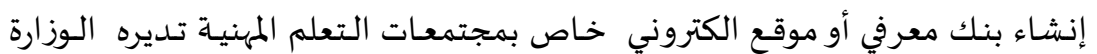

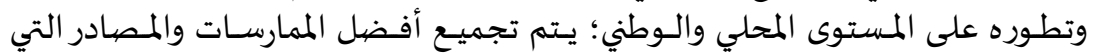

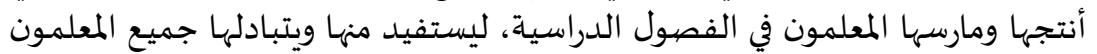
الدراسـات والبحوث نطاق مجتمع التعلم.

- دراسة تقويمية لمجتمعات التعلم المهنية في التعليم الأزهري قبل الجامعي في مصر. - دراسة مقارنة بين مجتمعات التعلم المهنية والتدريبات التقليدية التي تقدمها إدارات التدريب بمديريات التربية والتعليم في مصر في تطوير الأداء المهني. - تطوير مجتمعات التعلم المهنية بالتعليم قبل الجامعي في مصر في ضوء تجارب بعض

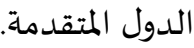
- تطوير رأس المال الفكري بمـدارس التعليم الفني في مصر في ضـوء مجتمعات التعلم المهنية . 


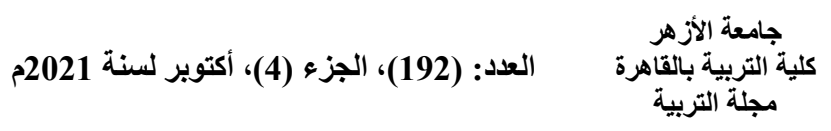

1- فريق النقرير العالمي لرصد التعليم، اليونسكو: الثقرير العالمي لرصد التعليم الدساءلة في مجال

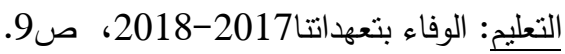

2- محمد صادق إسماعيل: تطوير التعليم الأساسي كمدل لإصلاح التعليم العربي، العربي للنشر

والتوزيع، القاهرة 2011م، ص ص الب 261-263.

3- محمد إسعاف فياض: الرضا الوظيفي وعلاقته بنطوير أداء المعلمين في مدارس لواء بني كنانة،

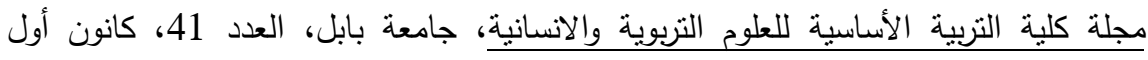

2018، ص563

${ }^{4}$-Hargreaves, A. :Push, pull and nudge: The future of teaching and educational change. In

X. Zhu \& K. Zeichner (Eds.), Preparing teachers for 21st century,2013,pp. 217-236.

$$
\begin{aligned}
& \text { 5- ملتون كوكس، و لاوري رتثلن: إنثاء مجنمعات تعلم في إطار الهيئة التدريسية: ترجمة سميح }
\end{aligned}
$$

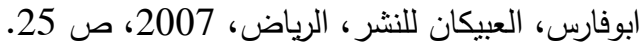

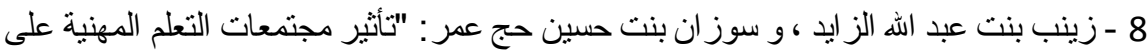

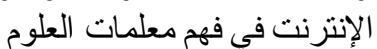

لطبيعة العلم وممارسات ندريسها"، المجلة الأردنية في العلوم التربوية، مجلا 12 ، عدد3 ، 2016م، ص350

7 -Gray Julie A., Summers Robert:International professional learning communities: The role of enabling school structures, trust, and collective efficacy, The International Education Journal: Comparative Perspectives ,Vol 14, No 3, 2015,p63.

8-Hairon, S.,\& Tan, C. : Professional Learning Communities in Singapore and Shanghai: Implications for Teacher Collaboration. Compare: A Journal of Comparative and International Education, 2016,p1.

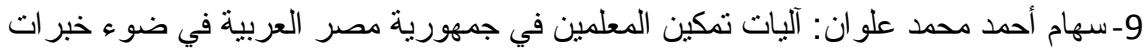

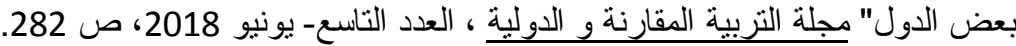

10 - Ministry of Education:Appendix G, Log of Teaching Practice for Experienced Teacher, Optional Form, Ontario, p15

11 - Elementary Teachers' Federation of Ontario :ETFO Voice, Vol. 9 , No. 4, April 2007,p20,Retrieved 25-1-2021: https://thesmalleroffice.files. /2012/05/engaging-in-lesson-study-etfo-voice- 4.pdf

12. Ontario Ministry of Education: Professional Learning Communities: A Model For Ontario Schools CAPACITY BUILDING SERIES ,October 2007,p3,Retrieved 24-1-2021:

http://www.edu.gov.on.ca/eng/literacynumeracy/inspire/research/PLC.pdf 


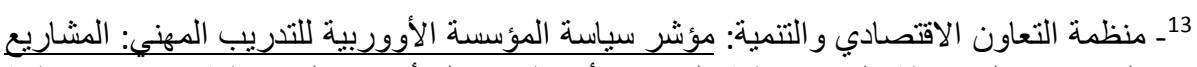

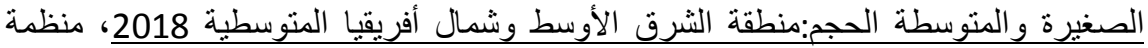

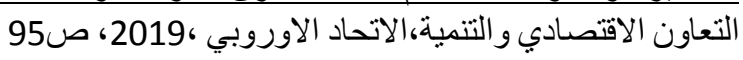

14 - عاطف عبد الحميد: فيروس كورونا: كيف بقدم التعليم عن بعد حلولا لبعض مشكلات المدارس

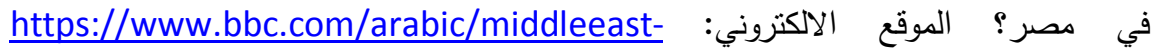

$5 \underline{5300272}$

15- الهيئة العامة للاستعلامات: نطوير التعليم مشروع مصر القومى الموقع الالكتروني: https://www.sis.gov.eg/Story/190871/\%D9\%81\%D9\%89-2019--

16- فيفي أحمد توفيق: سيناريو مستقبلي لتفعيل مجتمعات التعلم بمدارس التعليم العام بمحافظة

سوهاج، المجلة التربوية، كلية التربية، جامعة سوهاج، الجزء 47، 2017م، ص160

17- حشمت عبدالحكم محمدين، أحمد محمد بكري: متطلبات تطبيق مجتمعات التعلم المهنية بالمعاهد الأزهرية من وجهة نظر المعلمين، مجلة كلية التربية جامعة الأزهر، العدد(172) الجزء

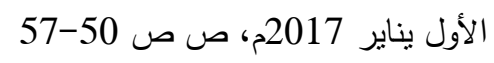

18- فيفي أحمد توفيق: مرجع سابق، ص صائر صن 116.

19-شاكر محمد فتحي، وهمام بدراوي زيدان(2003):التربية المقارنة:المنهج - الأساليب-

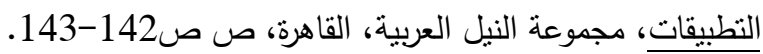

20- Chen, Yi: The Implementations of Professional Learning Communities (PLCs) in Beijing and Ontario Schools, Unpuplished Master Thesis, Faculty of Education, Brock University, St. Catharines, Ontario,2014,p5.

21 - ماهر أحمد حسن: بناء مجتمعات التعلم المهنية كمدخل لتجويد الأداء الأكاديمي في مدارس التعليم العام بالمملكة العربية السعودية، مجلة الجامعة الإسلامية بغزة، مجلداءة العدد

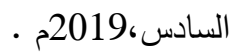

22 - علاء الدين حسن سعودي: برنامج قائم على مدخل مجتمعات التعلم المهنية لتمية مهارات تدريس القواعد والاتجاه نحوها لدى معلمي المرحلة الإعدادية، مجلة القراءة والمعرفة، كلية التربية ، جامعة عين شمس، العدد195، بناير 2018م.

23 - زينب بنت عبد الله الز ايد ، و سوز ان بنت حسين حج عمر : "تأثثر مجتمعات التعلم المهنية على الإنتزنت في فهم معلمات العلوم

لطبيعة العلم وممارسات تدريسها"، المجلة الأردنية في العلوم التربوية، مجلد 12 ، عدد3 ، 3 ، 2016م، ص350

24- عمرو صالح عبد الفتاح ابو زبد : بناء مجتمعات التعلم المعرفي الشبكي وأثزها على معلمي العلوم، مجلة كلية التربية ، جامعة الفيوم. العدد 11 ، ديسمبر 2011م. 
25 -Philipsen, B., Tondeur, J., Pareja Roblin, N., et al.:". Improving teacher professional development for online and blended learning: A systematic meta-aggregative review", Educational Technology and Research Development, 67, 2019.

${ }^{26}$-Hanifi Parlar: The relationship between social capital and innovativeness climate in schools, The intermediary role of professional learning communities, International Journal of Educational Management, Vol. 34 No. 2,Feb.2019

27- Warangkana Lin, Moosung Lee: Linking Network Learning Capacity to professional community and organizational learning in an International Baccalaureate school in Taiwan, Journal of Educational Administration ,July2018,Vol. 56 No. 6.

${ }^{28}$-E. Verbiest1. Developing Professional Learning Communities Paper presented at the AERA conference, 2011, April 7th - 12th.

29 -Lee, D. H. L., Hong, H., Tay, W. Y., \& Lee, W. O. : Professional learning communities in Singapore schools. Journal of Co-operative Studies, Special issue: Transformative power of co-operation in education, 46(2), 2014,p1.

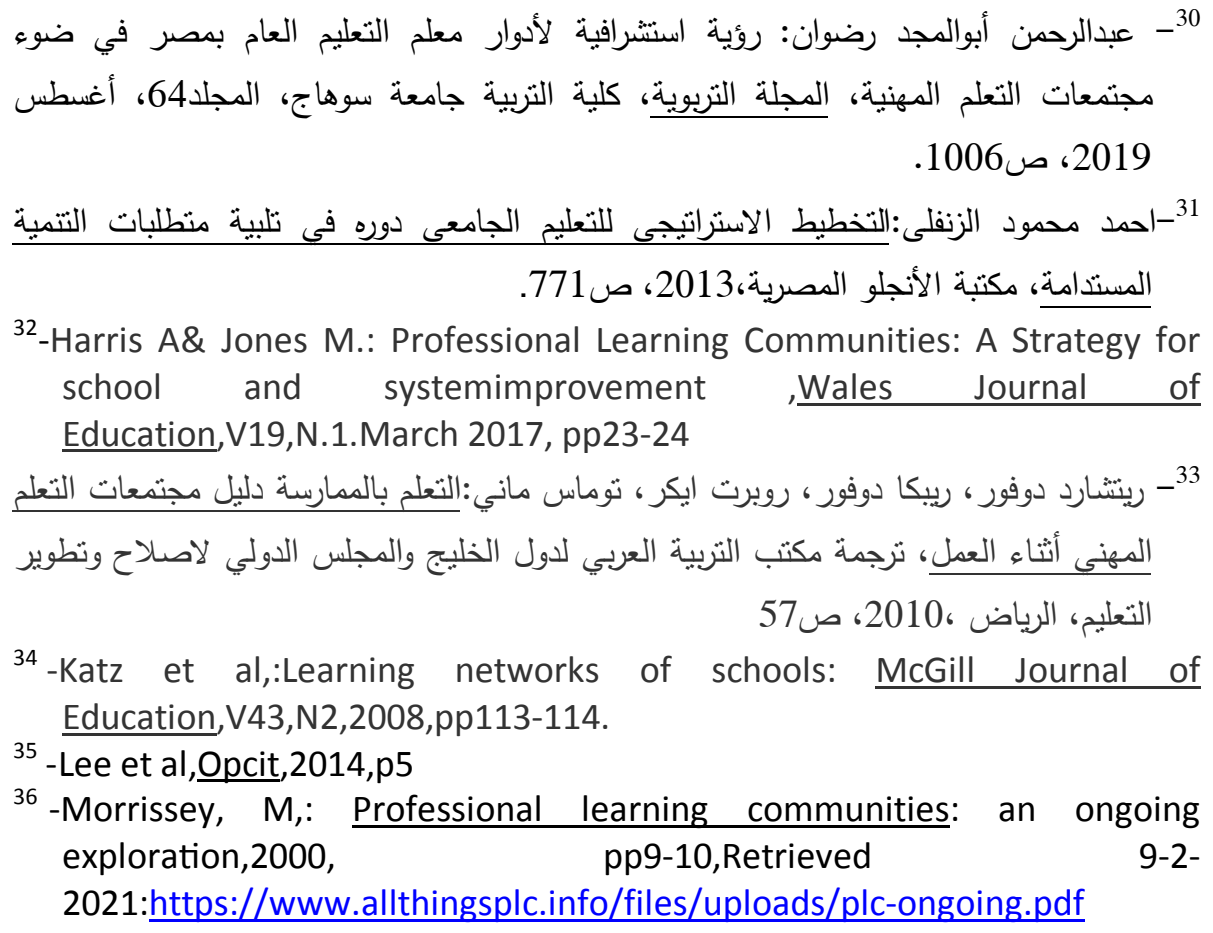


37 - حسنية حسين عبدالرحمن:"مجتمعات التعلم: مدخل لتحقيق التتمية المهنية لـعلمي الددارس

الثانوية في مصر على ضوء خبرتي الولايات المتحدة الأمريكية وسنغافورة" ، مجلة التربية

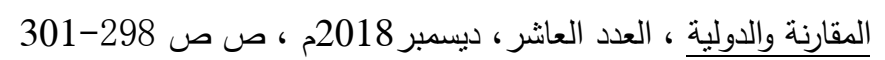

38- Jennifer Serviss: "4 benefits of an active professional learning community", Retrieved 19-1-2021, https://www.iste.org/explore/4benefits-active-professional-learning-community

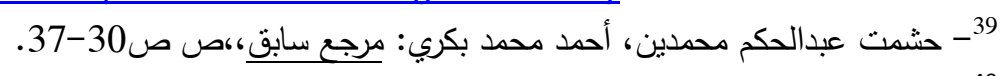

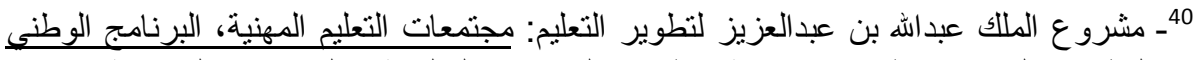

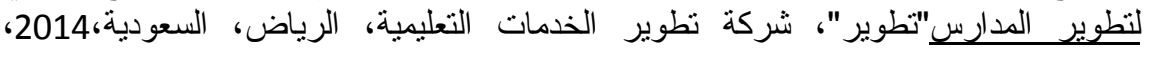
ص29. (n)

${ }^{41}$-East, K. A. : "A study of professional learning communities: Characteristics of implementation and perceived effectiveness in improvement schools in West Virginia", Unpuplished Doctor dissertation, Marshall University, 2015, p90

${ }^{41}$-Carpenter, D.: "Professional Learning Communities' impact On Science Teacher Classroom Practice in A Midwestern Urban School District". Public Access Theses and Dissertations from the College of Education and Human Sciences, (157). Lincoln, University of Nebraska, 2012, pp. 97, 98

${ }^{4} 2$--UNESCO: COVID-19 Webinar: A new world for teachers, education's frontline workers - COVID-19 education webinar \#2, Retrieved 3-2-2021: https://en.unesco.org/news/covid-19-webinar-new-world-teacherseducations-frontline-workers-covid-19

${ }^{43}$ - Jia Zhang, Rui Yuan and Shulin Yu:"What impedes the development of professional learning

communities in China? Perceptions from leaders and frontline teachers in three schools in Shanghai", Educational Management Administration \& Leadership, 2017, Vol. 45(2),p222.

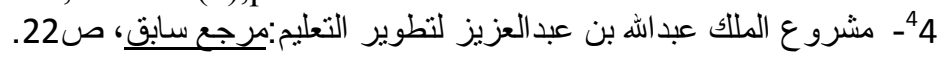

${ }^{45}$ - Carpenter, D. :"Professional Learning Communities' impact On Science Teacher Classroom Practice in A Midwestern Urban School District". Public Access Theses and Dissertations from the College of Education and Human Sciences, (157). Lincoln, University of Nebraska, 2012,p73.

${ }^{46}$-Schaap, H., \& de Bruijn, E.:"Elements affecting the development of professional learning communities in schools". Learning Environments Research, 21(1),2018, p127.

47- Jia Zhang, Rui Yuan and Shulin Yu:"What impedes the development of professional learning 
communities in China? Perceptions from leaders and frontline teachers in three schools in Shanghai" , Educational Management Administration \& Leadership, 2017, Vol. 45(2),p222.

$$
\text { 48 - مشروع الملك عبدالله بن عبدالعزيز لنطوير النعليم:مرجع سابق، ص ص27-22 }
$$

49- Savethechildren :ENABLING TEACHERS TEACHER PROFESSIONAL DEVELOPMENT: Module: COVID-19 for Teachers (I), For Master Trainers and Trainers, Savethechildren, Registered charity England and Wales, Scotland, Global Education Cluster ,2020,pp14-16.

${ }^{50}$-Danguolè Bylaitè-Šalavèjienè Vytautas: Professional Development Activities: Meeting the Challenges of the COVID-19 Pandemic, Own elaboration, Institute for Professional Development data, 2020, Retrieved: $\quad$ https://evbb.eu/news/2020/07/01/professionaldevelopment-activities-meeting

51- مكتب اليونيسف الإفليمي للشرق الأوسط وشمال إفريقا:الجاهزية للعودة: حزمة تدريب إعداد

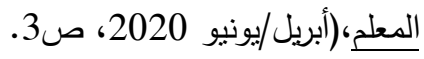

52-UNESCO: COVID-19 Webinar: A new world for teachers, education's frontline workers - COVID-19 education webinar \#2, Retrieved: https://en.unesco.org/news/covid-19-webinar-new-world-teacherseducations-frontline-workers-covid-19

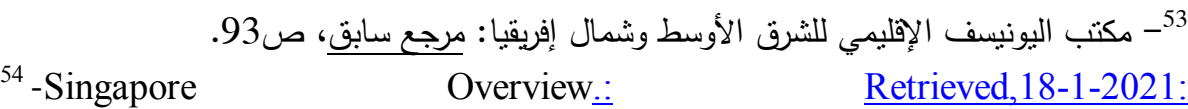
http://www.ncee.org/programs-affiliates/center- on-internationaleducation-benchmarking/top-performing-countries/singapore-overview/

55- عزام بن محمد الدخيل: نعلومهم - نظرة في تعليم الدول العشر الأوائل في مجال التعليم عبر

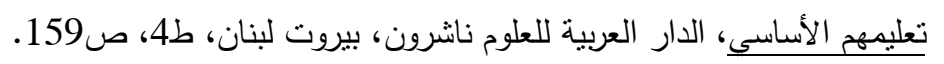

${ }^{56}$-Hairon, S.,\& Tan, C.:Professional Learning Communities in Singapore and Shanghai: Implications for Teacher Collaboration. Compare: A Journal of Comparative and International Education, Article in Compare. March 2016,p3.

57- Ministry of Education, Training and Development Division (TDD) : Schools as professional learning communities. Singapore, Training and Development Division,2010

${ }^{58}$-Ministry of Education (MOE): Schools as professional learning communities., 2010

- Hairon, S.,\& Tan, C.:Professional Learning Communities in Singapore, Opcit,p3 
${ }^{59}$-Hairon, S., \& Dimmock, C.: Singapore schools and professional learning communities: teacher professional development and school leadership in an Asian hierarchical system. Educational REview, 64(4), 2012,pp405-424

- Lee, D., Hong, H., Tay, W., \& Lee, W. O. : Singapore Professional Learning Communities in Singapore Schools. UK Society for Co-operative Studies, 46(2), 2013,pp53- 56.

60 - Academy of Singapore Teachers: PROFESSIONAL LEARNING COMMUNITIES,2020, Retrieved:

https://academyofsingaporeteachers.moe.edu.sg/professionalexcellence/professional-learning-communities

61- Fung F. Man , Ng Tao Magdeline, Robert K Kamei:How to create engaging online learning amid COVID-19 pandemic: lessons from Singapore-1-18 2021, Retrieved:

https://theconversation.com/how-to-create-engaging-online-learning-amidcovid-19-pandemic-lessons-from-singapore-138979

62- Ibid

63 -Academy of Singapore teachers,11-8-2020, Retrieved: https://academyofsingaporeteachers.moe.edu.sg/professionalexcellence/professional-learning-communities/3-big-ideas-4-criticalquestions-5-dimensions

64 - Academy of Singapore teachers 2020, subject,history chapters, role based,Retrieved12-1-2021:

- $\quad$ https://academyofsingaporeteachers.moe.edu.sg/about-us/office-ofsubject-chapters

65-Teacher-Researchers Networked Learning Community,11-8-2020, Retrieved:

https://academyofsingaporeteachers.moe.edu.sg/professionalexcellence/networked-learning-communities/teacher-researchersnetworked-learning-community-(tr-nlc)

66 -Hairon, S. and Dimmock, C. ::Opcit,pp. 411-412.

67-Tan Oon Seng: 21stCentury Teacher Education: A Singapore Case, AsiaPacific Educational Research Association , National Institute of Education, Singapore, 22 June 2010, p. 4

${ }^{68}$-Low, E.L., Goodwin, A.L., Snyder, J. : Focused on Learning: Student and Teacher Time in a Singapore School. Stanford, CA: Stanford Center for Opportunity Policy in Education,2017,p34.

${ }^{69}$-Hogan D. , Gopinathan S. :Knowledge management, sustainable innovation, and pre-service teacher education in Singapore, Teachers and Teaching , 14(4):August 2008 ,pp369-384.

70 - Harion, S., \& Tan, C. : Opcit, 2016,p8. 


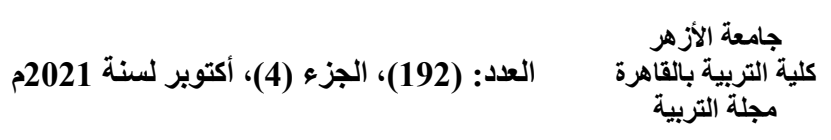

$$
71
$$

72- أون سينغ تان:ممارسات المعلم التعليمية:أفضل الممارسات العالمية الهادفة لتطوير مهنة صلئة التعليم،

$$
\begin{aligned}
& \text { مؤتمر القمة العالمى للابتكار في التعليم، مؤسسة قطر ، ص43ن. }
\end{aligned}
$$

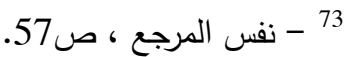

74- May Lim : Educating despite the Covid-19 outbreak: lessons from Singapore, Retrieved,2-12-2020,

https://www.timeshighereducation.com/blog/educating-despite-covid-19outbreak-lessons-singapore\#survey-answer

$$
75 \text { - أون سينغ تان:ممارسات المعلم التعليمية :مرجع سابق ، ص57. }
$$

76- Feng Zengkun: Homegrown enrichment provider offers learning lessons amid online education revolution, Retrieved,2-12-2020

https://www.straitstimes.com/business/homegrown-enrichment-provideroffers-learning-lessons-amid-online-education-revolution

77 - Ndaruhutse Susy, Emma Gibbs \& Rachael Fitzpatrick:" What are countries doing that already use remote learning extensively? What can we learn from them?" Education Development Trust, Reading, Berkshire, United Kingdom,May2020,p3.

78 - Ibid,p7.

79- مجموعة البنك الدولي: إدارة تأثير فيروس كورونا المستجد على الأنظمة النعليمية في أنحاء

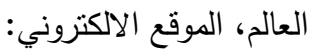

https://blogs.worldbank.org/ar/education/managing-impact-covid-19world-how-countries-are-preparingeducation-systems-around 80ـ محمد سينان: من داخل سنغافورة.. كيف تمكنت الحكومة من إدارة أزمة كورونا؟ ، الموقع

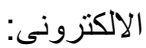

https://www.shorouknews.com/columns/view.aspx?cdate=27032020\&id 81 https://www.alroeya.com/60-65/2121993

$$
\text { 82 - الموسوعة العالمية ويكيبيديا: سذغافورا الموقع الالكتروني: }
$$

https://ar.wikipedia.org/wiki/\%D8\%B3\%D9\%86\%D8\%BA\%D8\%A7\%D9\%8 91\%D9\%88\%D8\%B1\%D8\%A

$$
\text { 83- الاستخبارات الامريكية : سنغافورا ، الموقع الاكتروني: }
$$

https://www.cia.gov/library/publications/the-world-factbook/geos/sn.html

${ }^{84}$ - Byron Auguste, Paul Kihn, and Matt Miller:"Closing the talent gap: Attracting and retaining top-third graduates to careers in teaching", McKinsey Company,Australia, 2010,p5. 
${ }^{85}$-Zongyi Deng \& S. Gopinathan: PISA and high-performing education systems: explaining Singapore's education success, Comparative Education, 52.4, 2016,p16.

86 - Ndaruhutse Susy, Emma Gibbs \& Rachael Fitzpatrick: Op Cit, p7.

87 - ابتسام محد العامري: التجربة التتموية في سنغافورا، مركز الدراسات الاستراتيجية والدولية،

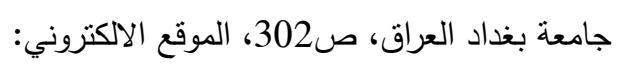

https://mercj.journals.ekb.eg/article_37953 b589a2a7e1a1180dace7cc8 e87cd61e3.pdf

88- Susan Sclafani: "Rethinking Human Capital in Education: Singapore

As A Model for Teacher Development", A Paper Prepared For The

Aspen Institute Education and Society Program, The Aspen Institute,

Washington, 2008, p7.

89 - Ibid, p7.

${ }^{90}$-Education in Canada: Retrieved,6-9-2020

https://www.canada.ca/en/immigration-refugees-citizenship/services/newimmigrants/new-life-canada/enrol-school.html

91 - Education in Canada: An Overview. Retrieved, 5-9-2020:

http://www.cmec.ca/299/Education-in-Canada-An-Overview/index. html\#01

92 -Elementary Teachers' Federation of Ontario :Professional Learning Communities (PLCs),6-9-2020:

https://www.etfo.ca/SupportingMembers/Employees/PRSMattersBulletin/ Pages/Professional\%20Learning\%20Communities.aspx

93 - ETFO STAFF: It's Up to You: Participating in Professional Learning Outside the School Day is Your Decision, Magazine Of The Elementary Teachers' Federation Of Ontario,Retrieved,6-9-2020: etfovoice.ca/node/207

${ }^{94}$-Elementary Teachers' Federation of Ontario :Professional Learning Communities (PLCs), Opcit.

95 -lbid

96- ETFO STAFF: It's Up to You: Participating in Professional Learning, Opcit.

97 -Elementary Teachers' Federation of Ontario :Professional Learning Communities, Opcit.

${ }^{98}$-Marion Huffman, Darryl Whitney, Jan Skillen: Professional Learning Communities Sharing Knowledge And Leadership: Collaboration Creates And Inclusive Classroom, Magazine Of The Elementary Teachers' Federation Of Ontario, Retrieved, 6-9-2020:

http://etfovoice.ca/node/119

99 - Ministry of Education:Appendix G, Log of Teaching Practice for Experienced Teacher, Optional Form, Ontario, p15 
${ }^{100}$-Marion Huffman, Darryl Whitney, Jan Skillen: Professional Learning Communities,Opcit.

101 - Ministry of Education:Appendix G, Log of Teaching Practice for Experienced Teacher, Opcit, p15.

102 - Elementary Teachers' Federation of Ontario :ETFO Voice, Vol. 9 , No. 4, April 2007,p20,Retrieved 25-1-2021:

https://thesmalleroffice.files.wordpress.com/2012/05/engaging-in-lessonstudy-etfo-voice- 4.pdf

103 -Elementary Teachers' Federation of Ontario :Professional Learning Communities (PLCs),6-9-2020:

ttps://www.etfo.ca/SupportingMembers/Employees/PRSMattersBulletin Pages/Professional\%20Learning\%20Communities.aspx

104 -lbid

105 - Ontario Ministry of Education: Professional Learning Communities: A Model For Ontario Schools CAPACITY BUILDING SERIES ,October 2007,p2,Retrieved 24-1-2021:

http://www.edu.gov.on.ca/eng/literacynumeracy/inspire/research/PLC.pdf

106 -Ibid,p3

107-Marion Huffman, Darryl Whitney, Jan Skillen: Professional Learning Communities Sharing Knowledge And Leadership: Collaboration Creates And Inclusive Classroom, Magazine Of The Elementary Teachers' Federation Of Ontario, Retrieved, 6-9-2020: http://etfovoice.ca/node/119

108 - Ontario Ministry of Education: Professional Learning Communities: OpCit ,p2

109 - Ministry of Education:Appendix G, Log of Teaching Practice for Experienced Teacher, Optional Form, Ontario, p15.

110 -Leanne Miller: Professional Learning Communities ,Model for collaborative teaching or the latest bandwagon, Retrieved,6-9-2020: https://professionallyspeaking.oct.ca/june 2005/plc.asp

${ }^{111}$-Marion Huffman, Darryl Whitney, Jan Skillen:Op cit .

112 - Ministry of Education:Appendix G, Log of Teaching Practice for Experienced Teacher, Optional Form, Ontario, p15

113 -Ontario Ministry of Education :"2018-19 Teacher Learning and Leadership Program" Retrieved 22-1-2021:

${ }^{114}$-lbid. 
${ }^{115}$-Marion Huffman, Darryl Whitney, Jan Skillen: Professional Learning Communities Sharing Knowledge And Leadership: Collaboration Creates And Inclusive Classroom, Magazine Of The Elementary Teachers' Federation Of Ontario, Retrieved, 6-9-2020: http://etfovoice.ca/node/119

116 - Elementary Teachers' Federation of Ontario :ETFO Voice, Vol. 9 , No. 4, April 2007,p20,Retrieved25-1-2021:

https://thesmalleroffice.files.wordpress.com/2012/05/engaging-in-lessonstudy-etfo-voice-vol-9-4.pdf

117 - Elementary Teachers' Federation of Ontario :ETFO Voice, Op Cit,p32.

118 - Ontario Ministry of Education :Guide to reopening Ontario's schools, Retrieved 22-1-2021:

https://www.ontario.ca/page/guide-reopening-ontarios-schools

119 - Ontario Ministry of Education: COVID-19: reopening schools, Retrieved 22-1-2021:

https://www.ontario.ca/page/covid-19-reopening-schools\#section-0

120 -ETFO : ETFO Virtual Learning - Spring 2020, Retrieved,6-9-2020:

https://www.etfo.ca/SupportingMembers/ProfLearning/Pages/distancelear ning.aspx

$$
\text { 121- ويكيبيديا، الموسو عة الحرة : كندا، الموقع الاككتروني: }
$$

https://ar.wikipedia.org/wiki/\%D9\%83\%D9\%86\%D8\%AF\%D8\%A7\#cite note $\underline{-13}$

$$
{ }^{122} \text {-Education in Canada: Retrieved,6-9-2020 }
$$

https://www.canada.ca/en/immigration-refugees-citizenship/services/newimmigrants/new-life-canada/enrol-school.html

$$
\begin{aligned}
& { }^{123} \text {-Ibid } \\
& \text { 124 ـ ويكييديا، الموسو عة الحرة : كندا، مرجع سابق. } \\
& \text { 125- موسوعة ويكيبيديا العربية: نقافة كندا ، الموقع الالكتروني: }
\end{aligned}
$$

https://ar.wikipedia.org/wiki/\%D8\%AB\%D9\%82\%D8\%A7\%D9\%81\%D8\%A 69 \% D9\%83\%D9\%8

$$
126 \text { - موسوعة ويكيبيديا العربية: النعليم في كندا ، الموقع الالكتروني: }
$$

https://ar.wikipedia.org/wiki/\%D8\%A7\%D9\%84\%D8\%AA\%D8\%B9\%D9\%84\% D9\%8A\%D9\%85 \% D9 \%

$$
\text { : Retrieved,6-9-2020 127-Government of Canada: Elementary and secondary education }
$$

https://www.canada.ca/en/immigration-refugees-citizenship/services/newimmigrants/new-life-canada/enrol-school/elementary-secondary.html

Education in Canada: An Overview. Retrieved, 5-9-2020: - ${ }^{128}$ http://www.cmec.ca/299/Education-in-Canada-An-Overview/index. html\#01 129- البنك الدولي: الإنفاق العام على التعليم، الموقع الالكتروني: https://data.albankaldawli.org/indicator/SE.XPD.TOTL.GD.ZS 
130

- Ministry of Education,Education Facts, 2018-2019*

(Preliminary),Ontario, ,Retrieved 22-1-2021:

http://www.edu.gov.on.ca/eng/educationFacts.html

131 - Ontario Government website:Teaching Profession Act, R.S.O. 1990, CHAPTER T.2, Last amendment: 2019, c. 3, Sched. 4,p1.Retrieved,22-12021: https://www.ontario.ca/laws/statute/90t02

132 -Leanne Miller: Professional Learning Communities ,Model for collaborative teaching or the latest bandwagon, Retrieved,6-9-2020:

https://professionallyspeaking.oct.ca/june 2005/plc.asp

133 - Ontario Government website:Teaching Profession Act, Opcit.

134 - Klaus Schwab(Editor):Competitiveness Global Report,2018-2019, World Economic Forum, p. xiii,Retrieved 22-1-2021: http://www3.weforum.org/docs/WEF TheGlobalCompetitivenessReport 2019.pdf

135

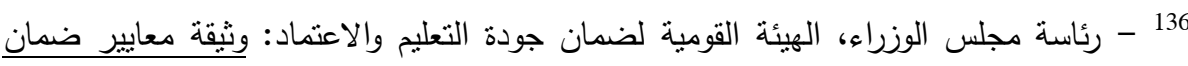

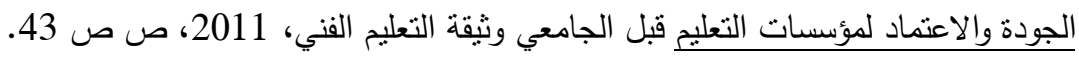

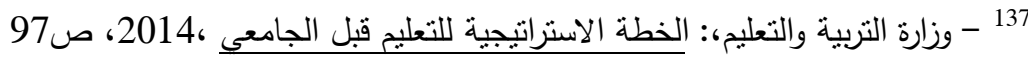

138 - خريطة مشروعات مصر : برنامج المعلمون أولاً ، الموقع الالكتروني الإني

:https://egy-map.com/ initiative/ \%D8\%A8\% D8\%B1\%D9 \%86\%D8\% A7\%D9\%85\%D8\%A

139

140ـــوازرة التربية والتعليم، وحدة السياسات والتخطيط الاستراتيجى: مسودة التقرير السنوي الثالث،

لمتابعة

الإستراتيجية القومية لإصلاح التعليم قبل الجامعى 2010/ 2009، القاهرة، 2010 ، ص33.

141 - خريطة مشروعات مصر : برنامج المعلمون أولاً ، مرجع سابق.

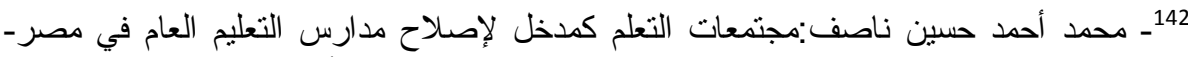

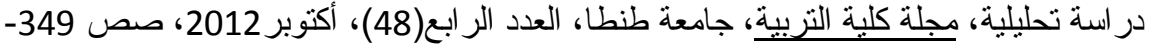

350

143ـ فيفي أحمد نوفيق: مرجع سابق، ص 116.

144 - محمود طه حسين: التعليم تخاطب المديريات لتفعيل دور التوجيه الفنى فى التتمية المهنية

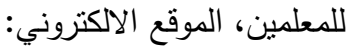

https://www.youm7.com/story/2020/11/29/\%D8\%A7\%D9\%84\%D8\%AA\%D

8\%B9\%D9\%84\%D9\%8A\%D 
Siham Ahmed Mohamed Alwan: Mechanisms for empowering teachers in the Arab Republic of Egypt in the light of the experiences of some countries" Journal of Comparative and International Education, issue ninth - June2018 AD.

OECD: European Vocational Training Corporation Policy Index: Small and medium-sized enterprises: the Mediterranean region of the Middle East and North Africa2018Organization for Economic Co-operation and Development, European Union,2019 AD..

Atef Abdel Hamid: Corona Virus: How does distance education provide solutions to some of the problems of schools in Egypt?

Fifi Ahmed Tawfiq: A future scenario for activating learning communities in public education schools in Sohag Governorate, The Educational Journal, Faculty of Education, Sohag University, Part.47, 2017 AD.

Heshmat Abdel Hakam Mohamedin, Ahmed Mohamed Bakri: Requirements for the application of professional learning communities in Al-Azhar institutes from the point of view of teachers, Journal of the College of Education, Al-Azhar University, No.172) Part One, January 2017.

Shaker Muhammad Fathi and Hammam Badrawi Zidan: Comparative Education: Curriculum - Methods - Applications, The Arab Nile Group, Cairo,2003 AD.

Maher Ahmed Hassan: Building Professional Learning Communities as an Entrance to Improving Academic Performance in Public Education Schools in Saudi Arabia, Journal of the Islamic University of Gaza, Vol.27, Sixth Issue, 2019 AD.

Aladdin Hassan Saudi: A program based on the entrance of professional learning communities to develop grammar teaching skills and the trend towards them among preparatory stage teachers, Reading and Knowledge Magazine, College of Education, Ain Shams University, No.195, January 2018.

Zainab bint Abdullah Al-Zayed, and Suzan bint Hussein Hajj Omar: "The impact of online professional learning communities on understanding science teachers.

On the Nature of Science and its Teaching Practices, The Jordanian Journal of Educational Sciences, Vol12, Issue 3, 2016.

Amr Saleh Abdel Fattah Abu Zaid: Building Networked Knowledge Learning Communities and Its Impact on Science Teachers, Journal of the College of Education, Fayoum University. the number11, December 2011.

Abd al-Rahman Abu al-Majd Radwan: A Foresight View of the Roles of the General Education Teacher in Egypt in the Light of Professional Learning Communities, Educational Journal, Faculty of Education, Sohag University, Vol.64, August 2019. 
Ahmed Mahmoud Al-Zanfali: Strategic planning for university education and its role in meeting the requirements of sustainable development, Anglo-Egyptian Library,2013 AD.

Richard Dufour, Rebecca Dufour, Robert Ecker, Thomas Money: Learning by Doing: A Guide to Professional Learning Communities on the Job, translated by the Arab Bureau of Education for the Gulf States and the International Council for Education Reform and Development, Riyadh,2010NS.

Hosnia Hussein Abdel Rahman: "Learning Communities: An Introduction to Achieving Professional Development for Secondary School Teachers in Egypt in the Light of the Experiences of the United States of America and Singapore," Journal of Comparative and International Education, Issue Ten, December2018AD

King Abdullah bin Abdulaziz Project for Education Development: Professional Learning Communities, the National School Development Program "Tatweer", Educational Services Development Company, Riyadh, Saudi Arabia,2014, p. 29.

UNICEF Regional Office for the Middle East and North Africa: Readiness to Return: Teacher Preparation Training Package (April/June .)2020.

Azzam bin Muhammad Al-Dakhil: Their Education - A look at the education of the top ten countries in the field of education through their basic education, Arab House for Science Publishers, Beirut, Lebanon. NS4.

On Sing Tan: Teacher Education Practices: Global Best Practices Aiming to Advance the Teaching Profession, World Innovation Summit for Education, Qatar Foundation.

The World Bank Group: Managing the impact of the emerging coronavirus on educational systems around the world,

Muhammad Sinan: From within Singapore, how did the government manage the Corona crisis?

Vision agencies: Despite "Corona" .. Singapore reopens schools

World encyclopedia Wikipedia: Singapore

Ibtisam Muhammad Al-Amri: The Developmental Experience in Singapore, Center for Strategic and International Studies, University of Baghdad, Iraq

Presidency of the Republic, Constitution of Egypt 2014, Al-Amiriya Press, 2014, Article 22.

The Presidency of the Council of Ministers, the National Authority for Quality Assurance and Accreditation of Education: Quality Assurance and Accreditation Standards Document for Educational Institutions Pre-university technical education document, 2011 AD.

The Ministry of Education,: Strategic Plan for Pre-University Education,2014 AD. 
Map of Egypt's projects: Teachers First Program.

Ministry of Education, Policy and Strategic Planning Unit: Draft of the third annual report, to follow up on the implementation of the national strategic plan to reform pre-university education2009/2010, Cairo .

Muhammad Ahmed Hussein Nassif: Learning Communities as an Entrance to Reform of Public Education Schools in Egypt - An Analytical Study, Journal of the Faculty of Education, Tanta University, No. IV)48), October 2012.

Mahmoud Taha Hussein: Education addresses the directorates to activate the role of technical guidance in the professional development of teachers.

Ministry of Education: Programs implementation of the strategic plan 20142017, Education, the National Project for Egypt.

Ministry of Education: Fax No.3149, dated 6/8/2020 AD, a memorandum for presentation to the Deputy Minister regarding the dismantling of the field coordination network for the Teachers First Program, the Office of the Deputy Minister

Amal Saeed Mohammed Habaka :A comparative study of the roles of the teacher in developing creative thinking in pre-university education in some foreign experiences and the possibility of benefiting from them in Egypt, Education, The Egyptian Association for Comparative Education and Educational Administration, vol.14, No. 34, November 2011, the National Center for Educational Research and Development. 